\title{
National Ignition Facility Project Site Safety Program
}

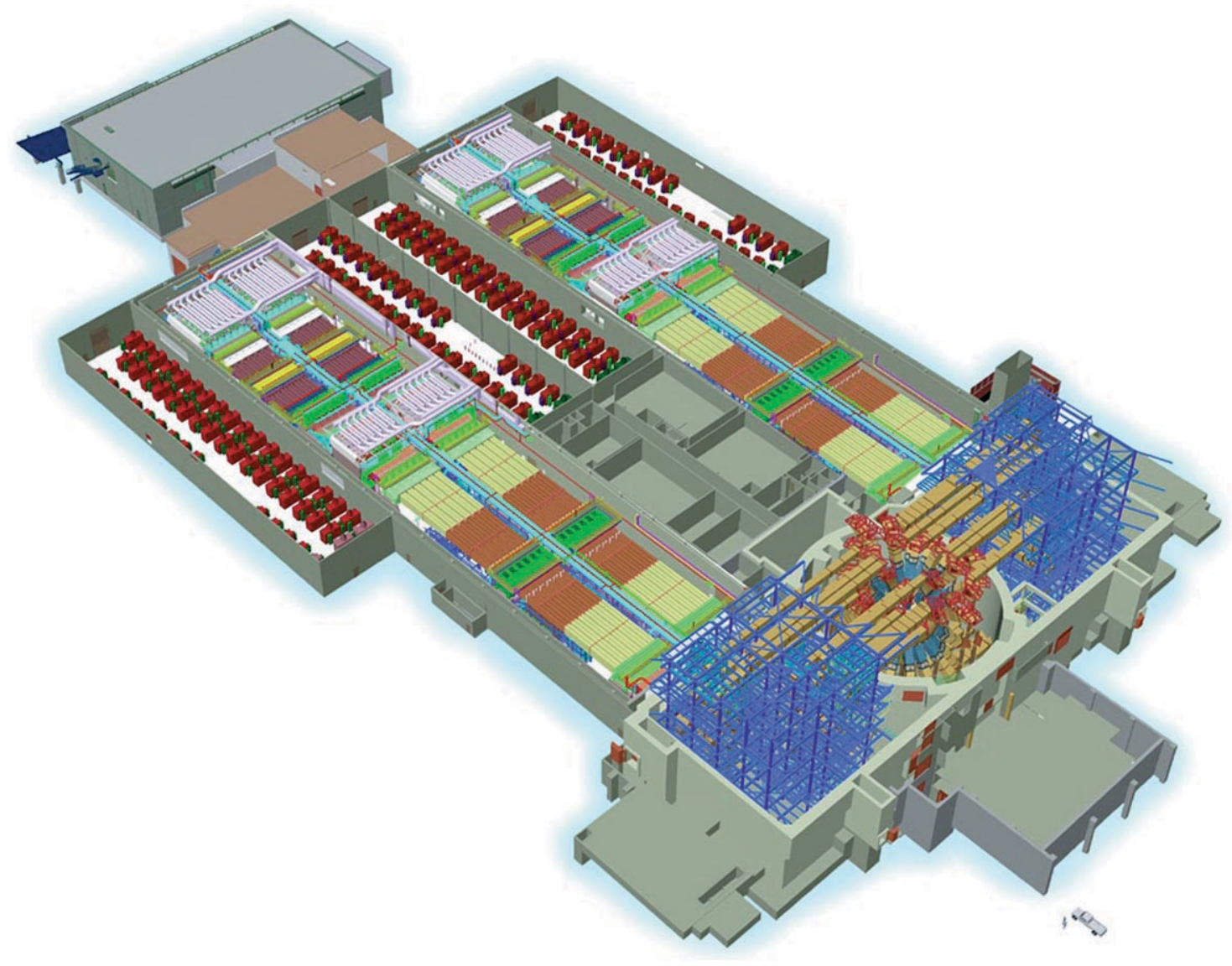

Lawrence Livermore National Laboratory

University of California • Livermore, California $\bullet 94550$ 


\section{DISCLAIMER}

This document was prepared as an account of work sponsored by an agency of the United States Government. Neither the United States Government nor the University of California nor any of their employees, makes any warranty, express or implied, or assumes any legal liability or responsibility for the accuracy, completeness, or usefulness of any information, apparatus, product, or process disclosed, or represents that its use would not infringe privately owned rights. Reference herein to any specific commercial products, process, or service by trade name, trademark, manufacturer, or otherwise, does not necessarily constitute or imply its endorsement, recommendation, or favoring by the United States Government or the University of California. The views and opinions of authors expressed herein do not necessarily state or reflect those of the United States Government or the University of California, and shall not be used for advertising or product endorsement purposes.

This report has been reproduced directly from the best available copy.

Available to DOE and DOE contractors from the

Office of Scientific and Technical Information

P.O. Box 62, Oak Ridge, TN 37831

Prices available from (615) 576-8401, FTS 626-8401

Available to the public from the

National Technical Information Service

U.S. Department of Commerce

5285 Port Royal Rd.

Springfield, VA 22161

This work was performed under the auspices of the U.S. Department of Energy, National Nuclear Security Administration by University of California Lawrence Livermore National Laboratory under Contract W-7405-Eng-48. 


\section{National Ignition Facility Project Site Safety Program}

Ed Moses

NIF Project Manager 


\section{Safety and Health Policy for the National Ignition Facility}

Environment, safety and health (ES\&H) are priority considerations in the planning and execution of work related to the National Ignition Facility (NIF) Project at the Lawrence Livermore National Laboratory (LLNL). The management of the NIF Project is committed to providing a safe work environment for NIF workers and to protecting the public from hazards associated with all activities performed on the NIF Project site. Work related to activities on the NIF Project site will be performed in a manner that protects the safety of the individual worker, preserves the quality of the environment, and prevents property damage.

This policy is applicable to workers including LLNL, non-LLNL, contractor and subcontractor employees, and visiting experimentalists and their teams working at the NIF Project site. NIF Project site safety requirements, safety protocols, and the NIF Code of Safe Practices and General Rules for Environmental, Safety and Health issues are covered in Appendix A. The NIF Project site includes the B581/B681 site and support areas shown in Appendix B.

Environment, safety, and health policy statements specific to NIF:

- Incidents, whether personal injury or other loss, are unacceptable.

- Management is responsible for safety at the NIF Project site.

- Management, supported by the safety team, will provide consistent guidance and enforcement of a safety program that governs the activities of workers at the site.

- Workers will be involved in the work planning process, including the identification of hazards and controls.

- Each worker is directly responsible for ensuring his or her own safety, and for creating a safe work environment.

- Working safely is a condition of employment, and disciplinary action policies for violations of safety rules will be enforced by management.

- A strong program of independent audit, self-assessment, and surveillance will review the effectiveness of the safety program.

- Any incident that results in personnel injury or illness, significant damage to buildings or equipment, or impact to the environment, or is considered a significant near-miss will be investigated by management.

The NIF Project will comply with applicable safety, health, and environmental laws, regulations, and requirements. Anyone willfully or thoughtlessly disregarding standards will be subject to immediate removal from the site.

It is the Project's policy to integrate safety into all aspects of work performed. This approach is based on the seven guiding principles of Integrated Safety Management (ISM) contained in Department of Energy (DOE) P 450.4 Safety Management System Policy. 
Approve:

Date:

Edward I. Moses

NIF Project Manager

Concur:

Date:

James M. Mecozzi

Team Leader,

ES\&H Team 2

Concur:

Date:

Vaughn Draggoo

NIF Programs Operations Manager

Concur:

Date:

Bob Ehrlich

Safety Documentation Review Board Chairman

(acting) 


\section{NIF Project Site Safety Program Revision Log}

This Revision Log page has been added with Revision 5 of the NPSSP.

September 30, 2003, Revision 5

Sections I, II, and III, and Appendix B, C, D, and E of the NPSSP have been extensively revised, therefore, vertical bars are not used to indicate changes. Revision 5 incorporates all individual change releases since September 2001, removes reference to the construction contractor (IMI, Jacobs), adds the work permit process, revises the project organization and site area sections, and changes the scope of the NPSSP to cover all workers and contractors on the NIF Project site.

The revision of Appendix A incorporates all released page changes, additions, and revisions since September 2001. Revision markings are used to indicate the sections with changes. 


\section{Contents}

Safety and Health Policy for the National Ignition Facility ..............................................ii

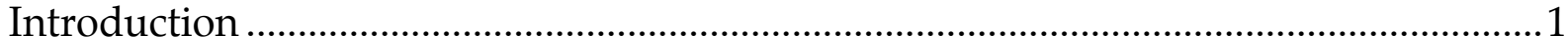

II. Project Organization and Management Responsibilities.................................................. 3

III. Core Safety Management Processes ................................................................................

III.A Setting Management Expectations and Monitoring Work ............................ 4

III.A.1 Contractor Pre-Qualification and Post-Evaluation Process........4

III.A.2 Disciplinary Process for Safety Violations ..................................... 4

III.A.3 NIF Project Site Access ..................................................................... 4

III.A.4 Site Orientation Safety Training......................................................

III.A.5 NIF Safety Management Training …………...................................

III.A.6 Construction Work Activities...........................................................

III.A.7 Augmented Work Controls ................................................................. 6

III.A.8 Walkabout Process for Evaluating Safety Implementation ........6

III.A.9 Emergency Response and Notification............................................

III.B Work Planning and Authorization Process ......................................................

III.B.1 NIF Project Site Work Authorization............................................

III.B.2 Safe Plan of Action (SPA) …………………................................ 8

III.B.3 Permits.......................................................................................... 8

III.B.4 Incident Investigations, Notification, and Lessons Learned ........9

III.B.5 Work Coordination...............................................................................

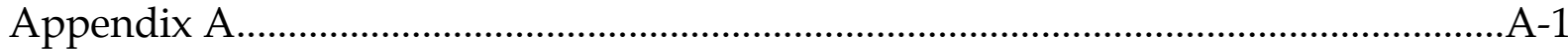

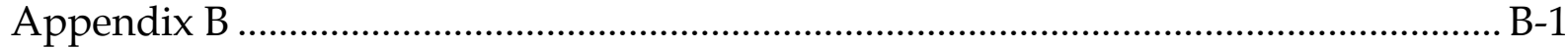

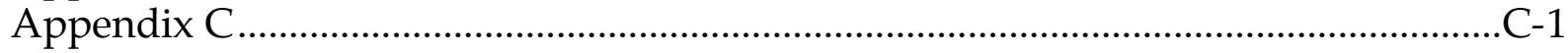

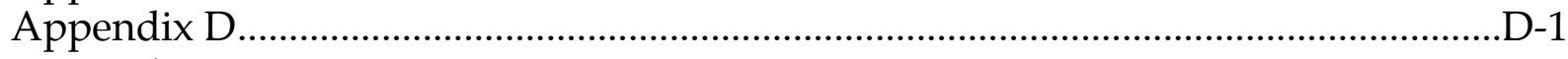

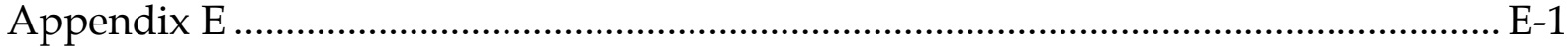

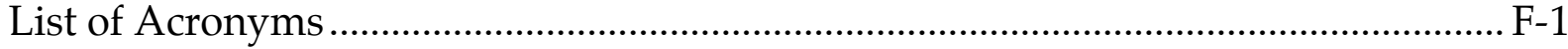




\section{Introduction}

This Safety Program for the National Ignition Facility (NIF) presents safety protocols and requirements that management and workers shall follow to assure a safe and healthful work environment during activities performed on the NIF Project site. The NIF Project Site Safety Program (NPSSP) requires that activities at the NIF Project site be performed in accordance with the LLNL ESEH Manual and the augmented set of controls and processes described in this NIF Project Site Safety Program.

Specifically, this document:

- Defines the fundamental NIF site safety philosophy.

- Defines the areas covered by this safety program (see Appendix B).

- Identifies management roles and responsibilities.

- Defines core safety management processes.

- Identifies NIF site-specific safety requirements.

This NPSSP sets forth the responsibilities, requirements, rules, policies, and regulations for workers involved in work activities performed on the NIF Project site. Workers are required to implement measures to create a universal awareness that promotes safe practice at the work site and will achieve NIF management objectives in preventing accidents and illnesses. ES\&H requirements are consistent with the LLNL ESEH Manual. This NPSSP and implementing procedures (e.g., Management Walkabout, special work procedures, etc.,) are a comprehensive safety program that applies to NIF workers on the NIF Project site. The NIF Project site includes the B581/B681 site and support areas shown in Appendix B.

Visitors to the NIF Project Site shall be controlled through implementation of the NIF Site Tour Procedure (see NIF Procedure 5.7, NIF Site Tours).

Integrated Safety Management (ISM) is practiced in the execution of activities associated with the NIF Project. The seven Principles of ISM are:

- Line management is responsible for safety.

- Clear roles and responsibilities are established and maintained.

- Personnel possess competence commensurate with responsibilities.

- Resource allocations are balanced, making ES\&H a priority in project planning and execution.

- Safety requirements are identified and implemented.

- Hazard controls are tailored to the project work.

- Work activities are authorized before they begin. 
The following five Core Functions are used to implement ISM:

- Define the scope of work.

- Analyze the hazards.

- Develop and implement hazard controls.

- Perform work within controls.

- Provide feedback and continuous improvement.

Successful application of the Principles of ISM is predicated on the proper implementation of the Core Functions when evaluating and controlling all activities. The NPSSP identifies how and where the Principles and Core Functions are to be implemented. Appendix C shows which specific sections of the NPSSP implement various aspects of ISM. NIF Project Control Policy 1.11 contains an attachment that lists other NIF Project documents that address the elements of ISM. 


\section{Project Organization and Management Responsibilities}

The Project Manager, supported by NIF Responsible Managers and staff, has the overall authority and responsibility for safety, work execution of the NIF Project and safety performance of individuals working on site.

The Project Manager, supported by the NIF Project Assurance Office, ensures that the NIF Project meets all applicable Department of Energy (DOE), federal, state, and regional ES\&H, quality assurance, ISM training, and security requirements.

The Project Manager will assure that NIF Project work is conducted under the principles and requirements of the LLNL Integrated Safety Management (ISM) system implementation of DOE Policy 450.4, Safety Management System Policy, NIF Project Control Procedure 1.11 (Integrated Safety Management), and the NIF Programs Directorate Integrated Safety Management System Implementation Plan (NIF-0054160).

NIF Responsible Managers, consisting of the Site Manager, Commissioning and Operations Managers, Laser and Experimental Systems (LES) Managers, Area Integration Managers (AIMs), Integrated Product Team Leaders (IPT), and Associate Project Managers (APMs), provide coordination, integration, and technical management through their line management organizations. They are responsible for ensuring the work at the site is conducted under the principles and requirements of this safety program.

The Project Manager serves as the Authorizing Individual (AI) for work at the NIF Project Site and may delegate the responsibility and authority of the AI to NIF Responsible Managers, and shall assure that these individuals are trained and knowledgeable of their ISM duties and responsibilities.

The Site Manager, Commissioning and Operations Managers, LES Managers, AIMs, and APMs may be AIs for a specific area. They are also Responsible Individuals (RIs) for personnel from their organizations assigned to work at the NIF Project Site and may delegate this authority to their subordinate managers.

When authorized by the Project Manager, management and supervisory workers may delegate safety authority to others in their organizations; however, the responsibility and accountability for safety performance and assurance is not transferable.

Work on the NIF Project Site is coordinated by the Field Area Managers (FAMs) who are responsible for specific NIF site areas. FAMs report to the AIMs; FAMs act on behalf of the AIMs and will coordinate safety in their areas.

It is the responsibility of workers to perform work safely and in accordance with the NPSSP.

Appendix D describes the safety organization's roles, responsibilities, and interfaces regarding safety at the NIF Project Site. Additional details about the roles and responsibilities of the NIF Responsible Managers and the NIF Project Organization are given in NIF Project Management Descriptions, NIF-0000810-0J. 


\section{Core Safety Management Processes}

The purpose of this chapter is to provide specific expectations with respect to safety management of work activities. THE FUNDAMENTAL ASSUMPTION IS THAT ALL INCIDENTS CAN BE PREVENTED!

Core safety management processes are the essential management activities that shall be used to control work safety and reliability. These activities focus on the following operational aspects of safety management:

- Setting expectations and monitoring work.

- Work planning, work authorization, and providing feedback (incident investigation, lessons learned, etc.).

It is management's responsibility to implement and monitor these core processes and ensure their efficiency through continuous improvement.

\section{III.A Setting Management Expectations and Monitoring Work}

It is management's responsibility to establish how work is conducted and monitored on the NIF Project site. The purpose of these management processes is to align senior management expectations and the performance of mid-level managers, supervisors, and workers.

\section{III.A.1 Contractor Pre-Qualification and Post-Evaluation Process}

In addition to other criteria, contractors will be selected based on past documented performance indicators consistent with expectations of this NPSSP. Contractors not demonstrating exceptional past performance in safety will not be invited to participate in NIF Project Site work. A copy of the NPSSP will be provided to all contractors and subcontractors prior to the placing of their bids. Any exceptions taken to the implementation of processes and procedures in the NPSSP will be submitted in writing and all issues will be resolved, prior to the execution of a contract with those firms and prior to their personnel entering the NIF Project Site.

\section{III.A.2 Disciplinary Process for Safety Violations}

Anyone violating site safety rules will be subject to discipline. LLNL employees and direct contractors will be subject to the LLNL disciplinary process.

\section{III.A.3 NIF Project Site Access}

Individuals may access the NIF Project site as a visitor, escort, or site worker. Anyone entering the site must complete appropriate site orientation and safety training 
established by NIF Project Management. NIF Managers and Supervisors are responsible for seeing that all individuals entering the site have completed the proper training prior to access.

Refer to the following NIF Project Procedures for details on the process for gaining access to the site and training requirements:

5.5 NIF Site Access - for anyone scheduled to complete work tasks on the NIF Project site;

5.7 NIF Site Tours - for visitors and escorts.

\section{III.A.4 Site Orientation Safety Training}

Site orientation safety training courses have been developed, managed, and delivered by management personnel. The purpose of the training is to provide an overview of the NIF Project site, general hazards, access control procedures, and basic roles and responsibilities. This is the initial step in the site access process for all personnel performing work activities on the NIF Project Site. Anyone absent from the site (e.g., rehire, temporary re-assignment, etc.) for more than 30 days is required to retake site orientation/site access training. Exceptions to retraining will be granted on a case-by-case basis by the Site Manager for returning consultants and contractors under active contracts and experimentalists. Each contractor/subcontractor will provide an additional orientation for all newly hired or rehired employees.

All NIF personnel must attend the required training course, coordinated through their line supervision, to receive approval for access to the NIF Project site. Personnel are also required to attend courses that prepare them for safe work activities. Site Access Safety courses cover:

- Project safety orientation, which includes an introduction to site safety, Job Hazards Analysis (JHA)/ Integration Work Sheets (IWSs)/Safety Plans (SPs), Safe Plans of Action (SPAs), personal protective equipment (PPE), and incident reporting.

- Clean construction protocol.

See NIF Project Procedure 5.5 for site access requirements, which include training requirements. Courses may be identified, scheduled, and recorded through the LLNL L-Train Training database.

\section{III.A.5 NIF Safety Management Training}

The purpose of NIF Safety Management training is to inform all Project Managers whose employees perform work on the NIF Project Site of the following:

- NIF Safety Management Culture. 
- Integrated "Owner Team" Responsibilities.

- Walkabout Process.

- JHA/IWS/SP, SPA, Safety Observation Report, and other Safety Management processes.

The course is a management course that is delivered in part by line managers.

\section{III.A.6 Construction Work Activities}

Construction work will be conducted in accordance with this NIF Project Site Safety Program.

\section{III.A.7 Augmented Work Controls}

The NPSSP requires that all activities at the NIF Project site be performed in accordance with the LLNL ESEH Manual, and an augmented set of controls. The augmented controls include the work processes described in Section III of this document, and the safety requirements described in Appendix A.

\section{III.A.8 Walkabout Process for Evaluating Safety Implementation}

All levels of management, supported by safety personnel, regularly viewing site work will perform walkabouts. The purpose of the walkabout is to:

- Assess management and work execution against the requirements of this NPSSP.

- Identify and correct the problems that hinder the NIF Project from achieving its safety objectives described in the NPSSP.

- Evaluate all levels of safety implementation at the site.

These management safety assessments will be supplemented by independent audits of the NIF Project Site Safety Program.

Details of the NIF Walkabout process are provided in the NIF Project Procedure 5.13, Layered Line Management Walkabout.

\section{III.A.9 Emergency Response and Notification}

Assistance for emergencies can be requested by telephone through the LLNL Hazards Control Department's Emergency Management Division Dispatch Center by dialing 911 from an on-site LLNL telephone or 447-6880 from a cellular telephone or other telephone that is not connected to the LLNL telephone exchange (LLIX). Response to emergencies should be in accordance with the NIF Programs Directorate Plan, "Do You Know What To Do in an Emergency," NIF-0064673. The Assembly Point, where personnel evacuating the NIF Project site must congregate in an emergency, is located adjacent to the Safety Trailer (T6870) in Kirschbaum field. 


\section{III.B Work Planning and Authorization Process}

Proper work planning and authorization are crucial for achieving safety. Work planning requires:

(1) developing the scope of work,

(2) analyzing the hazards, and

(3) developing a plan to mitigate those hazards.

Work must be coordinated and authorized before it can proceed and the work area and activity reviewed before the start of each work task. If incidents occur they must be investigated and actions taken to mitigate future occurrence. This process follows the overall safe work practices as outlined in the ISM program.

While each employer is primarily responsible for the safety of his/her worker's safety, the NIF NPSSP has implemented specific processes that are mandatory for all work activity on the NIF Project site. Procedures have been developed and are consistently applied for all work on the NIF Project Site. These are discussed in the sections to follow.

\section{III.B.1 NIF Project Site Work Authorization}

This process controls site access and ensures that the work is properly planned and authorized. Work is authorized and approval given to perform work at the NIF Project site only after completion of a Job Hazards Analysis/Integration Worksheet (JHA/IWS) form (and as needed for LLNL work, the Safety Plan [SP] attachment). This form is used to document the process of pre-job safety planning and hazard recognition. It identifies and analyzes the steps of a work activity for hazards and control measures prior to the work being performed.

The JHA/IWS:

- Identifies the tasks that need control.

- Identifies the hazards.

- Establishes the controls.

- Defines specific training prerequisites.

For LLNL work, the JHA/IWS form determines whether or not additional safety documentation in the form of an SP is required. All groups working on the NIF Project site including NIF elements, LLNL Plant Maintenance and Operations and any contractors or subcontractors and their subtiers are responsible to complete all or part of the JHA/IWS form and generally receive approval one week prior to performing the operation and or activity. The NIF Project Site Work Authorization Procedure is fully described in Project Control Procedure 5.12. 
In certain instances, if a significant new hazard is introduced, a Management Prestart Review may be required prior to work authorization as described in NIF Project Procedure 9.3, Management Pre-start Reviews. An identified set of Management Prestart Reviews exists in the NIF Integrated Project schedule.

\section{III.B.2 Safe Plan of Action (SPA)}

The purpose of the SPA is to ensure that all task leaders:

- Plan and review work daily.

- Assess the hazards in the actual work area and develop ways to mitigate those hazards consistent with the JHA/IWS/SP or contract/IWS that authorizes the work.

- Form and identify a team by involving workers in daily work planning and obtaining feedback from all team members.

- Obtain documented team acknowledgement of understanding of hazards and the associated controls.

All groups working on the NIF site are responsible for attending a SPA meeting prior to performing any work activity. This process is fully described in NIF Project Control Procedure 5.10, Safe Plan of Action.

\section{III.B.3 Permits}

There are several permits required for work on the NIF Project site. The fundamental premise for workers on the site is that all areas and operational systems within the NIF Project site are owned by the AIMs and controlled by the FAMs. The work permit has been developed to control the use of systems and work activities in a specific area after the JHA/IWS/SP is approved. A work permit is required for all work on the NIF Project site. The details of this process can be found in Project Control Procedure 5.8, NIF Project Site Work Permits.

In addition to work permits, specific hazards permits may be required, including hot work, excavations and on-grade slab penetration, penetration of concrete structures (floors, walls, and ceilings), work in confined spaces, work on energized equipment, and air and storm water work. Also included are permits for work near energized equipment and crane and hoist operation. (The process for specific hazards permits is described in Project Control Procedure 5.22, Specific Hazards Permits for the NIF Project Site. See also Appendix E-NIF Project Site Work Authorization and Safety Management Forms and Permits.)

NIF workers are responsible for obtaining or assisting with the processing of these permits and authorizations as necessary prior to starting the defined activity. Caution: All required permits and authorizations may not be addressed in this section, and any work activity that presents unusual work conditions impacting ES\&H issues should be 
brought to the attention of line management. Please refer to the NPSSP, Appendix E, Forms and Permits List, for a list of various permits and forms for site work planning and authorization.

\section{III.B.4 Incident Investigations, Notification, and Lessons Learned}

The timely evaluation of incidents is a valuable component of ISM to provide feedback and improvement to the safety process. It is the policy of the NIF Project to investigate all incidents related to NIF that result in personnel injury or illness or impact to the environment. Incidents resulting in equipment or facility damage will be investigated when the potential exists to improve procedures or methods, as identified in the Incident Investigation procedure, 5.11.

Incidents include personal injury, equipment damage, and near misses. Near miss incidents are events or a series of events that could have resulted in serious injury or illness or property damage, but did not due to circumstances or changes in events. The final decision on classifying an incident as a near miss will be made by the Project Manager, in consultation with the NIF Programs Assurance Manager, safety management, and the line management involved with the incident.

The analysis of incidents shall be considered a management function. All incidents shall be reported immediately to the work supervisor. The incident will then be reported, through the management chain, to the Site Manager.

- All NIF workers are responsible for reporting incidents to their supervisors.

- Supervisors are responsible for making appropriate notifications.

- Management is responsible for investigating incidents.

- Causes will be identified.

- Lessons Learned will be published.

- Corrective actions will be verified.

The Site Manager shall designate managers who will be trained in the NIF Project Incident Investigation process. The Site Manager shall monitor the implementation and manage the incident investigation process. This procedure is fully described in the NIF Project Procedure 5.11, NIF Project Site Incident Investigation.

The Incident Investigation (5.11) and Incident Notification (5.21) Procedures provide a basis for a Lessons Learned program, which enables the NIF Project to learn from any less-than-adequate management or work performance.

\section{III.B.5 Work Coordination}

Work that is executed on the NIF Project Site is to be planned and coordinated. The site has become increasingly complex as construction, commissioning, maintenance, 
and shot operations activites are occurring concurrently, requiring a higher level of coordination. FAMs are charged with ensuring that only work that has been planned is executed on the site-no unplanned work shall occur on the NIF Project Site. All work on site requries a work permit. Work is coordinated by the Commissioning and Operations Manager, AIMs, and the Site Manager. The electronic work permit process on the Location, Component, and State (LoCoS) tracking system should be used by AIs and FAMs to review and approve daily work permits. For a detailed description of the process, see Project Control Procedure 5.8, Work Permits. 


\section{Appendix A}

\section{NIF Project Site Safety Protocols and Requirements and NIF Code of Safe Practices}

\section{Contents}

1. General Rules and NIF Code of Safe Practices ..........................................................A-1

2. Personal Protective Equipment................................................................................A-9

3. Environmental Management.................................................................................

4. Traffic and Vehicles .............................................................................................

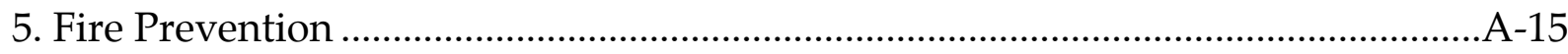

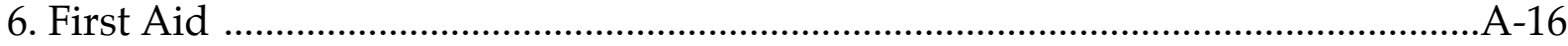

7. Confined Space Safety Requirements ......................................................................

8. Powered Industrial Truck Safety ……………….................................................

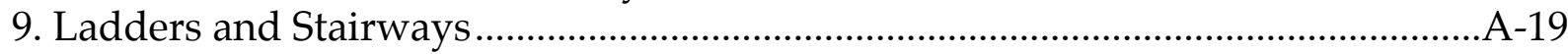

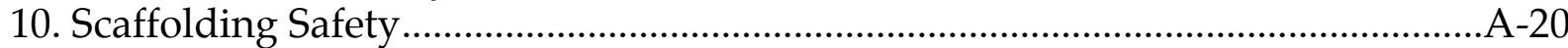

11. Welding, Cutting, and Burning...........................................................................

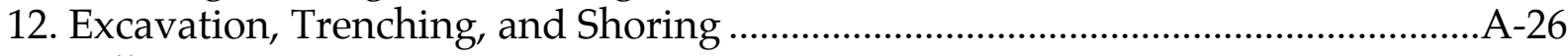

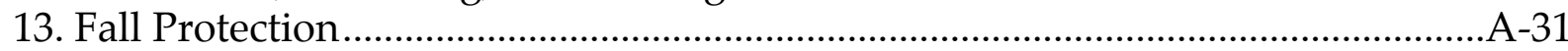

14. Steel Erection and Installation of Decking, Flooring, and Grating .......................A-34

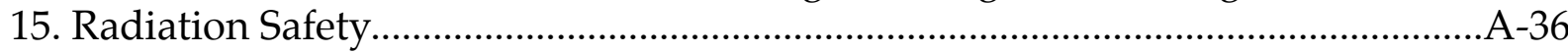

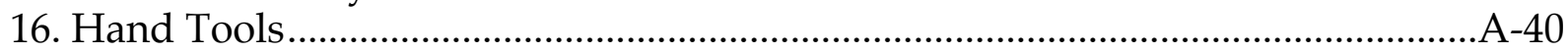

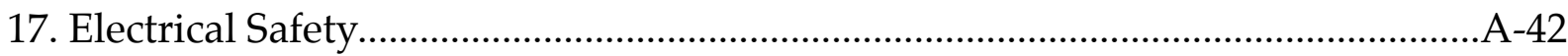

18. Aerial Lifts and Self-Propelled Elevating Work Platforms..................................A-48

19. Lockout/Tagout Requirements ...........................................................................A-52

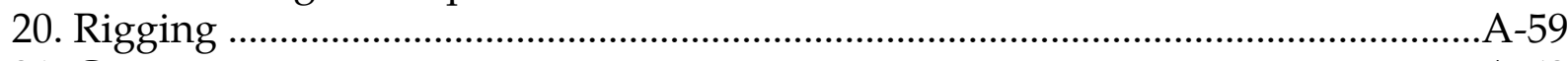

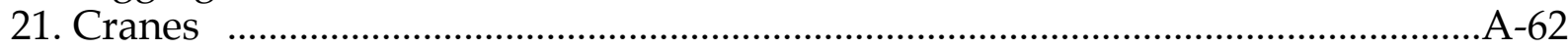

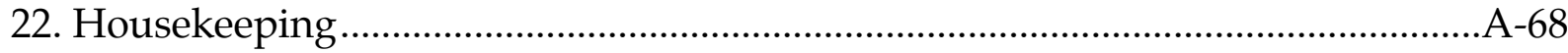

23. Material Handling and Storage ......................................................................

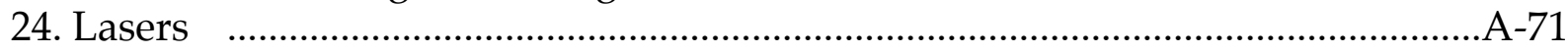

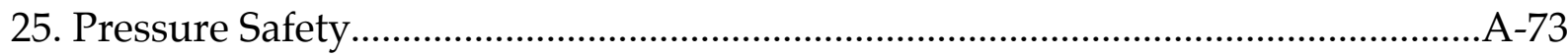

26. Safety Interlock System ....................................................................................

27. Permits and Authorizations................................................................................. 


\section{General Rules and NIF Code of Safe Practices}

These rules apply to all National Ignition Facility (NIF) workers (workers), which include Lawrence Livermore National Laboratory (LLNL) employees, non-LLNL employees (including contract labor, supplemental labor, vendors, personnel matrixed/assigned from other national laboratories, participating guests, visitors and students) and contractors/ subcontractors. The General Rules and NIF Code of Safe Practices shall be used by management to promote the prevention of incidents through indoctrination, safety and health training, and on-the-job application.

As a condition for contract award, all employers shall conduct an orientation for all newly hired and rehired employees before those workers will be permitted to start work in this facility. This orientation shall include a discussion of the following information.

The General Rules and NIF Code of Safe Practices must be posted at a conspicuous location at the job site office or be provided to each supervisory worker who shall have it readily available. Copies of the General Rules and NIF Code of Safe Practices can also be included in employee safety pamphlets.

The Environmental, Safety, and Health (ES\&H) rules at the NIF Project site are based upon compliance with the most stringent of Department of Energy (DOE), LLNL, Federal Occupational Safety and Health Administration (OSHA), California (Cal)/OSHA, and federal and state environmental requirements.

\section{Responsibilities}

All workers shall comply with the ES\&H requirements of their own parent organization, this NIF Project Site Safety Program, and as appropriate, subtier Health \& Safety Plans.

\section{Exceptions to the Requirements in Appendix A}

Requests for exceptions/modifications to NIF ES\&H requirements will only be approved if equivalent safety or environmental protection is demonstrated and regulatory requirements are met. Approvals shall be issued in writing by the cognizant Field Area Manager (or Site Manager) with concurrences from the NIF ES\&H Manager for Commissioning and Operations, NIF Site Safety Manager, and the ES\&H Team 2 Leader. 


\section{NIF Code of Safe Practices}

\section{General}

1. Only authorized personnel are allowed access to laboratory property. The direct line employer of each worker is responsible for assuring each worker complies with requirements of LLNL Site Access. Authorized personnel will receive a badge with a docimeter. This must be shown to the guard at the gate upon entry to the laboratory, and must be worn at all times while on site. The following privately owned items are not permitted on the laboratory site:

1. Pepper spray or mace

2. Alcoholic beverages

3. Illegal or unlawfully possessed controlled substances (drugs)

4. Poisons or corrosive materials

5. Dangerous weapons

6. Explosives

7. Binoculars or telescopes

8. Cameras

9. Any other items prohibited by law.

Once on site, workers are expected to report directly to their work location. Workers will be informed of all site access rules by their employer, including updates or changes in LLNL requirements when they occur.

2. All workers shall comply with this NIF Code of Safe Practices, assist all other workers in doing so, and report all dangerous conditions or practices immediately to their supervisors.

3. Supervisors shall insist on workers observing and obeying every rule, regulation, and order as is necessary to the safe conduct of the work, and shall take such action as is necessary to obtain observance.

4. Think Safety! If you have and maintain an attitude of safety on the job, then the chances of being injured are greatly reduced. Report all unsafe or unhealthful practices and conditions to your supervisor at once.

5. All injuries shall be reported promptly to the foreman or supervisor so that arrangements can be made for medical or first aid treatment.

6. When injuries occur, the first step is always to provide medical care for the injured and eliminate immediately any apparent cause of the injury. If a cause is not apparent, the work area and equipment shall be secured until the cause is determined by qualified authorities. 
7. All workers shall be given frequent instructions about how to prevent incidents. Instructions shall be given at a 5-minute (or more) safety meeting at the beginning of each shift, and at safety meetings.

8. It is a part of every worker's job to attend and take an active part in all safety training meetings and to actively support the company's safety program. Read and abide by all safety materials made available to you. They concern your safety and health and the safety and health of your fellow workers.

9. No one shall knowingly be permitted to work while his/her ability or alertness is impaired by illness, fatigue, medication, or other causes.

10. Reporting to work under the influence of alcohol, stimulants, tranquilizers, or barbiturates--or using them during working hours--will be cause for arrest and permanent removal from the LLNL work site and grounds for disciplinary or legal action if warranted.

11. Horseplay, scuffling, and other acts which tend to have an adverse influence on the safety or well-being of the workers shall be prohibited.

12. Work shall be well planned and supervised to prevent injuries in the handling of materials and in working together with equipment.

13. Workers shall not handle, or tamper with electrical equipment, machinery, vehicles, or air and water lines in a manner outside of the scope of their regular duty except with specific instructions from their supervisors.

14. Workers shall not enter manholes, underground vaults, chambers, tanks, silos, trenches, ditches, or any other subsurface area, or confined spaces without specific instructions from their supervisors, and only after it has been determined safe to enter.

15. Always be as familiar as possible and alert at all times to conditions and work processes in surrounding areas and with the presence of other workers and equipment so that you can foresee and avoid possible dangers.

16. Areas enclosed with barricades (hard barriers or red tape) are considered danger zones and shall be respected as such. Admittance to or passage through such areas is prohibited without permission except to those employees working within the barricaded area. Specific entrance point(s) shall be established, and a Barrier Tag showing control of the area shall be posted at each entrance point.

17. When work requires barricades or floor opening covers to be temporarily removed, keep area secured until the work is finished and then reinstall the barricade or floor covering immediately.

18. Be Sure.

a. You know how to do the job in a correct, safe manner.

b. You know the hazards and how to protect yourself.

c. You ask the advice of your supervisor if you are not sure.

19. Firearms and explosives are prohibited on the NIF Project site. 
20. Do not try to place speed above safety. An efficient, safe worker is better than a speedy, careless one. Running is not permitted on the Project site.

21. Throwing or dropping materials from one area or level to another is prohibited.

22. Be alert for and heed all warning signs at all times.

23. When lifting heavy objects, the large muscles of the leg instead of the smaller muscles of the back shall be used. Get help on lifting all objects too heavy for one person.

24. Hard hats, safety glasses with sideshields, and safety toe work shoes or boots shall be worn at all times. Inappropriate footwear or shoes with thin or badly worn soles shall not be worn. Other personal protective equipment such as gloves, goggles, respirators shall be worn when conditions require them for safety.

25. Observe good housekeeping. Keep work areas clear of debris and trash. Stack lumber and materials safely. Remove or bend nails from lumber, forms, etc.

26. Do not work or pass beneath suspended loads.

27. Only trained, qualified, and authorized persons shall install wiring or perform work or repairs on electrical equipment.

28. Excavations and trenches over 5 feet deep must be shored, sloped back, benched, or a trench shield used to prevent cave-ins. A Competent Person must evaluate all excavations and trenches each day. Ladders are to be provided within 25 feet of workers in excavations and trenches 4 feet or deeper.

29. Work shall be so arranged that employees are able to face ladders and maintain contact with three points (hands and both feet) while climbing. Defective ladders shall not be used. Do not stand or sit on or above the top step or top cap. Extend ladders at least three feet above the walking surface. Secure straight ladders to prevent unintended movement. Materials and tools shall not be carried while climbing; see Section \#9 Ladders and Stairways

30. No burning, welding, or other source of ignition shall be applied to any enclosed tank or vessel, even if there are some openings, until it has first been determined that no possibility of explosion exists, and authority for the work is obtained from the foreman or superintendent.

31. Any damage to scaffolds, falsework, or other supporting structures shall be immediately reported to the foreman and repaired before use.

32. Open sided floors, wall openings, floor holes, platforms, etc., more than 6 feet above the ground or floor must have standard guardrails or be covered.

33. Make sure handrails and walkways are in good repair and clear of tools, spare parts, and obstructions.

34. Workers exposed to fall hazards 6 feet or greater must be protected by a means of fall protection such as guardrails, nets, or personal fall arrest equipment such as a full body harness and shock-absorbing lanyard.

35. All equipment shall be locked out and tagged to protect against unintended or inadvertent operation when such operation could cause injury to personnel. 
36. Safe access shall be provided and maintained to all work areas.

37. Smoking and tobacco use is allowed on the NIF Project site only in identified, designated areas.

38. Finger rings shall not be worn on the NIF Project site or in areas covered under the NPSSP unless protected by gloves or tape. Individuals working in office/ administrative areas in the Diagnostics Building or FIT trailer (T5889) are exempt only while in or in transit to these areas from the perimeter gates. Visitors, such as tour participants, who will be on site for short periods, will also be exempt. As a good practice, other jewelry such as necklaces, wrist bracelets, and watches should be breakaway safe. Under no circumstances should any of these be worn when around live electrical equipment.

Working Alone

Working alone means performing any activity out of sight or communication for more than a few minutes. The major danger in working alone is sustaining an illness or injury that precludes self-rescue. Most common working alone situations occur during nights, weekends, and holidays, but can occur during normal working hours.

\section{Hazardous Work:}

1. Line manager or supervisor needs to review and approve the work before beginning work using an IWS. This ensures that all hazards and risks have been thoroughly evaluated and mitigated.

2. Contractors doing hazardous work are to be supervised

3. Authorization to perform hazardous work shall be given on a case-by-case basis (unless hazards have been specifically addressed by SP, FSP, permit or work procedures)

Non-Hazardous Work:

1. Line managers and workers need to exercise prudent judgment when working alone. If in doubt, don't. At a minimum, advise a co-worker or supervisor of the work location.

2. Give particular attention to non-Laboratory workers (e.g., contract workers, students) Are they adequately supervised (safety and technically), do they know the safety rules, do they have names and phone numbers of contacts should help be needed?

When a contractor is brought into LLNL, the contractor will be supervised by an LLNL (or equivalent) person.

Hazardous Materials

1. Material Safety Data Sheets (MSDS) are available through your supervisor for all chemicals, flammables, solvents, paints, and other hazardous products used on the project. 
2. Label/mark all containers of flammable, combustible, hazardous, and toxic materials.

3. If workers observe sandblasting dust, asbestos fibers, smoke, or other possibly dangerous pollutants in the air of a work space, they shall contact their supervisors for instructions.

4. Workers shall cleanse thoroughly after handling hazardous substances, and follow special instructions from authorized sources.

5. No smoking when handling flammable materials.

6. Store flammable and combustible liquids away from other combustible materials, or in special, flammable liquid storage lockers.

7. Gasoline shall not be used for cleaning purposes.

8. Smoking is prohibited at or in the vicinity of hazardous operations or combustible or flammable materials.

9. Use of asbestos components (gaskets, packing, floor tile, grout, seals) is prohibited. Any use of asbestos components or materials requires the approval of the Site/Facility Manager.

10. Due to the legacy aspects of compounds and paints that contain lead, lead shall not be used except as a shielding material unless there is no practical substitute wherein lead shall always be used only with the prior approval by the Site/Facility Manager. Any work involving the use of lead that is authorized by the Site/Facility Manager shall be conducted in a safe manner to prevent exposure to workers.

Use of Tools and Equipment

1. All tools and equipment shall be maintained in good condition.

2. Damaged tools or equipment shall be removed from service and tagged "DEFECTIVE."

3. No guard, safety device, or appliance shall be removed from tools, machinery, or equipment except for the purpose of making repairs. Such removal shall only be done by persons qualified to make the repair, and they shall first disconnect any power source and have the tool, machinery, or equipment in a safe area. All guards and other protective devices shall be in their proper places and adjusted. Workers shall report promptly all deficiencies to their supervisor.

4. Pipe or Stillson wrenches shall not be used as a substitute for other wrenches.

5. Only appropriate tools shall be used for the job.

6. Wrenches shall not be altered by the addition of handle-extensions or "cheaters."

7. Files shall be equipped with handles and not used to punch or pry.

8. A screwdriver shall not be used as a chisel.

9. Wheelbarrows shall not be pushed with handles in an upright position.

10. Portable electric tools shall not be lifted or lowered by means of the power cord. Ropes shall be used.

11. Electric cords shall not be exposed to damage from vehicles. 
12. Ground-Fault Circuit Interrupters (GFCI) are required on all temporary power circuits.

13. In locations where the use of a portable power tool is difficult, the tool shall be supported by means of a rope or similar support of adequate strength.

14. Compressed air shall not exceed 30 psi for cleaning purposes. Do not use pure oxygen for cleaning, especially on oily clothing!

\section{Machinery and Vehicles}

1. Only authorized persons shall operate machinery or equipment.

2. Loose or frayed clothing, or long hair, dangling ties, finger rings, etc., shall not be worn around moving machinery or other sources of entanglement.

3. Machinery shall not be serviced, repaired or adjusted while in operation, nor shall oiling of moving parts be attempted, except on equipment that is designed or fitted with safeguards to protect the person performing the work.

4. Engines shall be turned off before fueling.

5. Where appropriate, lockout procedures shall be used.

6. Workers shall not work under vehicles supported by jacks or chain hoists, without protective blocking that will prevent injury if jacks or hoists should fail.

7. Air hoses shall not be disconnected at compressors until hose line has been bled.

8. All excavations shall be visually inspected before backfilling, to ensure that it is safe to backfill.

9. Excavating equipment shall not be operated near tops of cuts, banks, and cliffs if employees are working below.

10. Tractors, bulldozers, scrapers and carryalls shall not operate where there is possibility of overturning in dangerous areas like edges of deep fills, cut banks, and steep slopes.

11. When loading where there is a probability of dangerous slides or movement of material, the wheels or treads of loading equipment, other than that riding on rails, should be turned in the direction which will facilitate escape in case of danger, except in a situation where this position of the wheels or treads would cause a greater operational hazard.

12. Crowding or pushing when boarding or leaving any vehicle or other conveyance shall be prohibited.

13. Always look around equipment before starting to make sure no one is near moving parts, making inspections or adjustments.

14. Stand clear of hauling equipment that is being loaded or is dumping material.

15. Do not touch or guide moving cables or running wires with any part of your body. Keep your hands and fingers away from blocks and sheaves. Stand clear of all cables, wires, and lines that are under strain. 


\section{$\underline{\text { Roofing Operations }}$}

1. Knotted hand lines should not be used.

2. Roofers tending kettles, or carrying buckets of hot tar, shall wear gloves that fit snugly at the wrists, and long sleeved shirts fastened at the wrists.

3. At no time should a roofer, while handling or exposed to injury from hot tar, work without a shirt or appropriate footwear.

4. Appropriate portable fire extinguishers shall be kept at or near the kettle, attached, if practicable, to the tongue of the kettle, away from the danger zone.

5. Kettle covers should be equipped with a handle that projects at least fourteen inches $\left(14^{\prime \prime}\right)$ away from the surface of the cover or lid.

6. Kettle covers shall be closed and latched when in transit and the kettle should be slop-proof when cover is closed.

7. When parked, means shall be provided to prevent inadvertent movement of the kettle.

8. Ladders should be used with great caution, and roof gutters should not be depended upon for support.

9. Workers handling buckets of hot tar should not carry anything that will interfere with the safety of this operation.

10. The gallows frame shall be securely anchored before hoisting materials.

11. Only muscular power shall be used to hoist materials by means of a gallows frame. A winch or power hoist shall not be used. 


\section{Personal Protective Equipment}

It is the responsibility of supervisors and foremen to provide all workers with directions about employer-provided and worker-provided protective equipment necessary for each operation. Personal protective equipment shall be worn as required. The requirements set forth herein pertaining to personal protective equipment shall apply at all locations, whether permanent or temporary. It is the employer's responsibility to provide personal protective equipment to its employees, and to ensure proper use wherever necessary.

Personal protective equipment shall be used to reduce the potential for injuries or detrimental affects on health, which are not controllable by engineering or administrative means, to all employees. The use of personal protective equipment for protection from identified hazards is mandatory under the following conditions:

1. Where required by law, NIF, or LLNL policy.

2. Where exposure to the hazard has the potential for injury or illness to an employee.

3. Where there is a potential for damage or contamination to property or the environment.

4. Where the failure to utilize the equipment would expose non-employees to a safety or health hazard.

The mandatory use of personal protective equipment will apply to all visitors in areas where use of such equipment is required.

\section{Responsibilities}

All NIF workers shall use the protective equipment prescribed by the regulatory authorities, such as Federal OSHA and employers' rules and regulations to control or eliminate any hazard or other exposure to illness or injury. Any employee who willfully refuses to use the prescribed protective equipment designed to protect him or her or willfully damages such equipment shall be subject to disciplinary action which may lead to his or her immediate termination. As necessary, each employer shall provide personal protective equipment to their employees.

\section{Basic NIF PPE Requirements}

1. Ear Plugs or Muffs. The use of hearing protection is mandatory where workplace daily noise levels exist with the possibility that employees receive exposure in excess of the allowable noise. The hearing protection devices chosen for use must conform to all applicable federal, state, and local safety and health regulations.

2. Eye Wear, Goggles, Safety Glasses, Face Shield, and Helmets. Situations that require this type of PPE could include, but not be limited to, grinding, chipping, 
sanding, sandblasting, or use of chemicals. Safety glasses with side shields or face shields must conform to the American National Standards Institute (ANSI), Standard for Occupational and Educational Eye and Face Protection, Z87.1. Welding shields, with no less than \#10 filter plate and safety lenses on both sides, shall be worn by personnel doing welding. Burning goggles, with no less than \#4 filter plate and safety lenses on both sides, shall be worn by personnel doing flame cutting. Face shields are required during activities such as grinding, cad welding, chain sawing, chipping, or handling corrosive liquids or molten materials. Face shields protect only the face and do not meet the requirements for eye protection; therefore, safety glasses are required with face shields.

If a laser hazard also exists, appropriate laser safety glasses must be worn if required. These laser safety glasses must also meet ANSI Z87.1 unless a waiver is obtained (see item 10).

Eye protection shall be worn at all times, except in administrative areas. Approved welding helmets and appropriate protective eyewear is required on-site by all contractors during machinery activities that require appropriate protection.

Wearing dark or shaded ("photochromatic" or light sensitive) glasses is not permitted inside buildings or at night. (This does not include laser eyewear.)

3. Hard hats are required in all NIF Project site areas. Hard hats shall be worn at all times in NIF Project areas, except in administrative areas. The head protection devices shall meet the specifications contained in the American National Standards Institute, Z89.1, Requirements for Industrial Head Protection. Field Area Managers can make specific exceptions.

Hard hats for the protection of employees exposed to high-voltage electrical shock and burns shall meet the specification contained in American National Standards Institute, Z89.2. All employees and visitors must wear company approved hard hats during work hours while inside NIF Project site areas.

4. Respirators. When it is determined that effective engineering control of oxygen deficiency or air contaminant exposure is not feasible, appropriate respiratory protection will be provided for use by the exposed employees. Use will be mandatory whenever a potential respiratory hazard exists.

The selection, use, and maintenance of respirators shall comply with all applicable state/federal, ANSI Z88.2 and local laws pertaining to safety and health. NIOSHcertified respirators will be used when excessive dusts, mists, fumes, gases or other atmospheric impurities are determined to be harmful to health. Contractors are responsible to provide a written respiratory protection program if respirators are used on-site.

5. Safety Harnesses and Lifelines. Full body safety harnesses will be used by all employees working from unguarded surfaces where falls to a different level GREATER THAN SIX (6) FEET present a hazard. Safety Belts will not be allowed (except when used as part of a positioning device system, or where allowed by OSHA, e.g., linemen's body belts); only the use of a full body harness and shockabsorbing lanyard will be acceptable. The project is a $100 \%$ tie-off project, requiring the use of two lanyards when exposed to a fall greater than six (6) feet. 
6. Footwear. All employees working in construction areas shall wear safety toe work shoes or boots. In all other areas where there is danger of falling or rolling objects, or objects piercing the sole, and where the employee's feet are exposed to electrical hazards, protective footwear shall be worn. All footwear shall meet the specifications contained in the American National Standards Institute, Z41, American National Standard for Personal Protection - Protective Footwear. Workers shall wear safety shoes with a square heel (not tapered) that are no greater than 1 inch in height (measurement at front edge of heel).

7. Hand Protection. Strong nonslip gloves are required for all workers, except working around rotating equipment/machinery or where the use of gloves could create greater risks. When cutting with a utility knife or similar tool where there is a risk of hand laceration, cut-resistant Kevlar gloves are required.

8. Dress Code. Employees working in construction areas are required to wear clothing for the appropriate season. Shirts shall have a minimum of 4 " sleeves. Tank tops and sleeveless shirts are not allowed. Pants should be long enough to cover the top of appropriate footwear. Winter clothing should be sufficient to protect against cold related injuries, i.e., hypothermia and frostbite.

9. Special Equipment. As heretofore stated, the use of personal protective equipment will be deemed mandatory when the hazard cannot be controlled at the source. This shall apply to the use of special protective equipment such as gloves, aprons, sleeves, shoes, hoods, and boots. When it has been determined through the site management, statistical analysis, or compliance requirements that the use of special protective equipment is needed to provide the hazard control, this mandatory use requirement shall apply.

10. Waivers. The responsible individual/supervisor can apply for a waiver from the requirement for certain PPE for a specific task in a specific area, if in their opinion the PPE is not warranted based on the hazards associated with the task or hazards present in the area. The waiver must be submitted to the appropriate Field Area Manager, and approved by the Field Area Manager and the Site Safety Manager. 


\section{Environmental Management}

All work shall be conducted in accordance with applicable federal, state, and local environmental laws, rules, and regulations and with the LLNL ES\&H Manual (web address: http:/ / www-r.llnl.gov/es and h/esh-manual.html). Note that requirements for hazardous waste management in the ES\&H Manual are, in some cases, more restrictive than regulatory agency requirements. All work shall comply with the applicable LLNL Storm Water Pollution Prevention Plan(s) and applicable environmental permits issued to LLNL or NIF. Environmental requirements are subject to change over time, resulting in a need for continuing compliance review. Environmental compliance assistance is available from the ES\&H Team 2 Environmental Analyst, the NIF Lead Environmental Engineer, the Team 2 Hazardous Waste Management Technician, and others in the LLNL Environmental Protection Department supporting Team 2.

The NIF Project materials recycling program shall be maintained until the facility is turned over to LLNL, at which time it will be covered by the LLNL recycling program. Recycling containers for paper, wood, cardboard, metals, and other appropriate materials shall be made available, and the estimated weights of recycled materials shall be reported on a monthly basis. 


\section{Traffic and Vehicles}

The provisions of the California Vehicle Code (CVC) and the Laboratory's requirements for pedestrians, traffic safety, and parking apply to all NIF workers, visitors, vendors, and guests. The CVC, while not legally binding on site, shall be considered as a source document and is enforceable through LLNL's Protective Force Division. Protective Force Division officers will cite operators (regardless of employment status) who violate on-site traffic and parking regulations. Speeding and moving traffic infractions are serious safety concerns. Anyone who violates either the CVC or Laboratory requirements while on site is also subject to corrective action by LLNL and the NIF Project management.

The requirements for all vehicles are based on the CVC, while those for commercial vehicles are based on the Department of Transportation (DOT) 49 CFR (various sections), "Federal Motor Carrier Safety Regulations," and the CVC.

Traffic control and routes are as indicated on site drawings and outlined in the written instructions. Sketches for the construction of certain detours in areas not indicated on the drawings shall be submitted to the NIF Site/Facility Manager for approval. Personnel are directed to become familiar with these details.

\section{Responsibilities}

All workers (pedestrians, motor vehicle operators, and bicycle riders) must comply with these requirements and the provisions of the California Vehicle Code (CVC) when operating Laboratory-owned, privately owned, rented vehicles, or bicycles to make the roadways and pathways safe. Individuals who operate their own motor vehicle, a Laboratory motor vehicle, or a rental vehicle on or off LLNL property must have on their person a valid, current driver's license from their state of residence and are responsible for operating vehicles in accordance with the applicable vehicle code. Nongovernment vehicles require a permit from the NIF Project prior to being driven on the construction site. Permits are available through the contractor.

\section{Basic Rules for Traffic Safety}

1. Seat belts must be used by the driver and all occupants of a motor vehicle. The driver shall ensure that occupants wear their seat belts. Riding on flatbed trucks or in the back of pickups is not permitted. Riding on equipment is not permitted unless the vehicle is so equipped to safely carry passengers.

2. Vehicles must be operated at a speed that is reasonable, safe, and proper for the weather, traffic, and road conditions. The maximum speed limit at the LLNL Livermore site is 25 miles per hour ( $\mathrm{mph}$ ), unless otherwise posted. The maximum speed limit in parking lots and alleys is $15 \mathrm{mph}$. The speed limit on the NIF Project site is $15 \mathrm{MPH}$, except when designated otherwise, e.g., "Construction Zone." 
3. All flagmen and other workers in traffic areas shall wear appropriate high-visibility vests and use placards and signs as appropriate.

4. Required safety, fire, instructional, and traffic signs shall be posted and obeyed. They shall not be removed until their removal is approved by the Site/Facility Manager.

5. Workers shall park personal vehicles in designated employee parking areas only.

6. Private vehicles are not permitted on the NIF Project site. Bicycles are not permitted on the NIF Project site.

7. Company vehicles shall park only in designated parking areas on the NIF Project site.

8. All vehicular incidents that occur on the Laboratory site, of whatever size and nature, whether injury or noninjury, shall be reported immediately to the superintendent and to the NIF Site/Facility Manager.

Note: Drivers operating equipment supplied with Roll Over Protection shall wear seat belts. 


\section{Fire Prevention}

Rules addressing fire prevention are provided in the LLNL ES\&H Manual (http://www-r.llnl.gov/es and h/esh-manual.html). For Fire Prevention questions, contact the LLNL Fire Department and/or the Team 2 Fire Protection Engineer.

A Hot Work Permit, which is issued by the Hazards Control Department's Emergency Management Division (LLNL Fire Dept.), is required for all hot work operations. See Appendix E for a list of forms and permits available on the NIF Site Resource web page. Hot work operations include cutting, welding, brazing, soldering, roofing or road work using tar pots, torches and hot air guns used in applying roofing, thermal spraying, use of open fires for any purpose, or any similar activity. The requirements of the permit shall be followed without exception. The Supervisor, Construction Inspector, or Site Manager must contact the LLNL Fire Department to arrange for the permit. A single "blanket" permit may be requested to cover long-term phases of the project, such as Conventional Facility construction.

An authorized fire watch person(s) shall be provided for all hot work operations in which there is the possibility that a smoldering fire may be started by hot work. The fire watch person(s) shall have no other assigned duties except to act as a fire watch. They shall remain in the area during the hot work operations and for not less than 30 minutes (60 minutes for torch-applied roofing) following the end of hot-work operations. The fire watch shall have a dedicated fire extinguisher of the appropriate type and size. 


\section{First Aid}

All injuries occurring on the NIF Project site must be reported immediately to the worker's supervisor. Contractors shall report to the safety trailer for first aid assistance. LLNL employees shall report to the laboratory medical facility, B663. In the event of an emergency, dial 911 from a wall phone, or 925-447-6880 from a cell phone. 


\section{Confined Space Safety Requirements}

This section outlines the responsibilities for individuals who work in confined spaces. Individuals who do not comply with these requirements risk the possibility of injury or death. These requirements are based principally upon the Federal OSHA requirements (29 CFR 1910. 146) for confined spaces.

A "confined space" is defined as an enclosed area that is large enough for an employee to enter and perform assigned work, has limited or restricted means of entry or exit, and is not designed for continuous human occupancy.

The following are examples of confined spaces that may exist:

- Storm drainpipes

- Sewers

- Storage tanks

- Utility pipelines

- Large vacuum vessels
- Vaults

- Manholes

- Trenches/excavations

- Transformer tanks

- HVAC ducting/units

OSHA has identified two categories of confined spaces: low-hazard confined space (nonpermit confined space) and high-hazard confined space (permit-required confined space). A confined space entry permit is required prior to entry into all confined spaces at NIF regardless of hazard category. See Appendix $E$ for a list of forms and permits that can be found on the NIF Site Resource web page.

Further requirements on confined space safety are provided in the LLNL ES\&H Manual, http://www.llnl.gov/es and h/esh-manual.html 


\section{Powered Industrial Truck Safety}

All powered industrial truck (commonly referred to as fork trucks) operation shall be conducted in accordance with the LLNL ESEH Manual http://www.llnl.gov/es and h/esh-manual.html.

Fork trucks shall be operated and maintained according to the manufacturer's instructions. It shall be the responsibility of the employer to assure the individuals in their employ are knowledgeable of this information and the rules of conduct for the operation of fork trucks as noted in the LLNL ESEH Manual. All powered industrial truck operators shall receive training as required under CFR 1910.178(1). 


\section{Ladders and Stairways}

All ladders and stairways shall be built, used, and maintained in a safe manner to prevent injury to workers. Rules governing the safe use of ladders and stairways is found in the LLNL ESEH Manual, http://www.llnl.gov/es and h/esh-manual.html.

\section{Basic Rules for Ladder and Stairway Safety}

1. Materials and tools should be raised and lowered by a rope or other mechanical means. A hoisting rope shall be provided with all portable and fixed ladders where workers are likely to need to hoist materials and / or tools.

2. Portable ladders shall be placed in storage racks, secured to prevent tip over, laid down and moved out of walkways, or removed from the work area when not in service.

3. Personal fall protection is required when working from a ladder when the worker's feet are more than 6 feet above the surface and when the midsection of the worker's torso (i.e., belt buckle) is outside of the side rails of the ladder, or if it is necessary to work backwards from a ladder. Personal fall protection shall not be anchored (tied) to portable ladders. If repositioning the ladder does not meet the fall protection requirements, it is recommended that an alternative means of access such as a scissors lift, aerial lift, or scaffold be used.

4. All portable (i.e., straight and extension) ladders must be tied off, blocked, or otherwise secured to prevent their being displaced. Stepladders should be tied off whenever possible. All ladders shall be secured when the forces applied by the worker while working on the ladder, and/or other forces, can overcome the stability of the ladder and cause the worker to fall. All portable ladders shall be provided with a 6-foot rope for securing the ladder.

5. Workers shall maintain three points of contact on a ladder when climbing or descending. 


\section{Scaffolding Safety}

All scaffolding shall be erected, used, maintained, and disassembled in a safe manner to prevent injury to workers, collapse or tip over.

\section{Responsibilities}

1. Each employer shall develop, document, and utilize scaffolding safety procedures as required.

2. Before erecting any scaffold that is more than three stories tall (greater than 36 feet), a detailed written Scaffolding Erection Plan shall submitted to the Field Area Manager for review and approval (see Appendix E for a list of forms and permits available on the NIF Site Resource web page). The plan shall show the design of scaffolding, bracing, attachment to the structure, maximum loading, or other provisions to be made to protect workers from the hazard of scaffolding collapse or tip over. The proposed plan shall comply with the standards established by State of California, CCR Title 8, and California Building Standards Code (CBSC)(formerly CCR Title 24). If the detailed plan varies from such scaffolding system standards, it shall be prepared by a California registered civil or structural engineer whose name and registration number shall be indicated on the drawings. If a dispute arises as to whether the plan shall be prepared by a registered civil or structural engineer, the University's determination of the matter shall be final and conclusive on the Subcontractor. The cost of required engineering services shall be borne by the Subcontractor and shall be deemed to have been included in the amount bid for the work as stated in the Agreement.

Neither the review nor approval of any plan showing the design of scaffolding, bracing, attachment to the structure, or other provisions for worker protection shall relieve the Subcontractor from the obligation to comply with CCR Title 8 and CBSC for the design and construction of such protective work, and the Subcontractor shall indemnify the University from any and all claims, liability, costs, actions, and causes of action arising out of or related to the failure of such protective systems. The Subcontractor shall defend the University, its officers, employees, and agents in any litigation or proceeding brought with respect to the failure of such protective systems.

3. Each employer must instruct their employees in the safety significance, purpose, and use of the scaffolding safety procedures and maintain a record thereof. Training records for contractors/ subcontractors employees shall be made available for review.

4. All contractors/subcontractors are responsible for advising all other affected persons when their safety will be impacted by scaffolding.

5. Each employer must conduct and document daily inspections of scaffolding under their control to ensure that the requirements are being followed. Scaffolding shall be 
inspected by a designated competent person. Inspection documentation shall be delivered to the Site Safety Manager.

6. Each employer shall submit a list of competent persons for scaffolding safety to Facility Management.

\section{Basic Rules for Scaffolding Safety}

1. All scaffolding shall be erected, maintained, and disassembled by workers trained in the safe erection, maintenance, and disassembly of scaffolding. The scaffolding crew shall work under the direction of a trained, certified, and competent scaffolding supervisor.

2. All manufactured scaffolding shall be erected and used in accordance with the manufacturer's instructions.

3. All platforms 6 feet or higher above the ground or surrounding surface shall be provided with standard guardrails, including top rail and midrail, on all open sides. Toeboards are required. Toeboards shall not be secured by nailing.

4. Midrails shall be located approximately midway between the top rail and the walking surface. Cross bracing can be used in place of midrails provided the cross meets at approximately the midheight between the top rail and the working surface. Cross bracing can be used in place of top rails provided the cross meets at approximately the height of the top rail and a separate midrail is also provided.

5. Portable ladders shall be used to provide safe means of access to scaffolds where ladders are not an integral part of the scaffolding framework.

6. Integral scaffold stairways shall be employed when scaffolds exceed three stories tall. Stairways shall be provided with standard handrails.

7. Workers shall not ride on scaffolds when they are being moved.

8. Scaffolds shall be level and plumb, and placed on adequate support. Plywood alone does not meet the support requirements. Metal base plates or wheels must be used on metal tubular or welded frame scaffolds. Castor wheels must be locked when the scaffold is not being moved.

9. A minimum of two scaffold grade planks shall be used to form a deck or walking surface. Manufactured scaffold planks must be used in accordance with manufacturer's instructions. All deck planking shall be secured to prevent movement.

10. Placing planks between ladders, or on top of buckets shall not be used in place of approved scaffolding. Heavy, industrial type saw horses capable of supporting planking, worker, and materials can be used to create scaffolding. Do not place saw horses on top of each other to gain a higher platform.

11. In order to prevent movement or tip over, scaffolding must be secured to the structure every 26 feet vertically and every 30 feet horizontally.

12. Scaffolds shall be maintained in a safe condition. Loose or missing guardrails, cracked or broken planks, structure out of plumb or level, unsupported bases, 
wheels unlocked, etc. make a scaffold unsafe. The scaffolding should not be used until unsafe conditions are corrected.

13. Do not overload a scaffold with materials or workers. Do not stand or climb on the guardrails. Portable ladders are not safe when used on top of scaffolds. Use of ladders on scaffolds must be reviewed and approved by a safety representative.

14. Scaffolds must be inspected daily and prior to use using the Daily Scaffolding Inspection form. (See Appendix $\mathrm{E}$ for a list of forms and permits available on the NIF Site Resource web page.) Do not work on slippery scaffolding until it is cleared of frost or ice or sanded.

15. For other types of scaffolds such as mason's or bricklayer's scaffolds, see OSHA requirements.

16. Makeshift scaffolds are not permitted.

17. All elevated platforms higher than 25 feet must have a 25 foot clear zone or barricaded perimeter around the base of the work platform. The only personnel allowed in the clear zone will be personnel loading or unloading materials or equipment from the platform. Platforms larger than 100 square feet must be screened around the perimeter to prevent falling objects.

18. A ladder safety device or a self-retracting lifeline shall be used for fall protection on all portable, hook-on, and attachable vertical scaffold ladders over 12-feet high. A separate anchorage point may be required for the fall protection, depending on the capacity of the scaffold being utilized. 


\section{Welding, Cutting, and Burning}

All welding, cutting, and burning shall be controlled in a safe manner.

\section{Responsibilities}

1. Each employer shall develop, document, and utilize welding, cutting, and burning safety procedures as required.

2. All workers involved with welding, cutting, and burning shall be instructed on the safety significance, purpose, and use of welding, cutting, and burning safety procedures. In addition, all workers involved with oxygen/fuel gas welding and cutting shall attend a separate class on the unique safety aspects of oxygen/fuel gas welding and cutting. Training records shall be made available for review.

3. Each employer shall advise all other affected persons when their safety will be impacted by welding, cutting, and burning.

\section{Basic Rules for Welding, Cutting, and Burning Safety}

\section{General}

1. Only trained workers, whose regular duties as assigned by their supervisors include welding, cutting, and burning shall perform this work.

2. Only standard, approved equipment shall be used.

3. Where stored in the open, cylinders should be protected from direct sunlight when the air temperature exceeds 125 degrees (F).

4. Screens or shields shall be provided for the protection of persons or combustible material exposed to sparks or falling objects.

5. When working on lead, zinc, or other materials that could generate harmful fumes, adequate ventilation and exhaust devices shall be provided. When ventilation is not practical or feasible, respiratory protection shall be used.

6. The designated safety representative or foreman shall inspect the work site before any use of welding, cutting, or burning equipment to ensure that all combustibles in the work area have been removed or otherwise protected from the welding or cutting work. He/ she shall also assure that a current Hazardous Work Permit for hot work is in effect at the designated job site. See Appendix E for a list of forms and permits available on the NIF Site Resource web page.

7. A fire watch may be required (see Section 5, Fire Prevention).

\section{Arc Welding}

1. Frames of welding machines operated from electric power sources shall be properly grounded. 
2. When arc welding, workers shall wear adequate masks or hoods with proper eye protection, gloves, and leather aprons as minimum protection; these shall be supplemented with hard hats, safety shoes, and other protective gear where warranted.

3. All workers and passersby near the welding area shall be protected from eye flashburns by use of partitions, screens, or other appropriate methods.

4. Welding cables, cords, and leads shall be neatly secured so as not to cause tripping.

5. Electrode stubs shall be disposed of immediately in a safe container.

6. Electrodes shall not be left in the holder when the welder is not in use. Do not store electrodes in the holder.

7. Straight and reverse current welding shall not be performed in close proximity to each other.

\section{Oxygen/Acetylene Welding}

1. Cylinders shall never be dropped or struck.

2. Cylinders shall be stored away from any source of heat.

3. Where stored in the open, cylinders shall be protected from continuous sunlight.

4 Oxygen cylinders shall be stored at least $20 \mathrm{ft}$ away from those containing any fuel gas.

5. Where stored inside, oxygen cylinders shall be separated from those containing fuel gases by a 5 -ft-high, noncombustible barrier with a fire rating of at least $0.5 \mathrm{hr}$, or they shall be separated by a $20-\mathrm{ft}$ distance.

6. Cylinders shall be stored vertically and secured to prevent them from falling over.

7. Cylinders shall never be lifted by machinery unless they are in a safe stand or cradle or are otherwise positively secured against falling or being dropped.

8. Special arrangements shall be made to secure cylinders while they are being transported. Carrying them loose on the back of a truck or in a pickup is prohibited.

9. Caps shall be firmly screwed onto cylinders except when the cylinders are connected to a regulator during use.

10. Oxygen cylinders shall be kept free from oil or grease. Use of oil or grease as a lubricant for oxygen valves or attachments is prohibited.

11. Smoking or flame is prohibited near welding gas cylinders or outlets.

12. Field adjustment or repair of gauges, valves, accessories, or safety devices is prohibited.

13. Acetylene shall not be used for welding or cutting at pressures exceeding $15 \mathrm{psig}$.

14. Fuel gas cylinder valves shall not be opened more than one full turn, and the wrench shall be left on the valve stem so that the valve can be closed quickly if necessary.

15. Oxygen cylinder valves shall be opened fully and made hand-tight against the back seat. This takes the high-range cylinder pressure off the packing. 
16. Mixing gases in cylinders, refilling cylinders, or using cylinders for any use except their original purpose is prohibited.

17. It is permissible to close torch valves alone only when work is briefly suspended and the operator is nearby. Any other interruption of use (e.g., if one cylinder becomes empty) necessitates closing the cylinder valves, followed promptly by opening the torch valves to purge lead-hoses and releasing the regulator screws.

18. Hoses shall never be hung from regulators, other equipment, or the cylinder tops.

19. Reverse-flow check valves or flashback arrestors shall be provided on oxygen and fuel gas systems. 


\section{Excavation, Trenching, and Shoring}

All excavations, including trenches shall be protected to prevent cave-in or loose soil falling into excavations through shoring, bracing, sheet piling, underpinning, sloping, or other methods.

\section{Responsibilities}

1. Each employer shall develop, document, and utilize excavation safety procedures as required.

2. Before beginning any excavation or trench that is 5 feet deep or more, the employer shall submit to the Field Area Manager for review and approval a detailed written plan showing the design of shoring, bracing, sloping, or other provisions to be made to protect workers from the hazard of caving ground during the excavation. The proposed plan shall comply with the standards established by State of California, CCR Title 8, and California Building Standards Code (CBSC)(formerly CCR Title 24). If the detailed plan varies from such shoring system standards, it shall be prepared by a California registered civil or structural engineer whose name and registration number shall be indicated on the drawings. If a dispute arises as to whether the plan shall be prepared by a registered civil or structural engineer, the University's determination of the matter shall be final and conclusive on the Subcontractor. The cost of required engineering services shall be borne by the Subcontractor and shall be deemed to have been included in the amount bid for the work as stated in the Agreement.

Neither the review nor approval of any plan showing the design of shoring, bracing, sloping, or other provisions for worker protection shall relieve the Subcontractor from the obligation to comply with CCR Title 8 and CBSC for the design and construction of such protective work, and the Subcontractor shall indemnify the University from any and all claims, liability, costs, actions, and causes of action arising out of or related to the failure of such protective systems. The Subcontractor shall defend the University, its officers, employees, and agents in any litigation or proceeding brought with respect to the failure of such protective systems.

3. Excavation Permit Process: Permission to proceed must be obtained from the Field Area Manager prior to all excavation/ penetration of soil surface areas and includes digging, tunneling, trenching, grading, cutting, drilling, jack-hammering, and use of power and pneumatic activated tools, etc. There is no exemption from this requirement based on depth of intended excavation/penetration. Of particular concern is the prevention of contact with live electrical conductors or other significant hazards (e.g., natural gas lines, water lines, air lines, etc.). The intent is to minimize the chance of injury or death to personnel and disruption of essential services. Penetrations related to replacement of existing appurtenances (fence posts, sign posts, and like items) within original space are exempted from this procedure. The Field Area Manager is responsible for obtaining a Soil Excavation (digging, 
grading, tunneling, trenching, and / or drilling) Permit from the LLNL Plant Engineering Maintenance Operations Division. Refer to Maintenance Operations Procedure (MOP) MOP-02003, Soil Excavation (Digging, Grading, Tunneling, Trenching, and / or Drilling) Permit Procedure. See Appendix E for a list of forms and permits available on the NIF Site Resource web page.

Prior to excavation or slab penetration, attempts must be made to locate underground utilities. The Field Area Manager (Responsible Person) for the soil excavation/penetration operation shall assure that the following actions are accomplished:

a. Review available project drawings and coordinate with the appropriate utilities.

b. Review drawings and other historical documentation.

c. Collect information from knowledgeable employees based on personal recollection of construction in a particular area.

d. Make on-site observation of existing conditions such as exposed conduit, manholes, valve boxes, nearby equipment, and like items.

e. Perform any additional methods the Responsible Person deems necessary to assure safe working conditions.

f. Mark the area to be excavated in white paint as per California Code 4216.

g. Bring all pertinent, most recent drawings, including an enlarged section of the site map showing the location of the proposed excavation, to the Central Permit Desk to schedule a PE Utility Locator survey or get a Locator tracking number and appropriate forms (for Locator Contractor).

h. Have a survey of the proposed work area completed by a qualified locator service and reviewed by the LLNL Utilities Group prior to pulling the permit. Locator services are available through off-site locator contractors or on-site through Plant Engineering Locators. The duties of the locator service are detailed in MOP-02003. They include using active/ conductive locating (radio frequency conductive equipment) as opposed to passive/inductive locating whenever practical, or any other means necessary.

i. Complete a Soil Excavation Job Safety Analysis Reference Checklist for the typical items that should be considered prior to any penetration action.

Issuance of a permit should not be considered as approval to begin penetration actions. Permission to start penetration actions shall be granted by the Responsible Person only after it has been determined that the workplace conditions are safe for these operations.

A copy of the Approved Permit Package shall be posted at the job site. The package will include the Permit, Locator report form, and detailed locator's drawing.

Upon completion of the excavation project, the Responsible Person shall submit a completed permit and required documentation. 


\section{Excavation Process for Identified Interferences}

The following procedures shall be followed when performing excavations near identified interferences:

a. Any jackhammer work performed under this procedure shall be accomplished using the following personal protective equipment: $0-5 \mathrm{kV}$ rated insulating gloves with moisture absorbing liners and rubber soled shoes. The insulating gloves must be tested in accordance with the manufacturer's standards.

b. Excavation within 30" of a known utility must be hand dug or excavated until the utility is located or to the required depth.

c. Excavation that will cross existing location utilities shall be performed by hand or air knife until required depth is reached or utility is physically located.

d. Excavation that is paralleling or nearly paralleling (15 degrees) utilities shall be performed by hand until required depth is reached or utility is located. Repeat every 25 feet along parallel or nearly parallel trenches if actual location is at uniform depth. Decrease distance to 10 feet if depth is not uniform.

e. If feasible, secure located utilities by proper lock and tag procedures during the hand excavation process.

f. As appropriate, execute work under supervision of a competent person as defined by CFR 1926, Section 650 to 651.

4. Each employer shall instruct their employees in the safety significance, purpose, and use of the excavation safety procedures, and maintain a record thereof. Training records shall be made available for review.

5. Each employer shall advise all other affected persons when their safety will be impacted by excavations.

6. Each employer must conduct daily inspections of excavations under their control to ensure that the requirements of the excavation safety program are being followed. Excavations shall be inspected by a designated competent person. Inspection documentation shall be delivered to Facility Management.

7. Each employer shall submit a list of qualified and competent persons for excavation safety to Facility Management. 


\section{Basic Rules for the Excavation Safety Program}

1. Workers shall not enter or work in any excavation that has not been properly shored, sloped, benched, shielded or otherwise protected from cave-in.

2. All excavations shall be under the control of a competent person who is both capable of identifying existing and predictable excavation hazards, and authorized to take prompt corrective measures to eliminate them. The competent person shall make daily inspections of excavations and the adjacent areas. Excavations shall be inspected by the competent person prior to work and as often as needed throughout the work shift. Inspections shall also be made after rainstorms.

3. All shoring shall be installed, maintained, and removed only by workers trained to install the shoring system being employed. Hydraulic shoring shall be installed in accordance with the OSHA tables, and the manufacturer's data and recommendations.

4. Suitable temporary barricades, fences, or other structures as required for the protection of public traffic and employees shall be provided around excavations. Barricading of excavations and trenches shall conform to LLNL standards. Lighted barricades must be used on all roadways. Excavations in remote locations shall be barricaded. Refer to the contract for barricading requirements.

5. All personnel bridges over trenches or excavations 2 feet or more wide must be equipped with standard safety railing. Workers shall not attempt to jump across excavations or trenches.

6. Excavations may be considered confined workspaces and shall initially be treated as such when access is necessary. Refer to Section 7 Confined Space Safety Precautions regarding entry into excavations.

7. Excavation spoil piles shall be located sufficiently far away from the excavation so that the toe of the pile of excavated material is at least 2 feet from the edge of the excavation.

8. A safe means of access including ladders, stairs, steps, ramps, etc., shall be provided for all excavations 4 feet or greater in depth. Ladders shall not be located further than 25 feet from workers in an a trench or excavation unless other means of access are provided.

9. When working in excavations, workers shall stay within the protected areas of the excavation (e.g. stay within the shoring, trench shield, etc.).

10. Workers must keep alert for changing ground conditions or signs of possible movement. If any unsafe excavation conditions are found, exit the excavation immediately and report the conditions to your supervisor and to the designated competent person. Do not allow others to enter the excavation until unsafe conditions have been corrected.

11. Heavy equipment shall not be allowed to work near the edge of excavations where personnel in the excavation would be at risk from the equipment toppling into the 
excavation. Stop logs, barricades, or berms shall be used to prevent heavy equipment from rolling into excavations.

12. SARA/OSHA training is required for employees handling contaminated soil. 


\section{Fall Protection}

Falling while on the job is a leading cause of serious injury to workers. Whether tripping and stumbling or falling from elevated work, the result can be a serious injury or worse. Protection from falling demands careful planning to prepare the work environment and provide all necessary equipment to control identified falling hazards. Constant diligence is also necessary on the part of workers to protect themselves from falling. Fall hazards should first be controlled through designs or engineering practices that eliminate the exposure. When this is not possible, fall protection is routinely provided through the proper use of guardrails, nets, and personal fall arrest systems. Fall restraint is an important practice that should be applied when using personal fall protection equipment. Fall restraint systems allow the employee to move only as far as the sides of the working level or working area, but avoid falling. This is different from the use of personal fall arrest systems that are designed to protect the worker but do not by themselves prevent the fall from occurring. Positioning device systems are also used to provide fall protection. These systems protect the employee only when he/ she is actually at his/her working location. While moving to or from that location, workers may not be adequately protected. Other controls are necessary when using positioning device systems. All fall protection shall be used and maintained in a safe manner to prevent injury to workers.

\section{Responsibilities}

1. Each employer shall develop, document, and utilize fall protection equipment and safety procedures as required.

2. All workers who may be exposed to fall hazards must be instructed on the safety significance, purpose, and use of fall protection equipment and procedures, and maintain a record thereof. Training records shall be made available for review.

3. Each employer must conduct inspections of fall protection equipment under their control to ensure that the requirements of the fall protection safety program are being followed. Fall protective equipment such as body harnesses, positioning belts, lanyards, safety lines, rope grabs, retractable lifelines and reels, monorails and trolleys, and other systems used for fall protection must be inspected monthly and documented. Inspection documentation shall be delivered to Facility Management.

4. Each employer shall submit a list of Qualified and Competent persons for fall protection to Facility Management. 


\section{Basic Rules for Fall Protection}

(Note: These fall protection requirements may be different from current OSHA regulations on fall protection. They are specific to work at the NIF Project. Additional fall protection requirements are addressed in other sections of this NPSSP Appendix.)

1. Workers shall be protected against falling whenever a fall hazard exists.

2. Personal fall restraint systems designed to prevent the potential for falling are preferable to dependence on personal fall arrest systems.

3. NIF is a $100 \%$ tie-off project requiring the wearing of two shock-absorbing lanyards, at least one of which must be attached to a secure anchorage when exposed to a fall greater than six (6) feet (i.e., the worker's feet are at or above 6 feet from the ground). The use of a positioning device and an additional shock-absorbing lanyard while climbing is also acceptable to meet this requirement.

4. Fall protection is required on all open sides and edges of walking/working surfaces (horizontal and vertical surfaces) with an unprotected side or edge that is 6 feet (1.8 $\mathrm{m}$ ) or more above a lower level. Fall protection is also required (but not limited to) when workers are exposed to a fall of 6 feet or more when working as follows:

a. Near leading edges.

b. In hoist areas.

c. Near holes (including unprotected skylights), shafts, pits, excavations, ramps, runways, and above dangerous equipment.

d. Near wall openings (where the inside bottom edge of the opening is less than 39 inches above the walking surface).

e. On formwork and reinforcing steel.

f. On scaffolding.

g. During steel erection, overhand bricklaying, precast concrete erection, and roof work.

h. Working on cranes and derricks.

i. Working from ladders when the worker's feet are more than 6 feet above the surface and when the midsection of the worker's torso (i.e., belt buckle) is outside the side rails of the ladder, or if it is necessary to work backwards from a ladder.

5. Fall protection shall be provided by use of guardrail systems, safety net systems, personal fall arrest systems, positioning device systems (when permitted), and covers, fences, or barricades as required. The use of warning line systems, controlled access zones, and safety monitoring systems must be reviewed and approved by the Site Manager prior to their implementation as a means of fall protection. All nonNIF equipment brought on site must be inspected by the NIF Fall Protection Coordinator prior to use. All non-NIF equipment brought on site must be inspected by the NIF Fall Protection Coordinator prior to use. 
6. Monthly inspections of fall protection equipment are required. A greater inspection frequency than otherwise required at LLNL is appropriate because fall protection equipment is more frequently used on the NIF project than elsewhere at the Laboratory.

7. Holes (including skylights) shall be protected by covers or guardrails. Floor hole covers shall be marked with the word "HOLE" or "COVER." Covers shall be strong enough to support the intended load, and shall be secured to prevent unintended displacement.

8. Standard guardrails shall be installed in accordance with OSHA requirements. Toeboards or screens are required when necessary to protect against falling objects.

9. Only full body harnesses are permitted. Body belts are not allowed except when used as part of a positioning device system or otherwise allowed. A lanyard made from chain, rope, webbing, wire, etc., may be used with a body belt for positioning use only.

10. Each worker shall also wear a safety harness with a safety lanyard secured to a separate lifeline while working from swing scaffolds, bos'n chairs or other suspended work platforms where a falling hazard is present.

11. Anchorage points used for personal fall arrest systems shall be capable of supporting at least 5000 pounds per employee attached. (Note: Anchorage points under the supervision of a qualified person may meet other requirements.) Anchorage points for positioning device systems shall be capable of supporting at least 3000 pounds. Anchorage points for personal fall restraint systems shall be capable of supporting four times the intended load.

12. Harnesses, body belts, lanyards, and other fall protection components shall be used only for employee protection and shall not be used to hoist or hold materials.

a. Personal fall arrest systems and components subjected to impact loading shall be immediately removed from service and shall not be used again for employee protection until inspected by a competent person.

b. Snaphooks shall be of a double-locking type. Unless the locking gate meets the 5000-pound breaking strength requirements for snaphooks, the snaphooks shall not be engaged to each other; directly to webbing, rope, or wire rope; to horizontal lifelines (a separate ring or carabiner should ride on the horizontal lifeline); or to any object that is incompatibly shaped or dimensioned in relation to the snaphook such that unintentional disengagement (e.g., roll-out) could occur.

c. Personal fall arrest equipment shall not be attached to guardrail systems.

d. Personal fall arrest equipment shall be inspected prior to each use for damage, wear, and other defects. Defective equipment must be removed from service.

e. Safety nets shall be provided when work places are more than 25 feet above the ground or other surfaces where the use of ladders, scaffolds, catch platforms, temporary floors, safety lines, or safety harness use is impossible. 


\section{Steel Erection and Installation of Decking, Flooring, and Grating}

Steel erection, including installation of decking, flooring, and grating is recognized as an inherently hazardous construction activity. All steel erection shall be conducted in a safe manner to prevent injury to workers.

\section{Responsibilities}

1. Each employer shall develop, document, and utilize steel erection safety procedures as required.

2. All workers involved with steel erection must be instructed on the safety significance, purpose, and use of the steel erection safety procedures, and maintain a record thereof. Training records shall be made available for review.

3. Before starting to install steel erection, flooring, decking or grating, a plan (see Checklist for Planning Steel Erection and Installation of Decking, Flooring, and Grating in Appendix E, a list of forms and permits that can be found on the NIF Site Resource web page )shall be developed that includes installation methods, fall protection, availability of erection drawings, and qualifications of personnel performing the work. Similar hazards exist during the removal of steel, flooring, decking, or grating, as during the installation. Thus, it is appropriate to develop a plan including methods, fall protection, personnel qualifications, etc., for a removal activity.

\section{Basic Rules for Steel Erection}

1. Fall protection shall be provided to workers when they are exposed to a fall hazard of 6 feet or more. Fall protection shall meet the requirements of Section 13 of this NPSSP Appendix A and OSHA Steel Erection requirements.

2. Workers are only permitted to walk on top of structural steel if it is over 24 inches wide, with LLNL Project Management concurrence. Beams smaller than 24 inches shall require the workers to traverse the steel by walking on the web while straddling the beam. Fall protection is required $100 \%$ of the time for all movement.

3. Ladders, scaffolds, lifts, etc., shall be used to reach elevated locations. Climbing or sliding down structural steel from one level to another is not permitted.

4. Welders and other workers who are performing stationary work shall use fall protection attached to a secure anchorage.

5. When placing solid web structural steel members, the load shall not be released from a hoisting line until the members are secured with not less than two bolts at each connection and drawn up wrench tight.

6. When placing open web steel joists on structural steel framework, or placing loads on open web steel joists, the structural framework and open web steel joists shall be safely bolted together. 
7. Structural steel framework shall be temporarily guyed or braced to prevent collapse.

8. Bolts, drift pins, tools, etc., shall be secured against falling. Air hose connections shall be restrained.

9. "Christmas-treeing" of structural steel shall not be allowed.

10. Tag lines shall be used to control loads.

11. When wire rope is used as a floor periphery safety railing, the wire rope shall be 1/2-inch diameter, installed approximately 42 inches high, and flagged at not more than 6-foot intervals. A minimum of three each drop-forged wire rope clips shall be used at each connection point or splice.

12. Workers shall not perform welding, burning, or open-flame work on any staging suspended by fiber or synthetic rope.

13. Workers shall use barricades to preclude any personnel below from being subject to any falling objects.

14. Signs shall be posted and barricades installed at stairways to warn of overhead work and incomplete floors, and to keep unauthorized personnel out of the work area until decking and/or grating is installed and secured and guardrails and mid-rails are in place.

15. Guardrails shall be installed when the decking or grating work has progressed far enough to allow installation to begin. Guardrails or covers for pipe chase and similar equipment openings shall be installed in the decking or grating. 


\section{Radiation Safety}

All use of radioactive materials, ionizing radiation generating devices (RGDs), or radiographic equipment shall comply with the requirements of LLNL ES\&H Manual, Volume II, Document 20.5, “Occupational Radiation Protection; Implementation of 10 CFR 835", and Document 2.4, "Construction Subcontractor Environment, Safety, and Health Program, Appendix C “Radiation Safety." The subcontractor's industrial radiographic operations shall comply with the rules and regulations stated in $10 \mathrm{CFR}$ 34, licenses for industrial radiography and radiation safety requirements for industrial radiographic operations. Because of complexity of the NIF building, logistics must be carefully thought out. The safety plans and health physics oversight will be determined on a case-by-case basis.

The responsible individual shall prepare safety plans (JHA/IWS/SP, LLNL Radiation Work Permit) of the proposed radiological operations with assistance from Assurance Office and ES\&H Team 2. Information about how to prepare a safety plan is contained in "Operational and Facility Safety Plans" (H\&SM S2.02) in Volume I of the ES\&H Manual.

The contractor/subcontractor or the responsible individual shall notify the Field Area Manager of any planned or pending work with sealed sources, RGDs, or radiographic equipment, including soil density measurement and field radiography of pipes, vessels, and structures, or when work will occur in areas where access is controlled for radiation safety purposes. An ES\&H Team health physicist must be involved as soon as plans are made to do radiography, or to work with radioactive materials. The health physicist will provide guidance to ensure that the proposed NIF operations meet applicable LLNL, federal, state, and local requirements for radiation protection.

Subcontractors must obtain written approval from the Hazards Control ES\&H Team before bringing radioactive materials (e.g., radioactive materials used in soil density gages or radiography equipment) on site and before using radiation generating devices (e.g., x-ray machines) on site.

\section{Guidance for Conducting Industrial Radiographic Operations by Contractor/Subcontractor}

The following controls are broadly applicable to field radiographic operations to be performed by contractor or subcontractor.

1. All workers shall comply with NIF radiation safety requirements stated in this document.

2. The Field Area Manager shall notify the ES\&H Team 2 Health Physicist or ES\&H Team 2 Team Leader, or Deputy Team Leader of planned work involving radiography.

3. The subcontractor/ radiographer shall supply a copy of the license (registration by the State of California Radiological Control Department or the Nuclear 
Regulatory Commission) for industrial field radiography for review and verification by Hazards Control.

4. The radiographic contractor is responsible for furnishing the following information:

a. A copy of radiographic training certification records for the employees who perform the radiography.

b. A copy of the contractor's emergency and operating procedures that define and describe the steps to be followed in the event of a radiation emergency.

c. The year-to-date radiation exposure records (or provide an estimate on the visitor's dosimetry form) of the employees who perform the radiography and their radiographic training certification records.

d. The type of sealed radioactive source, activity, and date on which this activity was measured. The model, manufacturer, and serial number of the source. Licensee's name, address, and telephone number. If an x-ray device (e.g., an accelerator) is used for radiography, provide similar information for the x-ray device.

e. The make and model of radiation survey equipment and documentation of current calibration.

f. The type of camera or source-handling device to be used and documentation of the current leak test on the source and/or container.

g. Whenever radiography is performed, the radiographer must be accompanied by at least one other individual assigned by the radiographer of the health physicist. The additional qualified individual shall observe the operations and be capable of providing immediate assistance to prevent unauthorized entry. Radiography may not be performed if only one qualified individual is present.

5. Prior to starting the radiographic work, the Field Area Manager shall furnish the ES\&H Team 2 Health Physicist the following information in writing:

a. A sketch of the exact location of the exposures and the planned locations of the barricades.

b. The number of radiographers to be used.

6. An LLNL radiation dosimeter shall be worn by contract/subcontract personnel and shall be exchanged at least on a quarterly basis (monthly, if required by the Health Physicist) and turned in at the completion of the assignment.

7. When work will be performed in a work area that has access controls for radiation safety, subcontractor personnel shall be briefed on radiation safety requirements.

8. The contractor is responsible for the handling of radioisotopes, or the x-ray device within the project boundaries. The contractor must do the following:

a. Ensure that carrying containers are properly shielded.

b. In accordance with U.S. Department of Transportation standards, post placards on all vehicles used to transport or store radioisotopes. 
c. Temporarily store radioisotope sources in the radiographer's vehicle only if the vehicle is locked, the keys are removed, and radiation-warning signs are prominently displayed.

d. Require that all contract personnel who transport radioisotopes must wear radiation monitoring badges.

e. Ensure that exposure levels on the exterior surface of the storage container is less than $200 \mathrm{mrem} / \mathrm{hr}$, and less than $10 \mathrm{mrem} / \mathrm{hr}$ at 1 meter from any exterior surface with the sealed source in the shielded position.

9. The contractor must supply at least two calibrated radiation survey meters for each work area.

10. Before the radiographic work begins, the radioactive source or RGD must be exposed so the radiographer and the ES\&H Team 2 Health Physicist or designee can ensure that the estimated radiation dose rate at the barricade or boundary is 2 mrem per hour or less. The radiographic work may not proceed until the Team 2 Health Physicist or designee is satisfied with the suitability of the barricade or boundary. If at any time, the estimated radiation dose rate exceeds 2 mrem per hour at the perimeter of the barricade, the radiographic contractor shall secure the source and reposition the barricade to maintain 2 mrem per hour dose level, or as determined by the ES\&H Team health physicist. During radiographic operations the sealed source assembly must be secured in the shielded position each time the source is returned to that position.

11. The Field Area Manager, FAM, or designee shall visually check to ensure that no unauthorized people are within the barricaded area. The Field Area Manager or designee must maintain a continuous patrol outside the barricade during normal working hours. After normal working hours, the Field Area Manager must maintain the patrol periodically during the radiographic activities

12. Each day the devices are used, the radiographer shall check each exposure device for proper operation prior to use.

13. Prior to the completion of each day's radiographic work, the radiography report must be completed and signed by the Field Area Manager and the contractor performing the work. The report must include a sketch of the barricade with approximate locations of radiation warning signs and all recorded survey readings. Copies of the report must be sent to the Field Area Manager and the ES\&H Team 2 Health Physicist. The radiographic report shall be distributed daily.

14. The contractor must immediately notify the Site Manager, Field Area Manager, FAM, and the ES\&H Team 2 Health Physicist of any unusual incident that is related in any way to the radiographic work.

15. Worker radiation exposures shall not exceed current DOE/LLNL exposure limits and shall be kept As Low As Reasonably Achievable below these limits.

16. All sources shall be checked for leaks at least every six months.

17. Radioactive sources shall be in the "off" or shielded position prior to allowing individuals to work on associated equipment or in vessels. 
18. Radioactive sources shall not be stored on the site without prior approval of the ES\&H Team 2 Health Physicist and the Field Area Manager. Radioactive sources shall be stored only in an approved storage area.

19. Barricades and signs must be placed so that the estimated radiation doses do not exceed 2 mrem per hour above background radiation at any point along the perimeter. Caution signs reading "Caution-Radiation Area" and "CautionRadiography in Progress" shall be placed in conspicuous places and at all probable entrance points.

20. If people could gain access to the area during radiography, an inside perimeter barricade must be defined so that the estimated radiation doses do not exceed 5,000 mrem per hour. "Very High Radiation Area" warning signs must be placed on all sides of the barricade.

21. Unauthorized personnel shall remain outside of the barricaded areas while the source is exposed.

22. Any individual who must enter a barricaded area before a source is exposed or after a source is returned to the camera must wear an LLNL dosimeter and must verify with the radiographer that the source has been returned to the shielded position.

The Field Area Manager shall submit the necessary documentation for review and approval by the ES\&H Team. Approval shall be documented using an LLNL Radiation Work Permit for Visitors (see the list of forms in Appendix E that can be found on the NIF Site Resource web page or contact the RI or FAM for the approved JHA/IWS/SP for the work activity). 


\section{Hand Tools}

All hand tools, whether self-owned or company-furnished, shall be maintained in safe condition and comply with the applicable requirements.

\section{Responsibilities}

1. Each employer shall develop, document, and utilize hand tool safety procedures as required.

2. All workers shall comply with the Basic NIF Project Site Hand Tool Safety Rules listed below.

\section{Basic NIF Project Site Hand Tool Safety Rules}

1. Damaged or Defective Tools. Do not use broken, defective, burned or mushroomed tools. Report defective tools to your supervisor and turn such tools in for replacement.

2. Hard Facing. Do not strike two hardened steel surfaces together; i.e., two hammers or a hammer and hardened steel shafts bearings, etc.

3. Power Tools. Only assigned, qualified operators will operate power, explosive actuated, or air-driven tools.

4. Proper Tool. Always use the proper tool and equipment for any task you may be assigned to do. For example: do not use a wrench as a hammer or a screwdriver as a chisel.

5. Storage. Keep tools in their proper storage place when not in use. Do not leave tools where they might present a tripping hazard, fall on somebody or be stolen. Do not carry sharp-edged tools in your pockets.

6. Securing. TOOLS THAT ARE EXPOSED TO A FALL FROM ONE LEVEL TO ANOTHER, SHALL BE TETHERED TO PREVENT INJURY TO PERSONNEL OR DAMAGE TO EQUIPMENT.

7. Guards. Guards required on power tools shall be used at all times. Switch-locking devices shall comply with the requirements of 29 CFR 1926.300. Power grinders shall have protective shields.

8. Refueling. All gasoline- or diesel-powered tools and equipment shall be stopped during refueling.

9. Power-actuated. Studguns, powder-actuated, and powder-assisted industrial tools must be designed and equipped to prevent free flight of any projectile. Operators shall be trained and licensed by the tool's manufacturer in the operation of the particular tool in use and carry a valid operator's card for the specific tool. Records of training and certification will be maintained by the subcontractor. Tools are never to be left unattended, except when properly stored.

10. Appropriate personal protective equipment shall be used. 
11. When using tools such as chisels, drift pins, aligning pins, punches, a separate tool holder shall be utilized to support the tool. 


\section{Electrical Safety}

Electricity when handled carelessly can lead to electrical shock, burns, or other serious injury or fatality. Electricity must be respected at all times. Worker exposure to electrical energy must be controlled.

\section{Responsibilities}

1. Each employer shall develop, document, and utilize electrical safety procedures as required.

2. All workers must comply with NIF electrical safety policy and requirements.

3. Any high-voltage work performed by LLNL High Voltage Crafts shall be performed in accordance with the LLNL High Voltage Operations Manual, including associated JHA/IWS/SPs, as well as the NIF electrical safety requirements.

\section{Basic Rules for Electrical Safety}

For more detailed information about electrical safety, see NIF Project Procedure 5.23, NIF Assured Grounding, Temporary Wiring, and Tool Testing. See Appendix E for associated forms that can be found on the NIF Site Resource web page.

1. Only trained, qualified, and authorized persons shall install wiring or perform work or repairs on electrical equipment.

2. Ground Fault Circuit Interrupter (GFCI) protection is required on all temporary 120V, 15-20-A, single-phase electrical power circuits. This applies both indoors and outdoors.

3. Electrical power equipment (tools, machines, extension cords, etc.) shall be maintained in safe working condition free of electrical hazards such as frayed cords, missing ground connector pins, loose or missing grounds, or electrical shorting. Defective equipment must be tagged out of use and removed from service immediately.

4. Electric tools shall be grounded using three-prong plugs and receptacles (except for double insulated tools). All electrical equipment must be properly grounded.

5. Temporary power cords (extension cords) shall only be used in continuous lengths, free of splices. Cords shall be routed in areas away from vehicle and pedestrian traffic flow. Temporary power cords shall not be supported with or attached to the building structures with nails, wire, or by conductive materials. Cords must be elevated above wet areas or standing water.

6. Temporary lights shall be equipped with guards to prevent unintended breakage or contact with energized parts. Guards shall not be required when the reflectors are constructed with bulbs that are deeply recessed. Temporary lights shall be equipped with heavy-duty electrical cords, with connections and insulation 
maintained in safe condition. Temporary lights shall not be suspended by their electric cords unless the cords and lights are designed for such suspension. Temporary power must not be obtained by connecting to temporary lighting circuits.

7. Power distribution boxes, also known as "spider boxes," approved for use in construction, shall be used to supply temporary power. Temporary power taps, better known as multiple outlet boxes, surge protectors, etc. are not approved for use in construction and shall not be used.

8. Only "Approved" electrical equipment and wiring methods shall be used. Improvising is not allowed. Modifications to approved equipment require reapproval.

9. Wiring methods and practices shall follow the National Electrical Code and the National Electrical Safety Code.

10. A warning tape shall be used to mark the route of all buried temporary conduits, ductbanks, and cables (also includes non-electrical utilities, e.g., gas line). The warning tape shall be located on centerline 12 inches above the top of the underground installation. Underground installations wider than 24 inches shall have warning tapes directly above the outermost edges of the installation and additional tapes running lengthwise at equal spacing, not to exceed 24 inches apart.

11. Control all sources of electrical power at all times. This can be accomplished during testing by closing equipment covers, installing temporary covers of equivalent protection (no use of cardboard covers), use of barricades, insulating blankets, or by stationing a person to warn others of exposed electrical energy.

12. High Voltage equipment, insulating gloves, blankets, grounding equipment, etc. shall be maintained in safe condition and tested for electrical defects at least quarterly. Results of testing shall be recorded and the records kept on file.

13. Only qualified High Voltage Electricians shall perform work on energized High Voltage circuits (i.e., 600 volts or greater) or equipment.

14. Use only the test instruments and insulated tools rated for the voltage and current specified.

15. Wear appropriate personnel protective equipment (PPE). 


\begin{tabular}{|l|l|l|}
\hline Level $^{1}$ & $\begin{array}{c}\text { Flash Protection } \\
\text { Boundary }\end{array}$ & \multicolumn{1}{c|}{ Personal Protective Equipment } \\
\hline 4 & $1^{\prime \prime}-6^{\prime \prime}$ & $\begin{array}{l}\text { Safety glasses, hardhat, leather gloves, long sleeve shirt of } \\
\text { nonmelting fiber construction such as cotton. }\end{array}$ \\
\hline 3 & $7^{\prime \prime}-12^{\prime \prime}$ & $\begin{array}{l}\text { Safety glasses, hardhat, leather gloves, minimum 4.5-oz. } \\
\text { Nomex }\end{array}$ \\
\hline 2 & $13^{\mathrm{R}}$-30" $30^{\prime \prime}$ & $\begin{array}{l}\text { Safety glasses, hardhat, minimum 6-oz. Nomex }{ }^{\mathrm{R}} \text { leather } \\
\text { long gauntlet gloves. }\end{array}$ \\
\hline 1 & $>30^{\prime \prime}$ & $\begin{array}{l}\text { Safety glasses, hardhat, 2 layers of 10-oz. Nomex }{ }^{\mathrm{R}} \text { coveralls, } \\
\text { polycarbonate face shield with hood, heavy leather long } \\
\text { gauntlet gloves. }\end{array}$ \\
\hline
\end{tabular}

16. IT IS LLNL POLICY TO ALLOW WORK ON OR NEAR ELECTRICAL CIRCUITS AND EQUIPMENT ONLY WHEN THEY ARE IN A DE-ENERGIZED STATE RESULTING FROM THE USE OF THE LOCKOUT AND TAG PROCEDURE.

Live parts to which an employee might be exposed shall be put into an electrically safe work condition before an employee works on or near them.

In the rare situation in which there are no alternatives and work on near an energized electrical system is required (when it is essential for the equipment to remain energized), it will be done contingent upon the following conditions. Programmatic convenience is not sufficient cause to work on or near energized equipment.

\section{Approval is required prior to performing work near or in energized equipment.}

a. A NIF Request for Shutdown form must be completed (see form at the end of this section). First determine if the work can be done in a deenergized state. Justification for performing work on or near energized electrical equipment must be based upon an analysis of the hazards, qualification of personnel, and the reason the equipment can not be placed in a electrically safe working condition. Consider rescheduling work to the next available shutdown to avoid performing electrically hazardous work. If the shutdown request is denied, the appropriate authorized person should give written explanation of why the equipment will not be deenergized.

b. Following denial of a shutdown request, a NIF Electrically Hazardous Task Plan must be secured prior to performing the work. The application for this plan will be made in writing to the NIF Site Manager.

The plan application will include a Job Hazard Analysis (JHA), specific to the activity, thoroughly identifying potential hazards and the procedures and supervision that will be implemented to eliminate them. It is intended that this type of work will only occur infrequently, in exceptional cases, and only when advanced planning could not have avoided it.

\footnotetext{
${ }^{1}$ Reference: NFPA 70E Standard for Electrical Safety Requirements for Employee Workplaces.
} 
c. There are four types of hazards associated with work on or near energized electrical equipment:

- Shock and burn due to contact or flashover.

- Electrical flash burn from arc.

- Blast injury resulting from electrical arcs.

- Upset or shutdown of an operating area.

The electrically hazardous task must be analyzed considering two primary hazards-flash hazard and shock hazard. The flash protection boundary must be determined when working on or near electrical equipment with exposed energized electrical conductors or circuit parts. The flash protection boundary is determined in accordance with NFPA 70E 2000, Part II, Paragraph 2-1.3.3.2.

Approach (shock hazard) boundaries are divided into three categories: "Limited Approach Boundary," "Restricted Approach Boundary," and "Prohibited Approach Boundary." Each boundary implies different levels of personnel and work controls. To determine the minimum approach boundary to an exposed energized conductor or circuit part for shock protection, refer to NFPA 70E 2000, Part II, Paragraph 2-1.3.4, and Table 2-1.3.4. Contact the NIF LLNL safety representative for further guidance.

Work involving equipment that has been placed in an electrically safe working condition or involving voltages below 50 volts are classified as electrically nonhazardous and do not require special protective equipment. Nonetheless, other hazards may be associated with work at low voltage, such as a startle or jerk reaction to a minor shock or the possibility of falls or damage to other equipment. Therefore, even electrically nonhazardous work must be carefully planned.

Diagnostics and Testing-Diagnostics and testing (e.g., start-up or troubleshooting) shall be performed only by a qualified person who is trained in the hazards of diagnostics or testing, the proper selection and use of diagnostic and test instruments, work methods, and selection of the proper personal protective equipment to perform the task. The preferred work method is to only apply and remove test equipment to de-energized equipment. Hot-probing of energized equipment is not recommended.

Barriers-Barriers should be considered when work must be done while the equipment is energized. Note: The placement of a temporary barrier may effectively protect personnel from shock hazard, but may not protect personnel from flash hazard. Since the flash hazard boundary often extends beyond the electrical shock boundary, flash protection may be required outside a temporary barrier designed to protect workers from only shock hazard.

These rules have been established to safeguard personnel from injury or death. The immediate supervisor (foreman) of a worker found to be working on or near an energized electrical system without having first secured the above-mentioned plan and/or followed the procedures and safety measures committed to in the JHA will be subject to removal from the NIF Project. 
17. Deenergize hazardous energy sources for the equipment or system. Lockout and tag all hazardous energy sources. Make sure that the controls will not operate the equipment or system and that all hazardous energy, including residual or stored energy is blocked, discharged, or relieved prior to starting work. Follow the Lockout and Tag Procedure, Section 19 when deenergizing any electrical power.

18. When handling acid or batteries, wear face shields and protective clothing such as rubber gloves and aprons. Immediately flush with water any acid coming into contact with your skin. Avoid breathing acid vapors.

19. Be alert to and strictly obey all warning and danger tags or signs around electrical apparatus. Do not close a switch that has a danger tag on it signed by or placed there by someone else.

20. LLNL has established hazard classifications for work on or near-energized electrical equipment. The safe work practices for each class are based on the potential contact with exposed, energized parts operating at the levels specified. All system voltages are measured as RMS or DC values; pulsed systems require further analysis. Where the operating level may be in more than one hazard class, the work practices for the highest hazard class shall apply.

Note: A three-phase power source is a one-branch circuit, which counts as one source. A split-phase power source with a common neutral circuit (Edison circuit) counts as two sources.

Note: For the purposes of this section, a qualified person, competent person, or safety watch must be qualified to perform cardiopulmonary resuscitation (CPR). Refer to Table A-1 from the LLNL ESEH Manual.

21. All nonelectrical work performed on or near* exposed high-voltage (i.e., 600 volts or greater) power distribution equipment, including electrical lines, substations, switchyards, manholes/vaults, and other similar installations requires completing a NIF Request for Shutdown form, and if the shutdown is denied, approval of a NIF Electrically Hazardous Task Plan prior to performing the work (see Appendix E for a list of forms and permits that are available on the NIF Site Resource web page). Nonelectrical work includes activities such as wire pulling and splicing, excavating and trenching, boom/crane/manlift operations, fencing, lighting, drilling, and other construction work.

*Near or in proximity to: A situation in which, in the most extreme case, there is a potential that an employee or any materials, tools, and/or equipment may come in contact with the energized high-voltage source or cross the "Prohibited Approach Boundary" distance for the voltage level being used. 


\section{Table A-1}

\section{Equipment/System Hazard Class}

Class 1: Includes systems with branch circuit voltage $<140 \mathrm{~V}$, branch circuit current limited to $<30 \mathrm{~A}$, and exposed voltage $<50 \mathrm{~V}$. If the source is limited to $<5 \mathrm{~mA}$, the exposed voltage may be $>50 \mathrm{~V}$. The stored energy for these systems is $<10 \mathrm{~J}$.

Class 2: Includes relatively simple systems with exposed voltage $<245 \mathrm{~V}$ and stored energy $<10 \mathrm{~J}$.

Workers must fully understand all hazards associated with these systems.

Class 3: Includes systems with exposed voltage $\geq 245 \mathrm{~V}$ and stored energy $\geq 10 \mathrm{~J}$. These systems shall have no more than two exposed energy sources $>50 \mathrm{~V}$. Workers must fully understand all hazards associated with these systems.

Class 4: Includes any system or equipment that is not described in one of the previous categories. These systems are complex because they have energized, exposed parts and large, dispersed arrangements of components, and may not be well understood.

\section{Work Practice}

One qualified person may work alone on the equipment with general supervision.

One qualified person may work alone on the equipment with general supervision, but another competent person shall be positioned within visible and audible range of the worker.

The project engineer or supervisor shall assign two qualified persons to perform the work. These individuals must work within audible and visible range of each other.

An SP or management-approved written procedure specifically addressing the electrical hazards and controls is required.

Two qualified persons and a safety watch are required to perform the work. An SP, specifically addressing the electrical hazards and controls, is required. If the $\mathrm{SP}$ is not signed by a Division Leader or higher level of management, then the worker must get written approval prior to beginning the work. 


\section{Aerial Lifts and Self-Propelled Elevating Work Platforms}

All aerial lifts and self-propelled elevating work platforms (e.g., powered scissor lifts) shall be operated and maintained in a safe manner to prevent injury to workers, collapse, or tip over. Aerial lifts include manual vertical aerial platforms, powered vertical aerial platforms, and boom-supported aerial platforms (e.g., extensible boom platforms, articulating boom platforms).

\section{Responsibilities}

1. Each employer shall develop, document, and utilize aerial lift safety procedures as required.

2. All workers involved with the operation and use of aerial lifts and self-propelled elevating work platforms must be instructed on the safety significance, purpose, and use of aerial lift and self-propelled elevating work platform safety procedures and the operation and record maintenance thereof. Operators of aerial lifts and selfpropelled elevating work platforms shall be trained in accordance with the manufacturer's operating manual and other rules as required. Operators shall be trained either on the same model of aerial platform or self-propelled elevating work platform or one having operating characteristics and controls consistent with the one to be used. Training records shall be made available for review.

3. Each employer shall advise all other affected persons when their safety will be impacted by the operation and use of aerial lifts or self-propelled elevating work platforms.

4. Each employer must inspect each aerial lift and self-propelled elevating work platform before use each day or at the beginning of each shift including a visual inspection and a functional test.

\section{Basic Rules for Aerial Lift and Self-Propelled Elevating Work Platform Safety}

1. All aerial lifts and self-propelled elevating work platforms shall only be operated by authorized and qualified workers.

2. All aerial lifts and self-propelled elevating work platforms shall be operated in accordance with the manufacturer's instructions. Only use the machine as it was intended.

3. Operators shall perform a workplace inspection before use and during use. The user shall check the area for the following types of hazards: drop-offs or holes, bumps and floor obstructions, debris, overhead obstructions and high-voltage conductors, hazardous locations, inadequate surface and support to withstand all load forces imposed by the lift, wind and weather conditions, presence of unauthorized persons, other possible unsafe conditions.

4. Operators shall not operate a damaged, defective, or malfunctioning machine. 
5. Operating manuals must be provided with each aerial lift and stored in a weather resistant storage compartment.

6. Scissors-type work platforms shall be operated on firm level surfaces. Articulating or extensible boom-type lifts shall be operated on firm level surfaces as much as is possible and within guidelines established by the manufacturer. Aerial lifts or scissors-type work platforms may be equipped with tilt or other motion/capacity warning alarms. These alarms shall be operational. Do not alter or disable the limit switch(s). Operators shall not depend upon the tilt alarm as a level indicator.

7. Repositioning aerial lifts and self-propelled elevating work platforms while elevated shall only be done cautiously and carefully. The operator must make certain that the unit is on a level, firm surface free from hazards such as drop-offs or holes, bumps and floor obstructions, debris, depressions, ramps, etc. The operator must maintain a clear view of the path of travel, maintain a safe distance from obstacles, and maintain a safe distance from overhead obstacles. Operators shall not drive over $0.5 \mathrm{mph}$ with the platform raised.

8. Traveling 50 feet or more with an aerial lift or self-propelled elevating work platform shall be done with the platform in the lowered or stowed position. Extensible or articulating booms should be retracted or folded. Care and slow speeds should be used while driving across uneven ground, ramps, debris, unstable or slippery surfaces, and near holes and drop-offs.

9. Outriggers, stabilizers, extendable axles, or other stability enhancing means are to be used as required by the manufacturer.

10. When other moving equipment and vehicles are present, special precautions shall be taken such as posting warning flags, roping off the area, using flashing lights, or installing barricades.

11. Care shall be taken to prevent entanglement of the aerial lifts and self-propelled elevating work platforms in ropes, electric cords, hoses, etc.

12. If the lift is to be left unattended, operators shall lower the platform, shut off the engine, engage the parking brake, and take necessary precautions to prevent unauthorized use.

13. Operators shall use the three (3)-point contact method (3 out of 4 arms and legs in contact with the machine) while mounting and dismounting. Never attempt to mount or dismount a moving machine or climb down the frame or boom from the platform or bucket when raised.

14. Operators shall not operate the machine unless the guardrails are properly installed and the entry is secured for operation. Operators shall attach the platform entry chain and close the entry gate before operating.

15. Only one designated person should operate the controls. Operators shall never allow anyone to tamper with, service, or operate a machine from the lower control stations while personnel are in the bucket or platform except in an emergency. 
16. Operators shall be aware of crushing hazards when grasping the platform guard rail or edges of a bucket platform. Operators shall keep hands and limbs out of pinch points such as on scissors lifts.

17. Maintain safe distances between the operator, the machine, and fixed objects. A hard hat should be worn at all times when operating aerial lifts and selfpropelled elevating work platforms.

18. Operators shall not use the drive maneuver in close to an obstruction. The operator shall place his/her machine, then use the raise, swing, and boom functions to get in close.

19. Operators shall wear approved fall protection devices as required for the type of machine. A full body harness must be worn by all occupants in a boomsupported aerial platform with a safety lanyard securely attached to the boom or bucket. The manufacturer's fall protection requirements shall be followed when working from any type of aerial lifts or self-propelled elevating work platform. Operators shall never attach their lanyard to an adjacent structure except as provided below.

20. Operators shall not sit, stand, or climb on the platform guardrails or edge of the bucket. They shall maintain a firm footing on the platform floor at all times.

21. When required to exit or climb out of an elevated aerial lift or self-propelled elevating work platform to a location not otherwise protected by guardrails, floors, or other continuous means of fall protection, operators shall use a second shock-absorbing lanyard to connect to the new location before disconnecting from the aerial lifts or self-propelled elevating work platforms. When entering an elevated aerial lift or self-propelled elevating work platform from an unprotected location, operators shall connect a shock-absorbing lanyard to the anchorage point in the aerial lift or elevating platform before entering.

22. Operators shall maintain safe distances from electrical power lines or conductors. They shall allow for boom or platform movement or electrical line sway or sag. Operators shall follow minimum safe approach distances (MSAD).

\begin{tabular}{|c|cc|}
\hline \multicolumn{2}{|c|}{ Minimum Safe Approach Distance (MSAD) } \\
\hline Voltage Range & \multicolumn{2}{|c|}{ Minimum Safe Approach Distance } \\
(Phase to Phase) & \multicolumn{2}{c|}{ (Feet) } \\
& \multicolumn{2}{|c|}{ AVOID CONTACT } \\
0 to 50 & 10 & 3.05 \\
51 to $300 \mathrm{~V}$ & 10 & 3.05 \\
Over 300 to $50 \mathrm{KV}$ & 15 & 4.60 \\
Over 50 KV to $200 \mathrm{KV}$ & 20 & 6.10 \\
Over 200KV to 350KV & 25 & 7.62 \\
Over 350KV to 500KV & 35 & 10.67 \\
Over 500KV to 750KV & 45 & 13.72 \\
Over 750KV to 1000KV &
\end{tabular}


23. Gasoline, diesel, or propane-powered lifts shall only be operated in areas with adequate ventilation to prevent the buildup of carbon monoxide or other hazardous gases. When these lifts are operated indoors, air monitoring is required.

24. Operators shall not operate the machine during lightning storms.

25. Operators shall not use the machine as a ground for welding. They shall disconnect both battery leads before performing any welding operations.

26. Operators shall not over load an aerial lift or elevating work platform. Occupants and equipment shall not exceed the maximum platform capacity (or the maximum capacity of the platform extension when so equipped).

27. Operators shall not increase the surface area of a platform or the load. By increasing the area exposed to the wind, the stability of the machine is decreased.

28. Operators shall not exceed manufacturer's limits when pushing on or pulling toward any object outside of the lift or platform.

29. Operators shall not attempt to increase the stability of a lift or elevating work platform by attaching it to an adjacent structure. Operators shall not tie or attach to adjacent structures.

30. Operators shall not modify or alter an aerial lift or elevating work platform. Mounting attachments for holding tools or other materials onto the bucket, platform, toeboards or guardrail system can increase the weight in the bucket or platform and the surface area of the platform or the load.

31. Operators shall not place or attach fixed or overhanging loads to any part of the machine.

32. Operators shall not place loads outside the platform perimeter.

33. Operators shall not use aerial lifts or a self-propelled elevating work platform as a crane.

34. Operators shall not use the machine to push or pull another object. Operators shall never use the boom to push the aerial lift along the ground or attempt to free a machine by lifting the wheels off the ground with the boom.

35. Operators shall not place ladders or scaffolds in platform or bucket, across handrails, or against any part of an aerial lifts and self-propelled elevating work platforms.

36. Operators shall not operate a machine in the path of any crane or moving overhead machinery unless the controls of the crane have been locked out and/or precautions have been taken to prevent any potential collision.

37. Operators shall not operate the machine or charge the battery in areas where potentially flammable or explosive gases or particles may be present.

38. Operators shall not use batteries that weigh less than the original equipment. Operators shall always wear protective clothing and eyewear when working with batteries.

39. No stunt driving or horseplay is allowed while operating a machine. 


\section{Lockout/Tagout Requirements}

This section establishes the lockout and tagout (LOTO) requirements for the NIF Project and establishes a minimum and uniform set of guidelines and requirements for proper and safe LOTO activities.

The primary purposes of this LOTO are to protect personnel from injury, protect equipment from damage, and maintain the integrity of the facility's systems.

All potentially hazardous energy sources must be isolated prior to any construction, installation, system modification, repair, or maintenance activity to protect against unintended or inadvertent operation when such operation could cause injury to personnel.

These LOTO requirements apply to LLNL and non-LLNL employees. All subcontractors who perform activities subject to LOTO shall have their own LOTO program that conforms to the requirements in this document. Subcontractor LOTO programs will be reviewed by the appropriate contracting organization. All employees of subcontractors are responsible for personally locking out and tagging the equipment that they are working on. Subcontractors shall supply all of the required hardware and other materials to effectively implement the LOTO procedure, and exchange information concerning the LOTO procedure with the Field Area Manager.

This program has been established from and expands on the Federal OSHA, General Industry Standards (29 CFR 1910.147) and the LLNL Lockout and Tagout Program (LLNL ES\&H Manual, Document 12.6) while focusing on the specific environment related to the NIF Project Site. This program is intended to cover new installations, repair, maintenance, servicing, test, and commissioning activities. Mandatory LOTO requirements can be found in "NIF Project Site Lockout and Tagout Requirements," NIF Project Procedure 5.15.

\section{Definitions}

Administrative Lock and Tags - Any lock and/or tag that is used for a purpose other than LOTO. The lock and / or tag may serve a safety function other than LOTO, a configuration control function, or other purpose. An administrative lock shall NOT be used with a DANGER LOTO tag. An administrative lock is not a substitute for a LOTO lock. A LOTO lock cannot be used as an administrative lock.

Examples of Administrative Locks:

- A locked fence around high-voltage transformers to prevent unauthorized entry. 
- Lock on an overhead crane disconnect switch to prevent unauthorized use

- Equipment out of order, locked and tagged to prevent use

Affected Individual - Any individual who is not performing servicing or maintenance on equipment but who typically operates or works in the vicinity of such equipment.

Authorized Individual - Individual qualified through training, system knowledge, and Lockout/Tagout training, who is authorized through the proper work planning use of the JHA/IWS and SPA who locks out and tags systems, machines, or equipment to perform work on the equipment.

DANGER LOTO Tags - Tag to be used with approved LOTO lock for identifying that the source is de-energized and under the control of the Authorized Individual who performed the LOTO process. Danger tags used for LOTO must never be used for any other purpose.

Energy owner - The individual having sole responsibility of an energy source and its energized state. Generally, this is a facilities person, manager, supervisor, or contractor having responsibility for an area of the facility or a specific system.

Energy Source - Any source that could cause harm to personnel or equipment by generating or transferring electrical energy, hydraulic, pneumatic, gas or steam pressure, vacuum, high temperature, cryogenic temperature, potentially reactive chemicals or stored mechanical energy. This also includes hot water in excess of 120 degrees Fahrenheit, fuel gases in pipelines or cylinders, radiation, lasers, gravity, and exposure to systems that contain materials that are toxic or otherwise injurious to one's health upon contact or inhalation.

Lock, Tag, Try and Test - Herein referred to as "LOTO." General terminology for the process for executing the Lockout/Tagout process and ensuring the source is safely de-energized to protect personnel and equipment.

The Lock, Tag, Try and Test process is:

1. Lock out the energy source once de-energized.

2. Place the appropriate tag on the lock.

3. Try the normal operator control(s) to ensure the lockout is effective.

4. Test to verify that hazardous energy is not present.

Work Supervisor - The first level of field supervision for any work effort with one or more members of a work team or crew on the site. 


\section{Responsibilities}

\section{Management}

Line Management is responsible for ensuring that all employees are trained in the content, safety significance, and use of the LOTO procedure (Project Procedure 5.15).

The Field Area Managers shall assure overall coordination of all LOTO activities.

Supervisors/foremen must ensure that the LOTO is performed according to the plan, and that no employees work beyond the protection of LOTO locks and danger tags.

\section{All Individuals Authorized for Access to the NIF Project Site}

1. The LOTO Program applies to all personnel and individuals entering the NIF Project Site.

2. Only the Energy Owner or his / her designee may approve the initiation or removal of the lockout and tagout process.

3. Each person who is performing construction, installation, system modification, repair, or maintenance activity is responsible for performing LOTO on that equipment.

4. A LOTO lock is only considered to protect one person. The key to that lock shall remain in the exclusive control of that person at all times.

5. Only authorized and trained employees shall perform the LOTO process in accordance with this program.

6. There is zero tolerance for violation of this procedure. Failure to comply will result in disciplinary action.

7. Any unauthorized person found tampering with or removing lockout/tagout equipment will be subject to disciplinary action.

8. Under no circumstances shall breakers, switches, and/or valves that are tagged by a DANGER LOTO- DO NOT OPERATE tag be operated.

9. No LOTO device shall be removed by anyone other than the Authorized Individual. (See NIF Project Procedure 5.15, "Special Removal of Lock and Tag" when the person applying them is not available.)

10. A tagout can NEVER be used without a lockout for LOTO. 


\section{Planning}

Proper planning and approval of work shall be initiated prior to scheduling any LOTO activities. All lockout activities must include planning and authorization with the Energy Owner and other management as appropriate. The two types of LOTO conditions - general and complex - each require planning.

\section{General LOTO}

The general LOTO procedure may only be used for equipment in which all of the hazardous energy is easily isolated with a single action e.g., the operation of only one switch or one valve. (See NIF Project Procedure 5.15 for conditions necessary for a general LOTO classification.)

\section{Complex LOTO}

A complex LOTO condition exists when any of the required conditions for a general LOTO are not met. A LOTO Work Plan is required to perform any complex LOTO.

\section{LOTO Work Plan}

An equipment-specific LOTO Work Plan is required for any complex LOTO condition. A LOTO Work Plan shall be written, and approved prior to beginning any complex LOTO activity. The LOTO Work Plan shall be included in, attached to, or referenced in an JHA/IWS/SP and SPA. The LOTO Work Plan must be reviewed with all workers participating in the LOTO activity. The Energy Owner shall retain a copy of the LOTO Work Plan and post a copy at the LOTO work site.

\section{Equipment Energy Isolation Checklist and Diagrams}

The appropriate Field Area Manager, assisted by the Energy Owner, shall ensure that detailed checklists and diagrams are developed, maintained, and available for review for equipment that requires complex LOTO. These plans should be referenced for every LOTO activity to ensure that all isolation devices and energy sources have been identified for the task.

\section{Program Equipment Requirements}

\section{Approved LOTO Locks and Tags}

LLNL employees shall only use the LLNL LOTO lock with NIF serialization, and LLNL LOTO Danger tag. The locks and tags are obtained from the work supervisor. There shall be no more than one key per lock. These locks and tags shall not be used for administrative lockouts. 

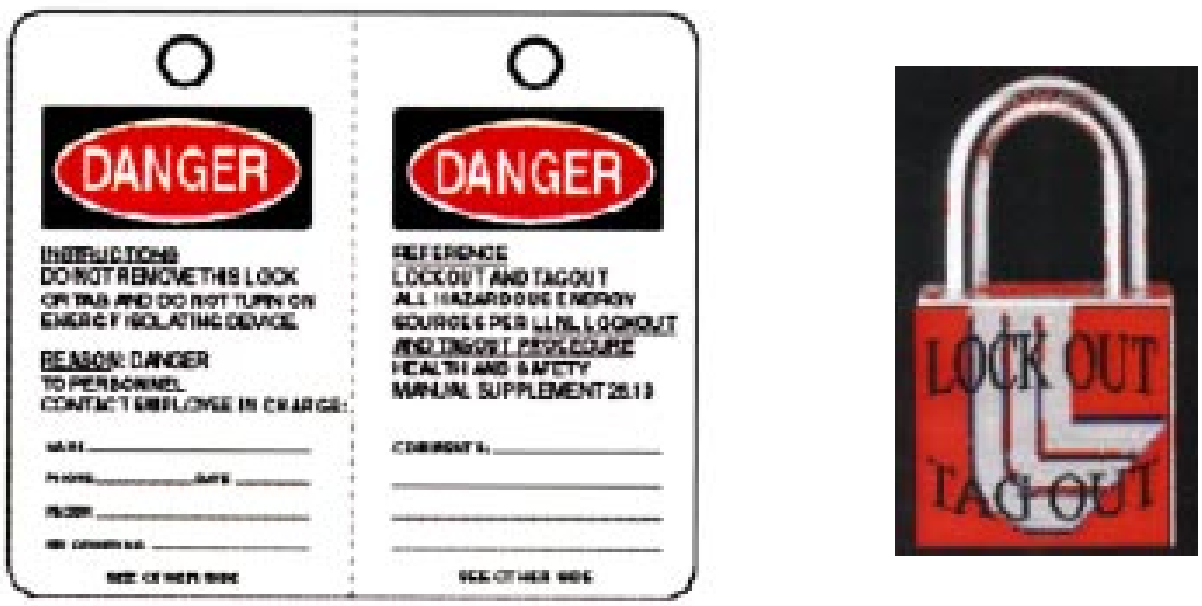

\section{LLNL Approved LOTO DANGER Tag and LOCK}

(Tag, LLNL stock number 4280-71737)

Contractors and subcontractors shall use the locks and tags identified in their LOTO program.

\section{Administrative Tags}

Administrative tags are used to highlight danger, cautionary, and notice conditions. The use of CAUTION tags is restricted to those situations in which a system or component may be functional, but when some precaution or information is necessary prior to operation. CAUTION tags shall not be used for LOTO.

\section{Multiple Hasp Adapters}

Multiple hasp adapters are used to permit a number of locks to be applied to one energy isolating device. They are available in different configurations. See Procedure 5.15 for acceptable has adapters.

\section{Special Equipment}

Special equipment required for LOTO of particular pieces of equipment (such as wedges, chains, key blocks, adapter pins, or self-locking fasteners) should be provided by the equipment supervisor.

\section{Group Lockbox}

Group lockboxes are only used for group LOTO. Lockboxes are available from the work supervisor. When a lockbox is used, it shall be located at a place that is convenient for the activity. 


\section{LOTO Log Book}

A LOTO Log Book shall be maintained in order to record the application of all locks applied as part of a LOTO activity. Complete all required entries on the LOTO Log Book when applying locks and tags for all LOTO's.

\section{Training}

Any individual locking out or tagging out of an energy source prior to work must have the appropriate electrical or mechanical safety training, and training on the LOTO process. See NIF Project Procedure 5.15 for detailed training information.

\section{NIF LOTO PROCEDURE}

The LOTO procedure for the NIF Project is based upon the concepts of Lock, Tag, Try, and Test. Strict adherence to these steps will help to assure successful, incident-free LOTO activities. The General LOTO Procedure is defined in NIF Project Procedure 5.15. The Energy Owner and the LOTO Authorized Individual(s) must review the planned LOTO activity. The Energy Owner shall consult with the cognizant Field Area Manager to determine if this lockout or tagout impacts other NIF Project areas or activities.

Any complex LOTO activity, (e.g., equipment with multiple energy sources) requires that a LOTO Work Plan be written and approved prior to beginning LOTO activities.

\section{Group Lockout}

Group lockout may occur when the number of workers on a crew, craft, department, or other group performing a LOTO activity makes it impractical for each of them to apply LOTO devices directly to the energy-isolating device(s). Group lockouts are under the authorization of the Energy Owner and LOTO Authorized Individual / person-in-charge on the LOTO Work Plan. Each person working under a group LOTO shall have a lock on the group LOTO lockbox. Group lockouts shall follow the Group Lockout Procedure outlined in NIF Project Procedure 5.15.

\section{Shift or Personnel Changes}

An orderly transfer of lockout/tagout devices shall take place when personnel or shifts change as described in this procedure. Control of energy sources that extend beyond a single shift or personnel change shall be logged in the LOTO Log Book.

\section{Testing or Positioning of Equipment}

"Bumping," testing, or positioning of machines, equipment or components may require the lockout and tagout devices to be temporarily removed. Refer to the Testing or Positioning of Equipment in NIF Project Procedure 5.15. 


\section{Annual Inspection of Lockout/Tagout Procedures}

Each employer whose employees utilize LOTO procedures shall perform an annual inspection of their LOTO program. See Annual Inspection of Lockout/Tagout Procedures in NIF Project Procedure 5.15. 


\section{Rigging}

All rigging shall be used and maintained in a safe manner to prevent injury to workers or dropping of loads.

\section{Responsibilities}

1. Each employer shall develop, document, and utilize rigging safety procedures as required.

2. All workers involved with rigging must be instructed in the safety significance, purpose, selection and use of rigging, and rigging procedures, and maintain a record thereof. Training records shall be made available for review.

3. Each employer shall advise all other affected persons when their safety will be impacted by cranes and hoists.

4. Each employer must conduct inspections of rigging under their control prior to use and quarterly to ensure that the requirements are being followed. Rigging shall be inspected by a designated competent person. Inspection documentation shall be delivered to Facility Management.

5. Each employer shall submit a list of qualified riggers to Facility Management.

6. A NIF Hoisting and Rigging Safety Review is required prior to performing hoisting and rigging. Please refer to NPSSP, Appendix A, Section 21 and Appendix E, Forms and Permits.

7. Rigging equipment shall be utilized per the manufacturer's instructions. Employers shall ensure that their riggers understand the manufacturers' requirements via the training mechanisms noted above.

\section{Basic Rules for Rigging Safety}

1. Rigging of loads shall be performed by workers trained, qualified, and authorized to perform such work.

2. Rigging shall be adequate to support the intended loads. Special lifting devices, spreader bars, custom designed grabs, clamps, etc., shall be capable of handling the intended loads. These devices shall be marked to indicate safe working loads, and shall be proof-tested prior to use to 125 percent of their rated loads. "Below-thehook" lifting devices shall be designed, fabricated, inspected, and tested per the requirements of ASME B30.20.

3. When temporary rigging such as wire rope lashing, come-alongs, chain falls, etc., are used for support during all erection sequences for machines, piping, platforms, walkways, and steel members such rigging shall not be removed until all leveling and alignment is complete and the item is secured in its permanent location.

4. Job or shop hooks formed from bolts, rods, rebar, etc., will not be used. 
5. No "Christmas Treeing" shall be allowed on the construction project.

6. Rigging equipment will be inspected before each use, and as necessary during its use, to ensure that it is sound. All rigging equipment including, but not limited to, slings (wire and nylon), chain-falls, come-alongs, spreaders, lifting beams, etc., shall be inspected on a quarterly basis. Records will be maintained and copied to the Safety Coordinator. The inspection shall be performed by a competent person, and the rigging equipment shall be color coded in accordance with the suggested color code for the quarter.

7. Defective rigging shall be tagged "Do Not Use" and immediately removed from service and repaired or destroyed to prevent their reuse.

8. Proper storage shall be provided for slings and other rigging.

9. Protection shall be provided between the sling and any sharp, unyielding surfaces.

12. Wire rope will be discarded when found to contain: Six randomly distributed broken wires in one rope lay, three broken wires in one strand of one rope lay, or when the rope shows signs of excessive wear, kinks, corrosion, or other defects. Wire ropes with splices will not have less than three tucks.

13. " $U$ " bolt wire rope clips shall be applied so that the " $U$ " section is in contact with the "dead end" of the rope. Only drop-forged "U" bolts shall be used.

14. Do not overload trash and material skip boxes.

15. When using chain hoists and lever operated chain hoists:

- Never use the load chain as a sling or choker.

- Do not load the point of the load chain's hook. Make sure the load is bottomed in the hook.

- Safety-latch or mouse all hooks.

- If one load hook must handle more than one lifting cable or chain, use a shackle to join the lifting cables or chain, and place the shackle in the hook. Do not allow the hook's safety latch to support any part of the load.

- Do not use chain hoists with chain that is twisted, kinked, or damaged. Make sure that multi-reeved chains are not twisted.

- Do not use chain hoists or lever-operated chain hoists to lift or support people.

- Before moving or rotating the load, make sure the load and the hoist will clear all obstacles.

- Avoid making angle lifts of greater than $30^{\circ}$ with a chain hoist. When drifting loads that use two or more chain hoists, be certain to pull the hand chain in line with the sheave.

- Never use a chain hoist for a horizontal pull because it is difficult to engage the sprocket properly. Use lever hoists for these conditions.

- Use only manual power to operate manual chain hoists.

- Use a hoist with the correct capacity for the weight to be lifted. 
16. Lever-operated hoists may be used safely to lift or pull a load at any angle or in any position. When using lever-operated chain hoists, observe the following minimum safety precautions:

- Rig the load chain carefully and keep it straight.

- Do not use hoist-handle extensions.

- To avoid serious chain damage or breakage, do not bend the load chain over objects under loading conditions.

- Never gouge the side of the hoist frame with the load chain. Keep the load chain aligned with the work.

17. To avoid dropping a load when using a lever-operated hoist, make sure the pawl is engaged properly when the direction of load travel is changed. 


\section{Cranes}

All cranes and hoists shall be operated in a safe manner to prevent injury to workers, collapse or tip over, or damage to property. They shall be erected, disassembled, moved, operated, and otherwise used in accordance with the manufacturer's instructions. Deviations/exceptions from the manufacturers' manuals and procedures therein shall be in the form of written information from the manufacturer, signed and dated, and noting the portion of the manual to which the deviation/exception shall apply.

Qualification of operators shall be, at a minimum, in accordance with appropriate ASME B30 Standard. Conduct of operations shall be, at a minimum, to the same B30 standard. Furthermore, mobile crane operators shall be qualified to the appropriate NCCCO (National Commission on the Certification of Crane Operators, Fairfax, Virginia) protocols; the core, the appropriate crane specialty and the practical examination for such.

\section{Responsibilities}

1. Each employer shall develop, document, and utilize crane and hoist safety procedures as required.

2. Prior to set up and operation of all mobile cranes, each employer shall present the crane for a safety inspection or review of current crane inspection certification by the Site Manager or his representative. The employer shall ensure and provide certification information as required by OSHA. Certification information shall verify that a thorough, annual inspection of the equipment has been made by a professional engineer or agency recognized by the governing body. Equipment owners are required by OSHA to maintain a record of the dates and results of inspections for each hosting machine and piece of equipment. Cranes found to be defective or not current in their annual inspection shall not be permitted to operate until all deficiencies have been corrected.

3. All workers involved with crane and hoist activities must be instructed on the safety significance, purpose, and use of crane and hoist safety procedures, and maintain a record thereof. Training records shall be made available for review.

4. Each employer shall advise all other affected persons when their safety will be impacted by cranes and hoists.

5. Each employer shall submit a list of qualified crane and hoist operators to Facility Management.

6. Each employer must conduct daily inspections of cranes and hoists under their control to ensure that the requirements are being followed. Cranes and hoists shall be inspected by a designated competent person. Inspection documentation shall be delivered to Facility Management. 
7. A NIF Hoisting and Rigging Safety Review is required for any activity or operation involving a crane or overhead hoist (including manual-lever, hand-chain, electric, or air-powered hoists) prior to performing any hoisting and rigging. See Appendix E for a list of forms and permits available on the NIF Site Resource web page.

8. A written Boom Assembly and Breakdown Plan is required when erecting or dismantling a crane boom (see Appendix E).

9. A permit for crane/equipment work around overhead electric lines and cables is required.

\section{Basic Rules for Crane and Hoist Safety}

1. Cranes and hoists shall be operated only by persons trained, qualified, and authorized to operate such equipment.

2. Cranes and hoists shall not be overloaded. Side pulls shall be avoided. Avoid sudden stops or starts that generate shock loading.

3. Loads shall not be passed or carried over workers. Employees shall not work beneath suspended loads until the load is safely blocked or landed.

4. Workers are not allowed to ride on loads, hooks, cables, load blocks, rigging etc.

5. All crane operation in proximity to electrical distribution and transmission lines shall be protected as outlined by OSHA requirements. A minimum separation distance of ten feet between the crane or load and an energized line is required at all times during operation.

6. All crane and hoist hooks shall have safety latches. There can be no more than one eye of a choker in a load hook at a time.

7. The swing radius of the counterweight on a mobile crane shall be barricaded.

8. A signal person must be present at all times whenever:

a. The crane is to be working within a boom's length of an electric power line(s).

b. The operator cannot clearly see the hook or load at times.

c. The machine is being backed or moved and the operator cannot see some parts of the machine or its path of travel.

9. The signal person shall:

a. Position himself / herself in full view of the operator and, if using hand signals, be close enough for the signals to be seen clearly. His/Her position shall allow a full view of the load and equipment at all times, yet be such that there is no danger of being injured.

b. Be qualified by experience, knowledgeable in the operation, and able to coordinate actions with the crane operator by signals.

c. Be responsible for keeping all authorized personnel beyond the crane's operating radius.

d. Direct the load, ensuring that it never passes over the other personnel. 
e. Stay in constant communication with the crane operator by either using approved hand signals, radio, sound-powered phones, or equivalent means of communication. High visibility gloves or vests may be used to help distinguish signal persons from other personnel, especially during night or inclement weather.

10. This procedure provides guidance for control of lifts with cranes that are considered to be "critical" lifts and not repetitive lifts.

a. General. Lifts considered to be critical are those lifts which:

i. $\quad$ Could cause significant work delay if not successfully completed (e.g., one of a kind equipment).

ii. Could cause undetectable damage resulting in future operational or safety problems.

iii. Could result in significant release of radioactivity or other undesirable conditions.

iv. Could present a potentially unacceptable risk of personnel injury or property damage.

v. Exceed $75 \%$ of the crane's rated capacity for the crane configuration.

vi. Require two cranes to make the lift.

vii. Require walking of the load by the mobile crane

viii. Utilize poles and derricks that have been erected for a specific lift.

b. Interpretation. Crane configuration as used in this procedure refers to variable parts of the crane such as boom length, boom angle, counterweight, outrigger's extended and set, tracks extended or retracted, and various jib attachments, headache ball, load block, lifting devices, etc.. All these items affect the gross capacity of the crane and shall be taken into consideration prior to lift.

c. Guidelines. If, in completing the permit, it is determined the lift equals or exceeds $95 \%$ of the crane configuration capacity for the greatest radius the load will achieve during pick, swing or set, the lift will not be made. If, changing the crane configuration within the manufacturing specifications, a greater gross capacity may be gained, the change shall be made. If not, a larger capacity crane shall be ordered and used. Bridge cranes are permitted to be operated up to, but shall not exceed, $100 \%$ of their rated capacity.

d. Responsibilities. A "Critical Lift" Plan will be completed by the employer prior to making any "critical lift," (see Appendix E for forms and permits list). After the plan has been completed by the supervisor, the required personnel will review and sign-off on the lift plan in order listed on the permit. A copy of the plan will be placed in the cab of the lift-crane and the original will be filed in the employer's on-site office.

In the event of a critical lift, the protocol defined in the DOE Hoisting and Rigging Standard, 1090-99 (hereafter referred to as the Standard), Section 2-2 shall be followed. Furthermore, a review of the noted procedure as required by Section 2-2 shall be conducted by the NIF Field Area Manager or his/her 
designee. When all requirements as defined by the Standard and the NIF Field Area Manager have been fulfilled, then and only then can the "critical lift" begin.

Futhermore, when a critical lift has been defined, all actions that define the movement of the "critical" object, lifting or otherwise, shall be clearly defined. This definition shall be in text and pictures and shall present a clear illustration as to how the "critical" object shall be moved. The "Person-In-Charge" as defined in the Standard shall assure that all of the information required in Section 2-2 is presented appropriately to the management, checklists, personnel assignments, engineering calculations, equipment readiness etc. for their approval.

e. Other Hazards. For any electrical or other hazard(s) involved or associated with the operations, the appropriate hazard permit(s) will also be completed prior to the lift.

11. Lifts performed in close proximity such that the load or the crane boom could fall onto electric power lines, transformers, pipelines, or vessels or reactors containing flammable, explosive, or hazardous gases or liquids, etc. require a Proximity Permit (see the list of forms and permits in Appendix E that can be found on the NIF Site Resource web page or contact the RI or FAM for the approved JHA/IWS/SP for the work activity).

12. The use of a crane to hoist workers on a personnel platform is prohibited, except when the erection, use, and dismantling of conventional means of reaching the work site, such as a personnel hoist, ladder, stairway, aerial lift, elevating work platform or scaffold, would be more hazardous, or is not possible because of structural design or work site conditions. Federal Occupational, Safety, and Health Administration (OSHA) Standard 29 CFR - 1926.550(g), at a minimum, must be followed whenever hoisting employees by crane. The Field Area Manager approval signature is required prior to each time a crane-suspended work platform is to be used.

13. The following are additional requirements when operating overhead cranes and hoists:

a. At the start of each work shift, operators shall perform a visual and functional inspection of the hoist and its controls including:

i. Test the upper-limit switch by slowly raising the unloaded hook block until the limit switch trips.

ii. Visually inspect the hook, load lines, trolley, and bridge as much as possible.

iii. If provided, test the lower-limit switch.

iv. Test all direction and speed controls for both bridge and trolley travel.

v. Test all bridge and trolley limit switches if operation will bring the equipment in close proximity to the limit switches.

vi. Test the pendant emergency stop

vii. Test the hoist brake to verify there is no drift without a load.

viii. If provided, test the bridge movement alarm. 
ix. Lockout and tag for repair any crane or hoist that fails any of the above tests.

b. Center the hook over the load to keep the cables from slipping out of the drum grooves and overlapping and to prevent the load from swinging when it is lifted. Inspect the drum to verify that the cable is in the grooves.

c. Use a tag line.

d. Plan and check the travel path to avoid personnel and obstructions.

e. Lift the load only high enough to clear the tallest obstruction in the travel path.

f. Start and stop slowly.

g. Land the load when the move is finished.

h. Never leave suspended loads unattended. In an emergency in which the crane or hoist has become inoperative, if a load must be left suspended, barricade and post signs in the surrounding area, under the load, and on all four sides. Lock open and tag the crane or hoist's main electrical disconnect switch.

i. When completed with the lift, raise the hook at lease 7 feet above the floor.

j. Store the pendant away from aisles and work areas, or raise it at least 7 feet above the floor.

k. Place emergency stop switch (or push button) in the OFF position.

14. Use of an overhead crane or hoist as a work platform should only be considered when conventional means of reaching an elevated work site are hazardous or not possible. Platforms shall meet the requirements in ASME B30.2: Platforms shall be provided with guardrails (42 inches high plus intermediate railing) and toeboards. The dimension of the working space in the vertical direction from the floor surface of the platform to the nearest overhead obstruction shall be a minimum of 48 inches at the location where a person is working on the platform. Crane travel shall be prohibited or restricted while a person is on a platform and the overhead platform clearance is less than 78 inches at any location in the path of travel of the crane. Platforms shall be designed to sustain a distributed load of at least 50 pounds per square foot. Workers shall not ride a moving bridge crane without an approved JHA/IWS/SP, which shall specify the following as a minimum:

a. Personnel shall not board any bridge crane unless the main disconnect switch is locked and tagged open.

b. Personnel shall not use bridge cranes without a permanent platform (catwalk) as a work platform. Bridge catwalks shall have a permanent ladder access.

c. Personnel shall ride seated on the floor of a permanent platform with approved safety handrails, wear safety harnesses attached to designated anchors, and be in clear view of the crane operator at all times.

d. Operators shall lock and tag open the main (or power) disconnect switch on the bridge catwalk when the crane is parked.

15. A written plan is required when erecting or dismantling a boom. 


\section{Hoisting and Rigging Safety Review}

Every hoisting and rigging activity requires the completion of a Hoisting and Rigging Safety Review. See the list of forms and permits in Appendix E that can be found on the NIF Site Resource web page or contact the RI or FAM for the approved JHA/IWS / SP for the work activity. Below are general instructions for the Hoisting and Rigging Safety Review.

The weight of the item(s) to be lifted must be provided. The method of estimating the weight (actual weight, calculation based on drawings, calculation based on dimensions taken from the item itself, etc.) must also be provided. The hoisting mechanism must be identified, and a brief description of the operation must be given. This should include where the item will be lifted from, and where it will be placed. Additional information related to the load path of the lifted load and any unusual movements/motions required during its transit should be provided.

If multiple objects are to be separately lifted during the operation, each item with its weight must be separately listed (note lifting multiple objects with one lift is prohibited).

This form must be reviewed by a competent rigging person and signed by the responsible individual ${ }^{2}$ for the activity. A competent rigging person is defined as someone designated by management and who is qualified (extensive knowledge, training, experience, and demonstrated ability to solve or resolve hoisting and rigging problems) in performing hoisting and rigging operations. The Hoisting and Rigging Safety Review form must be prepared prior to the lift, and reviewed with the team at the time of preparation of the Safe Plan of Action (SPA). All members of the hoisting and rigging crew must read the Hoisting and Rigging Safety Review and sign the SPA where the lift is addressed. The Hoisting and Rigging Safety Review form must be posted with the SPA at the work location. For repeated identical lifts, only one Hoisting and Rigging Review form need be prepared. However, specifics of the operation must be reviewed at the SPA meeting, at the beginning of each shift, or just prior to each operation.

Note: Any lift utilizing an LLNL-designed fixture or other LLNL-designed equipment must have an approved safety note.

\footnotetext{
${ }^{2}$ This refers to the Responsible Individual (RI) on the IWS covering the work or the work supervisor.
} 


\section{Housekeeping}

These rules apply to the NIF Project site, lay down areas, and adjacent areas of LLNL used to support NIF Project activities. Failure by a contractor/ subcontractor to keep areas under their control in a safe and clean condition may cause a Stop Work Order to be issued by the Facility or Field Area Manager.

\section{Responsibilities}

1. All employers and supervisors shall be responsible for ensuring the areas under their control are kept in a safe and clean condition.

2. Workers shall be responsible for maintaining their work areas in a safe and clean fashion.

\section{Housekeeping Rules for the NIF Project Site}

1. Clean-Up. Keep your work area clean and safe at all times. Always keep yourself, the equipment you operate or are using and your place of work as clean as practicable. All workers are responsible for clean "broom swept" areas. Dust control is the responsibility of all workers.

2. Employee Facilities. Cooperate in keeping change rooms, toilets, first aid, and drinking facilities in clean, sanitary condition.

3. Good Housekeeping. Good housekeeping will reduce confusion on the project and will result in a safer, more efficient operation. Housekeeping tags are to be placed on all equipment and materials staged in the area (tags are available at the tag boards).

4. Nails \& Exposed Rebar. Protruding nails, rebar, screws or other metal in form lumber, boards, etc., must be immediately removed, bent over, or capped to prevent puncture injuries.

5. Oily Rags and Wastes. Oily rags, waste, or other combustible debris shall be kept in metal containers provided for that purpose. Saturated oily rags must be managed as hazardous waste.

6. Removal of Debris/Garbage. When cleaning up, do not throw or drop materials from elevated levels to lower levels unless the area below is properly barricaded and adequate warnings are posted.

7. Slipping Hazards. Immediately clean up or eliminate slipping hazards such as grease, oil, water, ice, snow or other liquids on walkways, ladders, stairways, scaffolds, or other access ways or working areas. Install drip pans under equipment that has the potential for leaking oil to prevent slip or fall hazards. When this is not practical, absorbent material should be placed around the equipment.

8. Trash and Debris. Deposit trash, refuse, debris, lunch papers and other waste in the proper refuse containers. 
9. Tripping Hazards. Help keep the work area, especially roadways, access ways, aisles, stairways, scaffolds, ladders, electrical panels, and fire protection equipment, free of obstructions that may cause tripping or other hazards.

10. Falling Material Hazards. Secure loose materials and do not stack materials near floor openings or edges at heights greater than the level of protection to prevent falling material hazards. Remove all excess materials and equipment from the area when no longer required. 


\section{Material Handling and Storage}

These rules apply to the NIF Project site, laydown areas, and adjacent areas of LLNL used to support NIF Project activities. Failure by a contractor/subcontractor to keep areas under their control in a safe and clean condition may cause a Stop Work Order to be issued by the NIF Facility or Field Area Manager.

\section{Material Handling and Storage Rules for the NIF Project Site}

1. Access. When storing materials remember to leave adequate access ways. Do not block aisles or exits. Do not attempt to take shortcuts by climbing on or over stored materials.

2. Flammable/Toxic. Flammable and toxic or other harmful materials shall be stored in properly designated, well-ventilated areas. Observe and abide by "No Smoking" and other warning signs. Handling and Storage shall be in compliance with the requirements of this Appendix and the LLNL ESEH Manual.

3. Heavy Loads. Do not attempt to lift heavy loads without assistance. Learn how to lift properly by bending your knees and keeping your feet together. Avoid strain by lifting with your legs and arms, not your back. Use mechanical lifting equipment whenever possible and when necessary to avoid injury.

4. Noncompatible Materials. Avoid stacking noncompatible materials in the same pile.

5. Storage. Storage of materials shall not create a hazardous or unsafe condition. 


\section{Lasers}

All lasers shall be operated and maintained in a safe manner to prevent injury to workers. This section applies to the use of lasers as a construction tool, i.e., for surveying, setting ceiling and floor elevations, locating and aligning equipment, and also for the acceptance testing of NIF laser components and systems. It does not apply to operation of NIF laser components and systems once acceptance testing has been completed. Additional requirements for the operation of lasers are found in the LLNL ESEH Manual (http://www.llnl.gov/es and h/esh-manual.html).

Before the start of a job involving Class 3b or Class 4 lasers, the Field Area Manager shall notify the Site Safety Manager, who will alert the NIF Programs Laser Safety Officer (NIF LSO) for a site evaluation. Safety procedures (Operational Safety Plan) may be required for operation of these lasers.

\section{Responsibilities}

1. Each employer shall establish laser safety controls to ensure compliance with ANSI Z136.1-2000 requirements.

2. Each employer shall develop, document, and utilize laser safety procedures as required.

3. All workers involved with the use of lasers must be instructed on the safe use of lasers and maintaining a record thereof. Operators of lasers shall be trained in accordance with the manufacturer's operating manual and other rules as required. Operators shall be trained either on the same model laser or one having operating characteristics and controls consistent with the one to be used. Training records shall be made available for review.

4. Each employer shall advise all other affected persons when their safety will be impacted by the operation and use of lasers.

\section{Lasers Used for Construction and Surveying}

Only qualified and trained workers shall be assigned to install, adjust, and operate laser equipment.

- Operators of construction and surveying lasers shall read and understand the manufacturer's instructions and understand the hazards associated with the laser equipment.

- Proof of qualification of the laser equipment operator shall be available and in possession of the operator at all times.

- Workers, when working in areas in which a potential exposure to direct or reflected laser light greater than 0.005 Watts ( 5 milliwatts) exists, shall be provided with 
antilaser eye protection. Laser eyewear shall be suitable to protect for the specific wavelength of the laser and be of optical density adequate for the energy involved.

- Beam shutters or caps shall be utilized, or the laser turned off, when laser transmission is not actually required. When the laser is left unattended or not in use for a substantial period of time, such as during lunch break or overnight, the laser shall be turned off. If provided with a key, the key shall be removed from unattended lasers.

- The laser beam shall not be directed at employees.

- Laser equipment shall bear a label to indicate maximum output or laser hazard classification.

- Laser units in operation should be set up above or below eye height when possible.

- Workers should not stare into any laser beam regardless of hazard classification. They should avoid looking or staring at reflected or diffuse beams.

- The laser protective eyewear shall be worn at all times when required as determined by the NIF LSO.

- Areas in which lasers are used shall be posted with standard laser signs and labels appropriate to the wavelength and hazard classification. These signs shall be provided by the NIF LSO.

\section{Laser Installation and Acceptance Testing of NIF Operational Lasers}

- Site evaluations shall be made by the NIF LSO (or deputy LSO) when the use of Class 3b or 4 lasers are proposed. A Job Hazards Analysis (JHA)/Integration Worksheet (IWS) / Safety Plan (SP) related to a specific application will be required. Both require concurrence by the NIF LSO.

- Areas in which lasers are used shall be posted with standard laser signs and labels appropriate to the wavelength and hazard classification. These signs shall be provided by the NIF LSO.

- Appropriate laser barriers or shields shall be installed when necessary.

- Only trained workers shall be assigned to install, adjust, and operate laser equipment.

- Laser protective eyewear shall be worn at all times when required as determined by the NIF LSO. Laser safety glasses must also meet ANSI Z87.1 unless a waiver is obtained (see item 10, section 2, Personal Protective Equipment).

- Electrical hazards associated with laser testing or operation shall be controlled in accordance with NPSSP, Appendix A, Section 17 Electrical Safety. 


\section{Pressure Safety}

This section deals with pressure safety concerns including pressure and leak testing and vacuum safety.

\section{Responsibilities}

1. Each employer shall develop, document, and utilize pressure safety procedures as required.

2. All workers assigned to install, test, adjust, and operate and maintain pressurized equipment must be trained for this type of work and for exposure to pressure and vacuum-related hazards. Training records shall be made available for review.

3. Each employer shall advise all other affected persons when their safety will be impacted by the testing, operation, and use of pressurized equipment.

4. A written test procedure and permit shall be prepared and approved prior to any pressure (including vacuum) testing.

\section{Definitions}

Low pressure - Gas pressure less than 150 psig (1MPa), or liquid pressure less than 1500 psig (10MPa).

Intermediate pressure - Gas pressure from 150 to 3000 psig (1 -20 MPa gauge), or liquid pressure from 1500 to 5000 psig (10 - $35 \mathrm{MPa})$.

High pressure - Gas pressure greater than 3000 psig (20 MPa gauge), or liquid pressure greater than 5000 psig (35 MPa gauge).

Maximum allowable working pressure (MAWP) - The maximum pressure at which a vessel is designed to operate safely. Working pressure, rated pressure, service pressure, and design pressure are the same as MAWP. NOTE: The setting of vessel or system pressure relief devices must not exceed the MAWP (ASME requirement).

Maximum operating pressure (MOP) - The maximum pressure at which a pressure component is normally operated, usually 10-20\% below MAWP.

Pressure vessel - A relatively high-volume pressure component (such as a spherical or cylindrical container) that has a cross section larger than the associated pipe or tubing.

Manned-Area Operation - Pressurization in environments where vessel failure might cause personal injury. Such vessels or systems have been approved for operation, within specified limits, with personnel present.

Pressure relief devices - Devices (relief valves or rupture-disc assemblies) designed to protect those components that are rated at less than the system supply pressure. All manned-area gas-pressure vessels must be protected by a relief device that is set at a pressure not exceeding the MAWP of the vessel or system. 
Remote Operation - Pressurization in environments where vessel or system component failure would not cause personal injury. Remote operation equipment must be installed in test cells or behind certified barricades, or be operated from a safe location. Manned area operation (of a remote-operation vessel or system) for the purpose of leak checking or troubleshooting is limited to a maximum of $20 \%$ of the established and previously attained MAWP or $20 \%$ of the successful test pressure.

\section{Basic Rules for Pressure Safety}

\section{General Controls}

1. Only qualified and trained workers shall be assigned to install, test, adjust, and operate and maintain pressurized equipment.

2. Gauges shall be graduated to about twice the MAWP of the system-never graduated to less than 1.2 times the MAWP.

3. Gauge materials shall be compatible with the system fluid.

4. Do not consider a pressure regulator by itself as satisfactory overpressure protection. A regulator controls the delivery pressure. A pressure relief device protects from overpressurization.

5. Never place a valve between a relief device and the component it is installed to protect.

6. Never set a relief device above the MAWP of the lowest rated system component(s) it is installed to protect.

7. Locate and orient relief devices so that their discharge is not hazardous to personnel.

8. Install relief devices of adequate total flow capacity. When all supply ports are open, the pressure must never exceed $110 \%$ of the MAWP.

9. Do not reset relief devices unless specifically authorized to do so.

10. Use ASME code-approved (or LLNL-stocked) relief devices whenever possible.

11. Use metal pipe and tubing rated at or above the MAWP.

12. Use flexible hose only where it is impractical to use metal tubing or pipe.

13. Make sure there is no oil or organic materials in gauges used on oxygen systems.

14. Cryogenic liquids are gases that have been transformed into extremely cold liquids. They have many hazards including the potential to freeze tissue. Workers must be protected from freeze hazards by wearing the appropriate personal protection when handling cryogenic liquids. Wear loose fitting gloves. Wear cuffless trousers over boots. Wear eye and face protection.

15. When cryogenic liquids change to their gaseous state, they can expand to many times their liquid volume ( 700:1 for liquid nitrogen, 550:1 for carbon dioxide). Hazards include system overpressurization and asphyxiation in confined spaces. 
16. Requirements for gas cylinder handling, transportation, storage, and use are discussed in NPSSP, Appendix A, Section 11.

\section{Recommended Precautions for Leak Checking and Pressure Testing}

1. Use safety manifolds (see Figures 25-1 and 25-2) for performing gas and hydrostatic pressure testing.

2. Do not use an open flame for leak checking.

3. Contractors/subcontractors shall have an approved test procedure prior to performing leak checking and pressure testing.

4. Notify all affected persons in the area of the test.

5. Post warning signs and install barriers as necessary.

6. In general, testing with gas is more dangerous than testing with liquid because of the stored energy when testing with gas. Test with liquid whenever possible. When testing with liquid, the increased weight of the vessel/system versus its supporting method must be considered.

7. All tests with gas must be approved in writing by the Field Area Manager prior to their implementation.

8. If you detect a leak during pressure testing and decide to repair it before completing the test, reduce the pressure to as low as possible (not over one-half the immediately preceding test pressure) for locating the leak.

9. Leak check remote-operation vessels and systems remotely. Manned-area leak checking of successfully pressure-tested, remote-operation vessels and systems is limited to a maximum of $20 \%$ of the test pressure.

10. Never attempt to repair a system or vessel when it is pressurized, unless specifically authorized by a safety procedure (e.g., Operational Safety Plan).

11. No undocumented vessels or systems may be leak checked in a manned-area mode at pressures higher than $20 \%$ of the test pressure.

12. When the pressure test has been completed, vent test pressure to zero (0) psi gauge before removing any components or installing the pressure relief device.

\section{Vacuum Systems}

1. Vacuum systems that are used or operated only as vacuum systems shall be designed to withstand the intended external pressure.

2. Vacuum systems are designed for external pressure and contain components that make an overpressure internal proof test inappropriate; therefore, other means shall be used to document the safety of these systems.

3. Vacuum systems that have the capability of operating at greater than 2 psi gauge shall be designed, tested, and protected as pressure vessels.

4. Vacuum systems connected to high-pressure gas sources may require the use of pressure relief devices to protect the system for overpressurization. 
5. When purging or backfilling vacuum systems, protect the system with pressure relief device(s) or other adequate means to protect the lowest-rated component of the system (glass, windows, ion gauges, etc.).

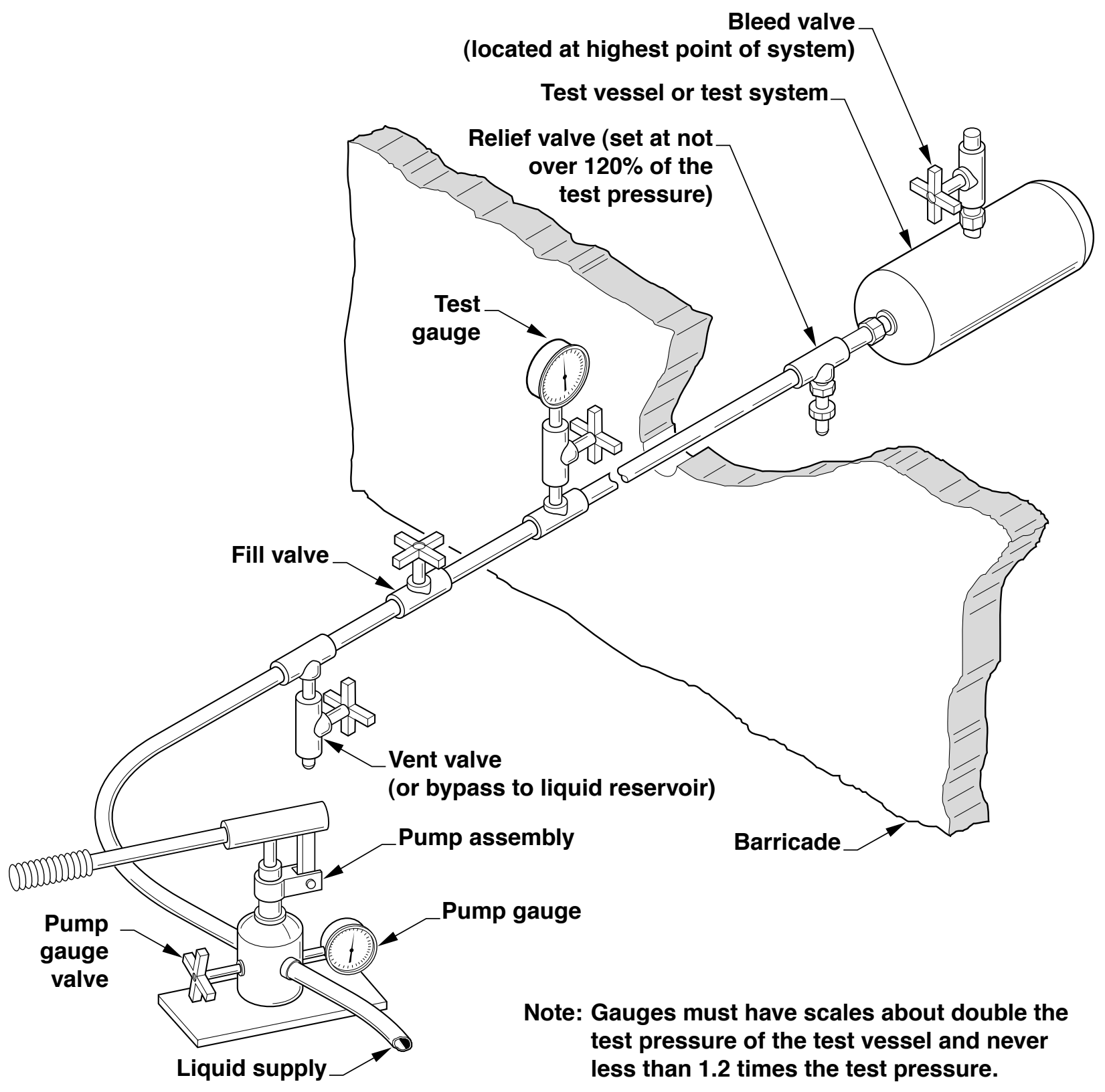

Figure 25-1. Safety manifold for hydrostatic pressure testing. 


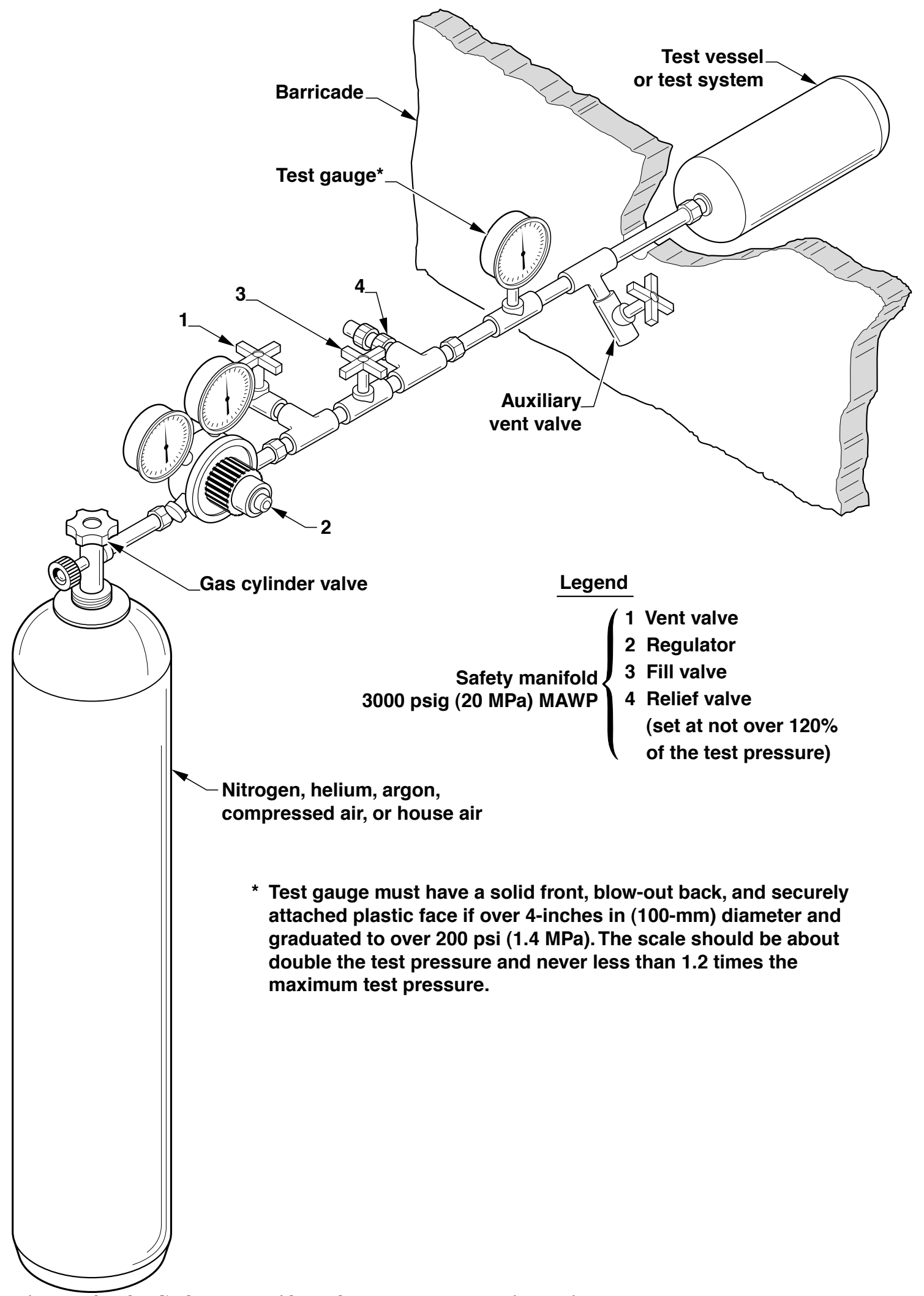

Figure 25-2. Safety manifold for pressure testing with gas. 


\section{Safety Interlock System}

The purpose of the LTAB Safety Interlock System (SIS) is twofold. The primary function is to work in conjunction with engineered barriers, access control, administratively controlled procedures, and operator training to protect personnel from exposure to various hazards. A secondary function is to protect high-value equipment in the event of an improper configuration or failure in a monitored component.

The SIS provides personnel safety interlocks throughout the facility for systems that can generate or propagate a hazard beyond their immediate controlled areas. It continuously displays the hazard levels in the facility and annunciates hazard-level changes.

\section{Responsibilities}

1. All workers performing work in the facility shall be instructed in the potential hazards that may be present in the different areas of the facility. Prior to working within areas bounded by the SIS, workers shall be instructed in the meaning of the SIS messages, alarms, and the action, if any, warranted by each alarm.

2. Workers shall wear the proper Personnel Protective Equipment (PPE) for the area of the facility in which they are working. This may consist of laser protective eyewear, lab coats, or other PPE as determined necessary by LLNL.

3. Workers shall heed all SIS status displays and warning messages. 


\section{Permits and Authorizations}

There are several permits and authorizations required on the NIF project. These include permits for hot work, excavations and on-grade slab penetration, penetration of concrete structures (floors, walls, and ceilings), work in confined spaces, work on energized equipment, use of radioactive materials, ionizing radiation sources, or radiographic equipment, and air and storm water work. Also included are authorizations for work near energized equipment, hoisting and rigging. All NIF workers are responsible for obtaining or assisting with the processing of these permits and authorizations as necessary prior to starting the defined activity. This section describes specific permits and authorizations and directs the reader to other sections of the NPSSP where they may find additional information about a specific permit or required authorization. Caution: All required permits and authorizations may not be addressed in this section. For a full listing of all work permits and plans, see NIF Project Procedure 5.8, NIF Site Work Permits. See Appendix E for a list of forms and permits that can be found on the NIF Site Resource web page

\section{Responsibilities}

All employers and workers shall comply with LLNL permit and authorization requirements of the NIF NPSSP.

\section{Required Permits and Authorizations}

A. Hot Work Permit: A Hot Work Permit is required for all hot work operations including cutting, welding, brazing, soldering, using tar pots or torches for roofing or road work, using hot air guns in applying roofing, thermal spraying, using open fires for any purpose, or conducting any similar activity. At present, a blanket Hot Work Permit is issued to the NIF Project on a monthly basis. A copy of the permit (monthly or otherwise) should be reviewed with the workers and its requirements followed without exception. Please refer to Section 5, Fire Prevention.

B. Confined Space Permit: Each employer is required to maintain their own confined space program including a permit system using their own personnel and permits. A copy of the Confined Space Permit must be posted at or near the location of the confined space. Please refer to Section 7, Confined Space Safety Requirements.

\section{Soil Excavation (Digging, Grading, Tunneling, Trenching, and/or Drilling)}

Permit: The Site Manager is responsible for obtaining an LLNL Soil Excavation (Digging, Grading, Tunneling, Trenching, and/or Drilling) Permit. Note that this permit also applies to penetration of slabs on grade independent of buildings. Each employer is responsible for notifying the Site Manager of their intentions to perform 
any of the identified actions and to assist the Site Manager with obtaining the permit. Please refer to Section 12, Excavation, Trenching, and Shoring.

D. Concrete Structure (Floor, Wall, and Ceiling) Penetrations Permit: The Site Manager is responsible for obtaining an LLNL Concrete Structure (Floor, Wall, and Ceiling) Penetration Permit. Contractors/subcontractors are responsible for notifying the Site Manager of their intentions to perform any of the identified actions and to assist the Site Manager with obtaining the permit.

Concrete Structure Penetration Process: All employers are required to obtain, from the Site Manager, permission to proceed prior to beginning any penetration action in concrete floors, slabs, walls, and/or ceilings in LLNL buildings or other concrete areas where utilities may be located. This applies to penetrations of concrete structures and includes saw cutting, core drilling, jack hammering, and using power and pneumatic activated tools, etc. Penetrations of slabs on grade, independent of buildings are covered by the Soil Excavation (Digging, Grading, Tunneling, Trenching, and / or Drilling) Permit. Of particular concern is the prevention of contact with live electrical conductors or other significant hazards (e.g., natural gas lines, water lines, air lines, etc.). The intent is to minimize the chance of injury or death to personnel and the disruption of essential services. The Site Manager is responsible for obtaining a Concrete Structure (Floor, Wall, and Ceiling) Penetration Permit from the LLNL Plant Engineering Maintenance Operations Division. Refer to MOP-03001 Concrete Structure (Floor, Wall, and Ceiling) Penetrations Permit Procedure.

Structural integrity of any facility is not meant to be covered or certified by this procedure. Structural integrity issues should be addressed with the appropriate engineering group. Potential safety related issues that could affect the integrity of facilities (e.g., handling radioactive materials, radiation shielding, handling hazardous substances) are not addressed by this procedure. LLNL Hazards Control should be contacted when this potential exists.

Prior to penetration of any concrete floor, slab, wall and/or ceiling, attempts must be made to locate where utilities may be located. The Site Manager (Responsible Person) for the penetration operation shall assure that the following actions are accomplished:

1. Concrete structure penetrations less than 3 inches in depth do not require a permit. However, the worker shall assure that the proposed work area is reviewed for the presence of embedded utilities.

a. At a minimum, a handheld scanner capable of detecting metal and interior wiring in concrete to a depth of 3 inches shall be used.

b. This review must occur prior to the start of work.

c. If embedded utilities are located, work may not begin until required safeguards are implemented.

The Responsible Person shall accomplish the following:

a. Review project drawings, prints, notes, etc. 
b. Review drawings and other available historical documentation.

c. Collect information from knowledgeable employees based on personal recollection of construction in a particular area.

d. Make on-site observation of existing conditions such as exposed conduit, conduit boxes, and personnel accesses, nearby equipment, and like items.

e. Perform any other method the Responsible Person deems necessary to assure safe working conditions.

2. Concrete structure penetrations greater than 3 inches in depth require a permit. The Responsible Person shall accomplish the following:

a. Review available project drawings prepared by a licensed professional engineer.

b. Review drawings and other historical documentation.

c. Collect information from knowledgeable employees based on personal recollection of construction in a particular area.

d. Make on-site observation of existing conditions such as exposed conduit, conduit boxes, manholes, nearby equipment, and like items.

e. Verify that no voltage greater than 600 volts is present. This must be done through the Site Utilities Division (Building Service), Site Manager (Programmatic Equipment), or Facility Point of Contact (FPOC).

f. Perform any additional methods the Responsible Person deems necessary to assure safe working conditions.

g. Mark the area to be drilled with soapstone, washable crayon, or other nonpermanent means prior to the locator survey.

h. Have a survey of the proposed work area completed by a qualified locator service prior to any penetration actions. Locator services are available through off-site locator contractors or on site through Plant Engineering Locators. The duties of the locator service are detailed in MOP-03001. They include using active/ conductive locating (radio frequency conductive equipment) as opposed to passive/inductive locating, whenever practical, or any other means necessary.

i. Structural review and approval is required by a California Licensed Civil/Structural Engineer when performing any penetrations to primary structural members (beams and columns) and penetrations six (6) inches and greater in diameter on floors, walls, and ceilings.

j. Complete a Concrete Penetration Job Safety Analysis Reference Checklist for the typical items that should be considered prior to any penetration action.

Issuance of a permit should not be considered as approval to begin penetration actions. Permission to start penetration actions shall be granted by the Responsible Person only after it has been determined that the workplace conditions are safe for these operations.

All workers performing this work shall use ground fault circuit interrupters with drilling tools and shall stand on an insulating mat. All workers performing this work 
shall wear the following personal protective equipment: $0-5 \mathrm{kV}$ rated insulating gloves with moisture-absorbing liners and rubber-soled shoes. The insulating gloves must be tested in accordance with the manufacturer's standards. Ground fault circuit interruption shall be utilized when electrical equipment is used in these operations.

A copy of the Approved Permit shall be posted at the job site.

Upon completion of the excavation project, the Responsible Person shall submit a completed permit and required documentation.

E. NIF Request for Shutdown Form and NIF Electrically Hazardous Task Plan: It is LLNL policy that work on or near electrical circuits and equipment should take place when they are in a deenergized state, using the lockout and tagout procedure, except when working on or near energized equipment is essential for the equipment to remain energized. Programmatic convenience is not sufficient cause to work on or near energized equipment. However, if there are no alternatives, and the NIF Request for Shutdown form is denied, a NIF Electrically Hazardous Task Plan is required. Please refer to Section 17, Electrical Safety.

\section{F. NIF Job Hazards Analysis/Integration Work Sheets}

On the NIF Project site or for work outside the site boundaries that could have a potential impact to the NIF site activities, a JHA/IWS is the process by which managers and various LLNL organizations (e.g., Plant Engineering), commercial vendors (e.g., laser repair technicians), or groups request and, following review, obtain authorization to access the NIF Project site to perform the work. In the JHA/IWS, the facility or area in which the work will take place, the hazards associated with the activity, and the individual that will be supervising the work activity are identified to ensure coordination of the requested work with other concurrent on-site work. The requestor must complete and receive approval of the JHA/IWS prior to starting work on the NIF site.

A JHA/IWS is used to document the approval for performing work. The JHA/IWS is prepared to plan activities, identify and understand the hazards, and develop and implement controls for the hazards. The organization authorizing a work activity is responsible for ensuring that a JHA/IWS is prepared, reviewed, and approved prior to performing any work. Please refer to the main NPSSP Chapter III.B Work Planning and Authorization Process. See also NIF Project Control Procedure 5.12, NIF Project Site Work Authorization Procedure.

G. Radiation Work Permit: A Radiation Work Permit must be obtained prior to allowing subcontractors to perform services such a soil density measurements or radiography that involve the on-site use of radioactive materials or the use of radiation generating devices such as x-ray machines. Written approval must be obtained from LLNL Hazards Control before radioactive materials may be brought onto the LLNL site or before using radiation-generating devices. The Operations Activation Area Manager 
or other responsible individual shall submit the necessary documentation for review and approval by LLNL Hazards Control. Please refer to Section 15, Radiation Safety.

H. Storm Water Pollution Prevention Plans: All employers are required to follow the NIF Storm Water Pollution Prevention Plans (SWPPPs), which are required documents under State Water Resources Control Board Order No. 99-08-DWQ, and National Pollution Discharge Elimination System General Permit No. CAS000002. The SWPPPs are included in the contract bid documents, and a contract specific scope sheet identifies the SWPPP elements within the responsibilities of each individual contract package. Project changes affecting storm water that are outside of the scope of these plans or regulation changes could require new pollution prevention practices to be implemented by the Project.

I. Portable Generators: The Bay Area Air Quality Management District (BAAQMD) regulates the use of portable internal combustion generators. BAAQMD sets performance standards for all generators and requires air permits for larger generators above a specified horsepower threshold. The BAAQMD regulations are subject to change at any time, and the contractor must comply with BAAQMD standards and provide air permits for generators, as required by BAAQMD.

J. Hoisting and Rigging Safety Review: All hoisting and rigging operations must be authorized by completing a NIF Hoisting and Rigging Safety Review form. The purpose of this review is to ensure that all hoisting and rigging operations receive adequate safety review prior to being performed. The responsible individual for the lift shall complete the review. Please refer to NPSSP, Appendix A, Section 20, Rigging, and Section 21, Cranes.

K. Critical Lift Plan: A critical lift plan is required for lifts that meet certain criteria. See NPSSP, Appendix A, Section 21. The plan will describe the details of the lift, and provide assurance that the lift can be performed safely.

\section{Proximity Permit for Crane/Equipment around Overhead Electric Lines and} Cables: In instances where the use of the crane must occur in close proximity to electrical lines, a proximity permit is required. This will review the lift activity with respect to the location of the electrical lines and provide assurance that the lift can be performed without contacting them.

M. Permit for Pneumatic Test: A pressure testing permit is required before any pressure/vacuum testing activities. It assures that all appropriate considerations, such as proper sizing of relief valves, have been factored in to the test. See NPSSP, Section 25, Pressure Safety. 


\section{Appendix B}

\section{Areas Covered by the NIF Project Site Safety Program}

For the purpose of determining where the requirements of the NPSSP shall govern, the NIF Project Site shall cover:

- All areas bounded by the perimeter fence around B581/681 and site trailers.

- B492, B493, B494, B495, B591, T4298, T4997A, T4998, T4999, T5900, T5997.

- B298 laydown, Kirshbaum field, B392 Corpyard. 


\section{NIF Project Areas Covered by the NPSSP}

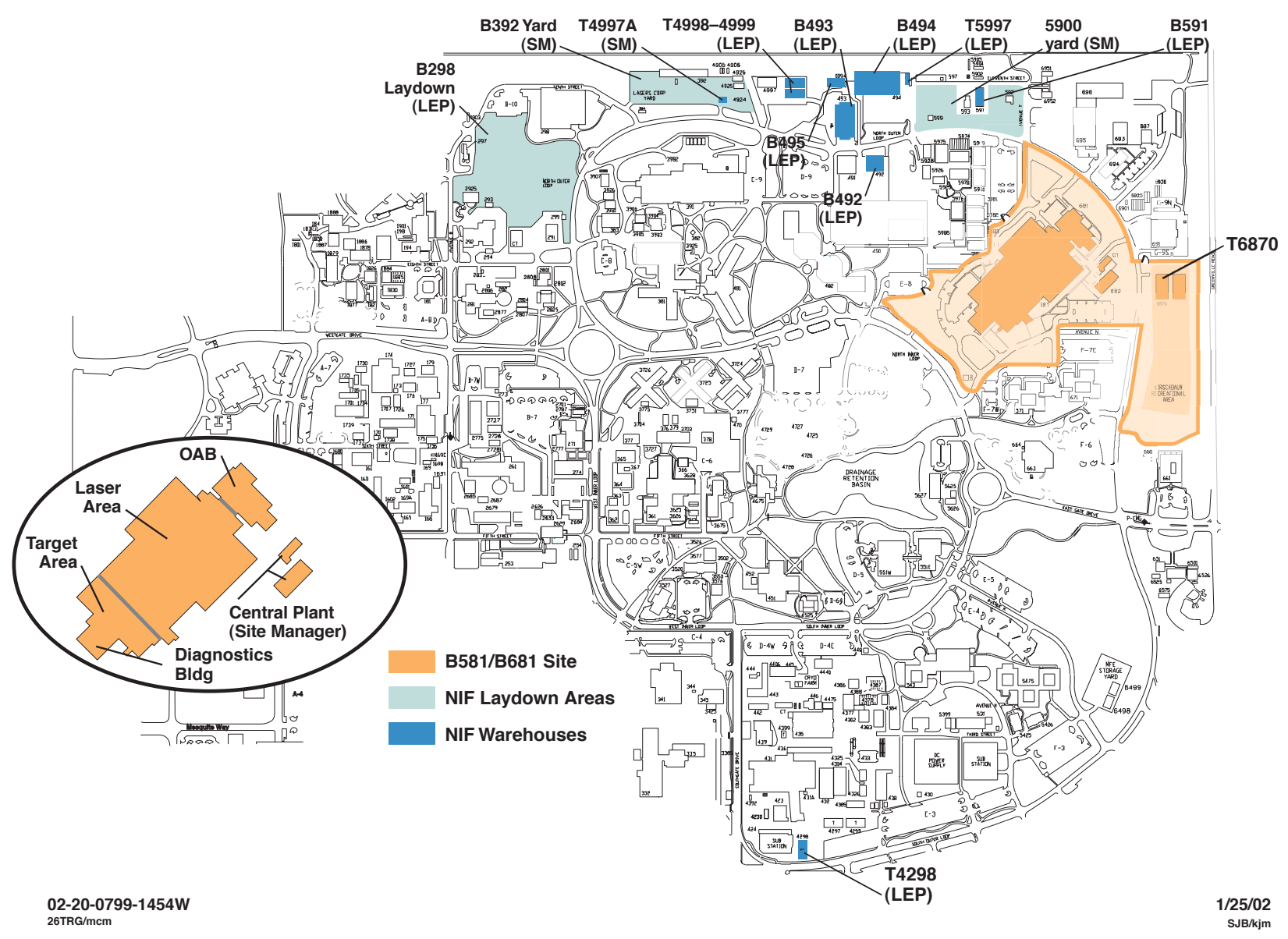




\section{Appendix C}

Sections of the NIF Project Site Safety Program that Implement the Various Guiding Principles and Core Functions of ISM

\begin{tabular}{|c|c|c|}
\hline $\begin{array}{c}\text { DOE P 450.1, } \\
\text { Safety } \\
\text { Management } \\
\text { Systems “ISMS" } \\
\text { Element }\end{array}$ & Title & $\begin{array}{c}\text { Applicable Section of this NIF Project Site } \\
\text { Safety Program }\end{array}$ \\
\hline \multirow[t]{2}{*}{$\begin{array}{l}\text { Guiding Principle } \\
1\end{array}$} & \multirow{2}{*}{$\begin{array}{l}\text { Line Management } \\
\text { Responsibility for } \\
\text { Safety }\end{array}$} & $\begin{array}{l}\text { Chapter II: Project Organization and } \\
\text { Management Responsibilities }\end{array}$ \\
\hline & & Appendix D: Management Responsibilities \\
\hline \multirow[t]{3}{*}{$\begin{array}{l}\text { Guiding Principle } \\
2\end{array}$} & \multirow[t]{3}{*}{$\begin{array}{l}\text { Clear Roles and } \\
\text { Responsibilities }\end{array}$} & $\begin{array}{l}\text { Chapter II: Project Organization and } \\
\text { Management Responsibilities }\end{array}$ \\
\hline & & Appendix D: Management Responsibilities \\
\hline & & $\begin{array}{l}\text { Appendix A: Responsibilities (in each } \\
\text { subsection) }\end{array}$ \\
\hline \multirow[t]{4}{*}{$\begin{array}{l}\text { Guiding Principle } \\
3\end{array}$} & \multirow{4}{*}{$\begin{array}{c}\text { Competence } \\
\text { Commensurate } \\
\text { with } \\
\text { Responsibilities }\end{array}$} & $\begin{array}{l}\text { Section III.A.4: Site Orientation Safety } \\
\text { Training }\end{array}$ \\
\hline & & $\begin{array}{l}\text { Section III A.5: NIF Safety Management } \\
\text { Training }\end{array}$ \\
\hline & & $\begin{array}{l}\text { Section III.B.1: NIF Project Site Work } \\
\text { Authorization Procedure }\end{array}$ \\
\hline & & $\begin{array}{l}\text { Project Procedure 5.12*: NIF Project Site Work } \\
\text { Authorization Procedure }\end{array}$ \\
\hline \multirow[t]{3}{*}{$\begin{array}{l}\text { Guiding Principle } \\
4\end{array}$} & \multirow[t]{3}{*}{$\begin{array}{l}\text { Balanced } \\
\text { Priorities }\end{array}$} & $\begin{array}{l}\text { Safety and Health Policy for the National } \\
\text { Ignition Facility }\end{array}$ \\
\hline & & $\begin{array}{l}\text { Section II.A.1: Project Manager } \\
\text { (Responsibilities) }\end{array}$ \\
\hline & & $\begin{array}{l}\text { Section III.B: Work Planning and } \\
\text { Authorization Process }\end{array}$ \\
\hline
\end{tabular}




\begin{tabular}{|c|c|c|}
\hline $\begin{array}{l}\text { Guiding Principle } \\
5\end{array}$ & $\begin{array}{l}\text { Identification of } \\
\text { Safety Standards }\end{array}$ & $\begin{array}{l}\text { Section III.B: Work Planning and } \\
\text { Authorization Process }\end{array}$ \\
\hline & and & Section III.B.2: Safe Plan of Action (SPA) \\
\hline & & $\begin{array}{l}\text { Project Procedure 5.10: Safe Plan of } \\
\text { Action }\end{array}$ \\
\hline & & $\begin{array}{l}\text { Section III B.1: NIF Project Site Work } \\
\text { Authorization Procedure }\end{array}$ \\
\hline & & $\begin{array}{l}\text { Project Procedure 5.12: NIF Project Site } \\
\text { Work Authorization Procedure }\end{array}$ \\
\hline & & Appendix A \\
\hline $\begin{array}{l}\text { Guiding Principle } \\
6\end{array}$ & $\begin{array}{l}\text { Hazard Controls } \\
\text { Tailored to the }\end{array}$ & $\begin{array}{l}\text { Section III.B: Work Planning and } \\
\text { Authorization Process }\end{array}$ \\
\hline & $\begin{array}{l}\text { Work being } \\
\text { Performed }\end{array}$ & $\begin{array}{l}\text { Section III.B.1: NIF Project Site Work } \\
\text { Authorization Procedure }\end{array}$ \\
\hline & & Project Procedure 5.8: NIF Work Permits \\
\hline & & $\begin{array}{l}\text { Project Procedure 5.12: NIF Project Site } \\
\text { Work Authorization Procedure }\end{array}$ \\
\hline & & Section III.B.2: Safe Plan of Action (SPA) \\
\hline & & $\begin{array}{l}\text { Project Procedure 5.10: Safe Plan of } \\
\text { Action }\end{array}$ \\
\hline & & Appendix A \\
\hline $\begin{array}{l}\text { Guiding Principle } \\
7\end{array}$ & $\begin{array}{l}\text { Operations } \\
\text { Authorization }\end{array}$ & $\begin{array}{l}\text { Section III.B: Work Planning and } \\
\text { Authorization Process }\end{array}$ \\
\hline & & Section III.B.2: Safe Plan of Action (SPA) \\
\hline & & Project Procedure 5.8: NIF Work Permits \\
\hline & & $\begin{array}{l}\text { Project Procedure 5.10: Safe Plan of } \\
\text { Action }\end{array}$ \\
\hline & & $\begin{array}{l}\text { Section III B.1: NIF Project Site Work } \\
\text { Authorization Procedure }\end{array}$ \\
\hline & & $\begin{array}{l}\text { Procedure } 5.6: \text { NIF Project Site Work } \\
\text { Coordination }\end{array}$ \\
\hline & & $\begin{array}{l}\text { Project Procedure } 5.12: \text { NIF Project Site } \\
\text { Work Authorization Procedure }\end{array}$ \\
\hline
\end{tabular}




\begin{tabular}{|c|c|c|}
\hline \multirow[t]{5}{*}{ Core Function 1} & \multirow[t]{5}{*}{$\begin{array}{l}\text { Define the Scope } \\
\text { of Work }\end{array}$} & $\begin{array}{l}\text { Section III.B: Work Planning and } \\
\text { Authorization Process }\end{array}$ \\
\hline & & $\begin{array}{l}\text { Section III.B.1: NIF Project Site Work } \\
\text { Authorization Procedure }\end{array}$ \\
\hline & & $\begin{array}{l}\text { Project Procedure 5.12: NIF Project Site } \\
\text { Work Authorization Procedure }\end{array}$ \\
\hline & & Section III.B.2: Safe Plan of Action (SPA) \\
\hline & & $\begin{array}{l}\text { Project Procedure 5.10: Safe Plan of } \\
\text { Action }\end{array}$ \\
\hline \multirow[t]{4}{*}{ Core Function 2} & \multirow[t]{4}{*}{$\begin{array}{l}\text { Analyze the } \\
\text { Hazards }\end{array}$} & $\begin{array}{l}\text { Section III.B.1: NIF Project Site Work } \\
\text { Authorization Procedure }\end{array}$ \\
\hline & & $\begin{array}{l}\text { Project Procedure 5.12: NIF Project Site } \\
\text { Work Authorization Procedure }\end{array}$ \\
\hline & & Section III.B.2: Safe Plan of Action (SPA) \\
\hline & & $\begin{array}{l}\text { Project Procedure 5.10*: Safe Plan of } \\
\text { Action }\end{array}$ \\
\hline \multirow[t]{7}{*}{ Core Function 3} & \multirow{7}{*}{$\begin{array}{l}\text { Develop and } \\
\text { Implement } \\
\text { Hazard Controls }\end{array}$} & Section III.B.2: Safe Plan of Action (SPA) \\
\hline & & $\begin{array}{l}\text { Project Procedure } 5.10^{*} \text { : Safe Plan of } \\
\text { Action }\end{array}$ \\
\hline & & $\begin{array}{l}\text { Section III B.1: NIF Project Site Work } \\
\text { Authorization Procedure }\end{array}$ \\
\hline & & $\begin{array}{l}\text { Project Procedure } 5.6^{*}: \text { NIF Project Site } \\
\text { Work Coordination }\end{array}$ \\
\hline & & Project Procedure 5.8: NIF Work Permits \\
\hline & & $\begin{array}{l}\text { Project Procedure } 5.12^{*} \text { : NIF Project Site } \\
\text { Work Authorization Procedure }\end{array}$ \\
\hline & & Appendix A \\
\hline \multirow[t]{2}{*}{ Core Function 4} & \multirow{2}{*}{$\begin{array}{l}\text { Perform Work } \\
\text { within Controls }\end{array}$} & Section III.B.2: Safe Plan of Action (SPA) \\
\hline & & $\begin{array}{l}\text { Project Procedure } 5.10^{*}: \text { Safe Plan of } \\
\text { Action }\end{array}$ \\
\hline \multirow[t]{5}{*}{ Core Function 5} & \multirow[t]{5}{*}{$\begin{array}{l}\text { Provide Feedback } \\
\text { and Continuous } \\
\text { Improvement }\end{array}$} & $\begin{array}{l}\text { Section III.A: Setting Management } \\
\text { Expectations, Monitoring Work and } \\
\text { Providing Feedback }\end{array}$ \\
\hline & & $\begin{array}{l}\text { Project Procedure 5.11*: NIF Incident } \\
\text { Analysis Procedure }\end{array}$ \\
\hline & & $\begin{array}{l}\text { Project Procedure } 5.13^{*}: \text { Layered } \\
\text { Management Walkabout Process }\end{array}$ \\
\hline & & $\begin{array}{l}\text { Section III.B.4: Incident Investigation } \\
\text { and Lessons Learned }\end{array}$ \\
\hline & & Section III.A.10 Safety Leadership Team \\
\hline
\end{tabular}

"Project Procedures referenced above are based upon the revision in force as of the effective date of this Construction Safety Program. 


\section{Appendix D}

\section{Management Responsibilities}

\section{D.1 Project Management}

Work authorization, the authority to do work, flows through the chain of command from the NIF Project Manager, through an AIM, APM, Commissioning and Operations Managers, LRU Managers, or Site Manager to the Authorizing Individual (AI), to the Responsible Individual (RI), (the "formal" first-line supervisor).

The three Work Authorization chains of command in NIF are:

- The AIM chain of command, which authorizes work for assembly, commissioning, and operations.

- The APM chain of command, which authorizes work that is conducted in areas other than the main NIF facility.

- The NIF Site Manager, who is part of a third Work Authorization chain of command for construction and facility-related work.

\section{D.1.1 Authorizing Individuals}

Authorizing Individuals, appointed by the NIF Project Manager and supported by the NIF Project management staff, Project Assurance, and safety staff, have the overall authority and responsibility for safety management, work authorization, and work control on the NIF Project Site.

Work Authorization and coordination of daily activities in an area is accomplished with JHA/IWS/SPs and work permits. AIs are responsible for reviewing and approving the JHA/IWS/SPs. AIs are responsible for the authorization and issuance of work permits for their area.

In addition, AIs shall:

- Monitor safety and technical performance daily.

- Prepare and participate in Incident Investigations when necessary.

- Review and approve the JHA/IWS/SP.

- Ensure safety deficiencies in their area are resolved in a timely manner based on a graded approach. 


\section{D.1.2 Associate Project Managers}

The Associate Project Managers (APMs) are responsible for the scope, schedule, budget, and technical and safety performance for their assigned NWBS elements. Associate Project Managers report to the NIF Project Manager and are responsible to:

- Serve as the primary Responsible Individuals at the site, delegating the RI role to their subordinate managers. Assure that subordinate RIs, supervisors, and workers under their supervision are knowledgeable in ISM requirements and NIF site work practices.

- When not acting as the RI themselves, concur on JHA/IWS/SPs covering work to be performed by their organization.

- Ensure the development and approval of JHA/IWS/SPs and Safe Plans of Action (SPAs) for work at the NIF Project site for all work under their supervision. Ensure the evaluation of the hazards and the mitigation/prevention controls needed to ensure the safety of work.

- Ensure that the workers under their supervision are current in the required safety training.

- Ensure safe work performance and obtain feedback and implement improvements.

- Ensure compliance with applicable environmental permits.

- Participate, as appropriate, in incident investigations.

- Work with the MPR Committees to develop an appropriate MPR plan defining the deliverables to be reviewed. Provide the agreed upon deliverables to the MPR committee for their review.

\section{D.1.3 Responsible Individuals}

RIs are appointed by the APMs and shall monitor work on a regular basis during the day. If the RI cannot monitor work on a regular basis, he or she shall appoint a Daily Work Team Leader (DWTL). RIs are responsible for safe planning of work and preparing work teams for work activities at the site. RIs must demonstrate not only the technical basis for their work proposals, but also that the operations can be accomplished safely. The RI shall:

- Ensure that facility procedures for safety (set forth in the NPSSP and Project Control Procedures), QA, and work processes are followed.

- Develop and ensure compliance with work permits and Specific Hazards Permits.

- Ensure SPAs are generated and proper preparation for and execution of SPA meetings are performed. 
- Ensure all individuals listed on the JH/IWS/SP are trained and qualified for the work to be performed.

- Monitor safety and technical performance daily.

- Ensure that accurate JHA/IWS/SPs are generated and approved.

- Ensure safety deficiencies in their area are resolved in a timely manner based on a graded approach.

- Prepare for and participate in Incident Investigations when necessary.

\section{D.1.4 Field Area Managers}

Field Area Managers (FAMs) have the authority to control all work within their assigned area. They report to the AIM for their area and shall:

- Support the AIMs in collecting work planning information, assessing interfaces, and confirming that work can be performed safely in an area before it is authorized.

- Review and approve Work Permits for their designated area.

- Ensure that approved JHA/IWS/SPs are in place for work performed in their area of responsibility.

- Oversee that SPA meetings are performed and permits posted in their area of responsibility.

- Interface with the APMs and IPT Leaders as appropriate to resolve conflicts and work priorities within their assigned areas.

- Ensure that facility procedures for safety (set forth in the NPSSP and subtier safety plans and procedures), QA, and work processes are followed.

- Coordinate safety in their assigned area and monitor compliance to the SPA procedure.

- Concur on work to be performed within the area prior to its commencement.

- Be responsible for definition of and control of interfaces between areas with the other FAMs.

- Participate, as appropriate, in incident investigations.

\section{D.1.5 Site Manager Organization}

The Site Manager Organization is responsible for the care, custody, and control of the Conventional Facility, site access control, site-institutional interface, and oversight of the implementation of this NPSSP. The Site Manager is appointed by the NIF Project Manager. The Site Manager reports to the NIF Project Manager and is responsible to:

- Act as the primary FPOC for the main NIF Project site. 
- As FPOC, concur on all JHA/IWS/SPs for work in the defined facilities ensuring that the proposed work is within the authorization basis for the subject area.

- Control requirements for access and access to the site. This includes safety, security, and training requirements; develop training, as needed.

- Participate in the NIF Project Safety Documentation Change Control Board (CCB) 5 that will review and approve revisions to the NPSSP (at least annually) and any new or revised project safety documentation.

- Ensure that the Site Emergency Preparedness Plan and provisions are effective and current.

- Ensure that the overall site environmental permits are carried out working with the NIF QA Manager (e.g., Storm Water Pollution Prevention Plan for the NIF site).

- Participate, as appropriate, in incident investigations.

- Interface with the institution (e.g., Plant Engineering) as necessary to support the work activities in their area.

- Review the results of the audits for compliance, for recommendations made for correction and prevention of recurrence, and for follow-up measures taken to develop compliance.

- Verify that the following safety requirements are met for contractors/subcontractors:

-Implementation of the site Substance and Alcohol Abuse Prevention Program.

-Work activities are preplanned to identify and control any safety and health issues that may pose a hazard to workers or others.

- Specific job safety training is completed.

- Investigation of all injuries, accidents, and incidents are conducted.

- Safety inspections are reviewed.

- Contractor/subcontractor safety plans for the Conventional Facility are reviewed for adequacy prior to contractor/subcontractor mobilization.

- Develop safe work recognition and disciplinary programs.

- Assure orientation of site management regarding policies and procedures, their responsibilities, and compliance.

\section{D.1.6 Integrated Product Teams}

Integrated Product Teams (IPTs) provide a multidisciplinary, multiorganizational, interdependent team approach to meeting specified mission requirements. The IPT Leaders report to the Area Integration Manager for their geographical area. IPT Leaders shall: 
- Concur on JHA/IWS/SPs for their responsible areas.

- Participate, as appropriate, in incident investigations.

- Act as AI when designated by the Project Manager or responsible AI.

\section{D.2 Safety Assurance}

\section{D.2.1 NIF Quality Assurance Manager}

The NIF Quality Assurance (QA) Manager is the support manager responsible for the oversight of QA aspects of the NIF Project. He/ she reports directly to the NIF Project Manager and in support of ES\&H and the NPSSP shall:

- Participate in the NIF Project Safety Documentation Change Control Board (CCB) 5 that will review and approve revisions to the NPSSP (at least annually) and any new or revised project safety documentation.

- With the AIMs and Site Manager, coordinate the development of core work procedures, training, and standards for working on the NIF site (e.g., job hazards analysis (JHA), access training, work authorization).

- Perform safety analyses of NIF construction and operation: Preliminary Hazards Analysis (PHA), Preliminary Safety Analysis Report (PSAR), and Final Safety Analysis Report (FSAR) with Operational Safety Requirements (OSRs).

- With the NIF Programs Assurance Manager, obtain the National Environmental Policy Act (NEPA) determination and the environmental permits. Assure that the requirements of the permits are met.

- With the NIF Programs Assurance Manager, interface with the ONIF-Office of the NIF (DOE) and outside regulatory agencies.

- Perform safety audits.

- Oversee updates to the Hazards Analysis Report (HAR) and Final Safety Analysis Report (FSAR) documents.

- Coordinate the Management Prestart Review (MPR) process.

\section{D.2.2 NIF Programs Assurance Manager}

The NIF Programs Assurance Manager reports to the NIF Programs Operations Manager and provides directorate oversight to NIF Project elements for assuring compliance with LLNL and applicable federal, state, and local rules and regulations. The NIF Programs Assurance Manager shall:

- Participate in the NIF Project Safety Documentation Change Control Board (CCB) 5 that will review and approve revisions to the NPSSP (at least annually) and any new or revised project safety documentation. 
- Oversee the NIF Occurrence and Incident Reporting Program for the NIF Project site.

- Perform safety audits of the NIF Project site.

\section{D.2.2.1 ES\&H Manager for Commissioning and Operations}

The ES\&H Manager for Commissioning and Operations shall:

- Coordinate the development and approval of and concur on all JHA/IWS/SPs for the NIF Project site.

- With the Site Manager and NIF QA Manager, coordinate the development of core work procedures and standards for working on the NIF site (e.g., job hazards analysis (JHA), access training, work authorization).

- Coordinate the review of safety plans of primary contractors/subcontractors to ensure such plans are consistent with LLNL policies, the NIF Project Site Safety Program, and the NIF Facilities requirements.

- Participate in the NIF Project Safety Documentation Change Control Board (CCB) 5 that will review and approve revisions to the NPSSP (at least annually) and any new or revised project safety documentation.

- Working with the Site Safety Manager, act as an interface among NIF elements on ES\&H issues pertaining to the work activities at the NIF Project site.

- Working with the Site Safety Manager, assist in the resolution of any issues related to ES\&H among NIF elements.

- Working with the Site Safety Manager, make recommendations on issues of conflict (pertaining to ES\&H) among NIF elements.

\section{D.2.2.2 Laser Safety Officer}

The Laser Safety Officer reports to the NIF Programs Assurance Manager, is the Program point of contact on any laser analysis or safety-related issue, and shall:

- Prepare and issue Laser SafetyGrams.

- Conduct all laser analysis and make final determinations on required protection and use of lasers on the site.

\section{D.2.3 Site Safety Manager}

The Site Safety Manager reports to the NIF Project Manager and advises the Project Manager on all coordination and implementation of the NPSSP and NIF Project-specific safety and health policies. This individual is the primary responsible party within facility management for assuring compliance with the NPSSP. The Site Safety Manager shall: 
- Act as an interface among NIF elements on ES\&H issues pertaining to the work at the NIF Project site.

- Coordinate the site safety representatives through the Site Safety Team.

- Develop and implement the safe work recognition and disciplinary programs.

- Support the NIF QA Manager with the performance of safety audits at the NIF Project site.

- Interface with the Emergency Management Division to ensure they are familiar with conditions at the site.

- Assure compliance with all applicable safety and health procedures through site inspections, documenting such with recommendations to Facility Management and immediate corrective action on Immediately Dangerous to Life and Health (IDLH) situations.

- Assure adequate investigations and analysis on all incidents, (noninjury and injury).

- Provide safety and health information for the education of site management and employees to include:

1. Safe work procedures

2. Incident analysis (results, causes, and corrective action)

3. Inspection results analysis

4. Trend analysis

- With the Site Manager and NIF QA Manager, coordinate the development of core work procedures and standards for working on the NIF site (e.g., job hazards analysis (JHA), access training, work authorization).

- Participate in the NIF Project Safety Documentation Change Control Board (CCB) 5 that will review and approve revisions to the NPSSP (at least annually) and any new or revised project safety documentation.

- Track ES\&H deficiencies and status of resolution during construction and commissioning of the NIF.

\section{D.2.4 Site Safety Representatives}

The Site Safety Representatives are members of the Site Safety Team and are coordinated by the Site Safety Manager. Site Safety Representatives are generally subject matter experts from support organizations (Hazards Control/ Engineering/Plant Engineering). These individuals, along with NIF Programs Assurance and NIF Project Assurances, have the responsibility to advise the Site Manager on implementation of the NPSSP and safety and health policies and procedures. In addition, these individuals assure compliance with applicable federal, 
state, local, and LLNL safety and health regulations. The Site Safety Representatives support the Site Safety Manager in the execution of his duties and shall:

- Assure adequacy of necessary personal protective equipment selected for employee use.

- Provide training, as required.

- Provide safety and health training information for management, supervision, and employees.

- Assure preparation and submittal of required safety and health record-keeping information.

- Assure documentation of required safety and health record-keeping information (i.e., inspections, training, first aid logs, OSHA logs, etc.).

\section{D.2.5 LLNL Environment, Safety, and Health Support}

\section{D.2.5.1 ES\&H Team 2}

ES\&H Team 2, a section in the LLNL Hazards Control Department (HCD), is an interface between the NIF Project and the LLNL ES\&H support organizations. This team provides technical, advisory, and oversight ES\&H support to the Site Safety Team, the NIF Project, and the NIF Programs Assurance Offices. The Section Leader for ES\&H Team 2 will concur with this NPSSP.

Specifically, ES\&H Team 2 shall:

- Review safety-related materials and submittals from the NIF Project including construction designs and specifications.

- Review Safety Plans submitted by primary contractors/subcontractors for NIF Assurances.

- Periodically audit the NIF Project safety performance and compliance with the requirements of the NPSSP at the request of the NIF Project Assurance Office.

- Participate in the NIF Project Safety Documentation Change Control Board (CCB) 5 that will review and approve revisions to the NPSSP (at least annually) and any new or revised project safety documentation.

- Perform injury /illness incident record keeping and trending for the NIF Project Assurance Office and Laboratory management.

- Review and concur on JHA/IWS/SPs, which cover personnel working at the NIF site, and for this work, perform the same duties as a site safety representative.

- Provide support to the Incident Investigation process at the request of the NIF Site Manager. 
- Respond to emergencies at the NIF site if requested by the on-scene Incident Commander (Fire Department) or the NIF Project Office.

- Provide ES\&H review of the purchase of LLNL contracted services under the LLNL ISM process.

- Assist in the preparation of written safety documents, e.g., JHA/IWS/SPs, SPAs, and Facility Authorization Basis documents.

\section{D.2.5.2 Emergency Management Division}

HCD, through its Emergency Management Division (EMD) manages the LLNL Fire Department.

The Fire Department shall:

- Respond to fire, medical, and hazardous material incidents.

- Provide basic and advanced life support emergency care and emergency medical transport for injuries or illnesses on the NIF Project site.

- Issue burn permits (Hot Work Permits). This responsibility may be delegated to the ES\&H Team 2 Fire Protection Engineer.

- Approve all fire safety system (sprinkler, fire, water, or alarm) outages.

- Inspect the NIF site to insure compliance with the LLNL fire protection program, including proper emergency vehicle access.

\section{D.3 NIF Workers}

NIF workers include LLNL, non-LLNL, and contractor/subcontractor employees working at the NIF Project site. Non-LLNL employees are visitors, students, participating guests, employees matrixed (or on assignment) from other National Laboratories, contract labor, supplemental labor and vendors, including those working for facility operations contractors. NIF workers shall:

- Know and understand the ES\&H requirements of their assignments including potential hazards in the work area.

- Perform work assignments in full compliance with guidelines, this NPSSP, and any relevant subordinate safety plan.

- Receive appropriate ES\&H training, or equivalent, or shall be escorted and supervised by personnel knowledgeable in the hazards to which they may be exposed.

- Immediately correct or inform the responsible work supervisor of any ES\&Hrelated problems. 
- Report all work-related injuries, illnesses, and near-miss incidents to their immediate work supervisor following the reporting process delineated in NIF Project Procedure 5.11, NIF Project Site Incident Investigation. 


\section{Appendix E}

\section{NIF Project Site Work Authorization and Safety Management Forms and Permits}

Work is authorized and conducted safely on the NIF Project Site utilizing the following forms and permits to identify and mitigate hazards and prepare Work Teams for their tasks on a daily basis. The list below identifies the forms and permits currently in use at the site. This list is subject to change. Project Control Procedures are identified for each form listed below, which describes the process for preparation and authorizations.

The latest release of all forms and permits may be found attached to the associated Project Control Procedure or on the NIF Site Resource Page:

http://www-r.llnl.gov/nif/nifproj/nifproj site resources/index2.html

\begin{tabular}{|l|l|l|l|}
\hline \multicolumn{1}{|c|}{ Site Project Forms or Permits } & $\begin{array}{c}\text { NPSSP/ } \\
\text { Appendix A } \\
\text { Reference }\end{array}$ & $\begin{array}{c}\text { Project } \\
\text { Control } \\
\text { Procedure } \\
\text { (PCP) }\end{array}$ & \multicolumn{1}{|c|}{ Purpose } \\
\hline NIF Site Request Form & III.A.3 & PCP 5.5 & $\begin{array}{l}\text { Request for access the site to } \\
\text { complete work }\end{array}$ \\
\hline $\begin{array}{l}\text { Job Hazard Analysis/Integrated } \\
\text { Work Sheet/ Safety Plan } \\
\text { (JHA/IWS/SP) }\end{array}$ & III.B.1 & PCP 5.12 & $\begin{array}{l}\text { Work Planning and Hazards } \\
\text { identification }\end{array}$ \\
\hline Work Permit & III.B.3 & PCP 5.8 & $\begin{array}{l}\text { Daily approval of work } \\
\text { activities in a specific area, } \\
\text { required for all work } \\
\text { activities on the site }\end{array}$ \\
\hline Safe Plan of Action (SPA) & III.B.2 & PCP 5.10 & $\begin{array}{l}\text { Work Team meeting to } \\
\text { prepare for daily work } \\
\text { activities and discuss hazards } \\
\text { and safe work planning }\end{array}$ \\
\hline Tour Sign-in Sheet & III.A.3 & PCP 5.7 & $\begin{array}{l}\text { Process for requesting and } \\
\text { conducting a site tour, tours } \\
\text { are conducted by authorized } \\
\text { tour guides }\end{array}$ \\
\hline $\begin{array}{l}\text { Line Management Walkabout } \\
\text { Worksheet }\end{array}$ & III.A.8 & PCP 5.13 & $\begin{array}{l}\text { Report for collection of data } \\
\text { on incidents and for } \\
\text { evaluation }\end{array}$ \\
\hline to evaluate safety processes \\
\hline
\end{tabular}




\begin{tabular}{|c|c|c|c|}
\hline Site Project Forms or Permits & $\begin{array}{l}\text { NPSSP/ } \\
\text { Appendix A } \\
\text { Reference }\end{array}$ & $\begin{array}{l}\text { Project } \\
\text { Control } \\
\text { Procedure } \\
(\text { PCP) }\end{array}$ & Purpose \\
\hline $\begin{array}{l}\text { Lockout/Tagout Work Plan } \\
\text { Lockout/ Tagout Removal Plan } \\
\text { Lockout/Tagout Inspection Form }\end{array}$ & Section 19 & РСP 5.15 & $\begin{array}{l}\text { NIF Project Site } \\
\text { Lockout/Tagout } \\
\text { Requirements }\end{array}$ \\
\hline $\begin{array}{l}\text { Temporary Power } \\
\text { Installation/Removal Form } \\
\text { Equipment Grounding log } \\
\text { Welding Machines - Inspection } \\
\text { Report }\end{array}$ & Section 17 & РCP 5.23 & $\begin{array}{l}\text { NIF Assured Grounding, } \\
\text { Temporary Wiring, and Tool } \\
\text { Testing }\end{array}$ \\
\hline $\begin{array}{l}\text { Fall Protection Equipment } \\
\text { Inspection Report }\end{array}$ & Section 13 & РСР 5.24 & $\begin{array}{l}\text { Routine inspection of fall } \\
\text { protection equipment }\end{array}$ \\
\hline NIF Confined Space Permit & Section 7 & РCP 5.22 & $\begin{array}{l}\text { Required prior to entry into } \\
\text { any confined spaces }\end{array}$ \\
\hline Hot Work Permit & $\begin{array}{l}\text { Section } 5 \\
\text { and } 11\end{array}$ & PCP 5.22 & $\begin{array}{l}\text { Issued by LLNL Fire } \\
\text { Department for any open } \\
\text { flame or potential flame } \\
\text { hazard. }\end{array}$ \\
\hline Soil Excavation & Section 12 & PCP 5.22 & $\begin{array}{l}\text { Required by NIF } \\
\text { Conventional Facilities } \\
\text { whenever soil is going to be } \\
\text { disturbed. }\end{array}$ \\
\hline $\begin{array}{l}\text { Concrete Structure (Floor, Wall, and } \\
\text { Ceiling) Penetration Permit }\end{array}$ & Section 27 & PCP 5.22 & $\begin{array}{l}\text { Needed prior to any } \\
\text { penetration action in concrete } \\
\text { floors, slabs, walls and /or } \\
\text { ceilings, less than } 3 \text { inches } \\
\text { does not require a permit }\end{array}$ \\
\hline $\begin{array}{l}\text { NIF Request for Shutdown Form } \\
\text { NIF Electrically Hazardous Task } \\
\text { Plan }\end{array}$ & Section 17 & РCP 5.22 & $\begin{array}{l}\text { Needed when working on or } \\
\text { near electrical circuits or } \\
\text { equipment for de-energizing } \\
\text { source prior to work. } \\
\text { Energized work is not } \\
\text { permitted on the NIF Project } \\
\text { Site. }\end{array}$ \\
\hline Radiation Work Permit & Section 15 & PCP 5.22 & $\begin{array}{l}\text { Need by subcontractors } \\
\text { performing any task using } \\
\text { radiation-generating devices. }\end{array}$ \\
\hline $\begin{array}{l}\text { Storm Water Pollution Prevention } \\
\text { Plans (SWPPPs) }\end{array}$ & Section 3 & $\mathrm{~N} / \mathrm{A}$ & $\begin{array}{l}\text { Required for all contractors } \\
\text { as part of their contract } \\
\text { scope. }\end{array}$ \\
\hline Portable Generators & Section 27 & РCP 5.22 & $\begin{array}{l}\text { Bay Air Quality Management } \\
\text { District regulates use of in- } \\
\text { ternal combustion generators } \\
\text { and contractors must provide } \\
\text { air permits for generators }\end{array}$ \\
\hline
\end{tabular}




\begin{tabular}{|c|c|c|c|}
\hline Site Project Forms or Permits & $\begin{array}{l}\text { NPSSP/ } \\
\text { Appendix A } \\
\text { Reference }\end{array}$ & $\begin{array}{l}\text { Project } \\
\text { Control } \\
\text { Procedure } \\
\text { (PCP) }\end{array}$ & Purpose \\
\hline $\begin{array}{l}\text { NIF Hoisting and Rigging Safety } \\
\text { Review }\end{array}$ & Section 21 & РCP 5.22 & $\begin{array}{l}\text { Required for all hoisting and } \\
\text { rigging operations. }\end{array}$ \\
\hline Critical Lift Plan & Section 21 & РСР 5.22 & $\begin{array}{l}\text { Required for lifts meeting a } \\
\text { certain criteria }\end{array}$ \\
\hline Permit for Pneumatic Test & Section 27 & РCP 5.22 & $\begin{array}{l}\text { Required before any } \\
\text { pressure/vacuum testing } \\
\text { activities }\end{array}$ \\
\hline $\begin{array}{l}\text { Proximity Permit, NIF Permit for } \\
\text { Crane/Equipment Work Around } \\
\text { Overhead Electric Lines and Cables }\end{array}$ & Section 21 & РCP 5.22 & $\begin{array}{l}\text { Used when a boom or crane } \\
\text { will be used in close } \\
\text { proximity to electrical lines }\end{array}$ \\
\hline $\begin{array}{l}\text { Boom Assembly and Breakdown } \\
\text { Plan }\end{array}$ & Section 21 & РCP 5.22 & $\begin{array}{l}\text { Required for the safe } \\
\text { planning of assembly and } \\
\text { disassembly of booms }\end{array}$ \\
\hline $\begin{array}{l}\text { Checklist for Planning Steel } \\
\text { Erection Installation and Removal } \\
\text { of Decking, Flooring and Grating }\end{array}$ & Section 14 & РCP 5.22 & $\begin{array}{l}\text { Required before starting the } \\
\text { installation or removal of } \\
\text { steel erection, flooring, } \\
\text { decking or grating }\end{array}$ \\
\hline Scaffolding Erection Plan & Section 10 & РCP 5.22 & $\begin{array}{l}\text { Required for any scaffold } \\
\text { greater than } 36 \text { feet }\end{array}$ \\
\hline Daily Scaffolding Inspection & Section 10 & РCP 5.22 & $\begin{array}{l}\text { A daily inspection of } \\
\text { scaffolding must be } \\
\text { documented by the group } \\
\text { having the scaffolding under } \\
\text { their control }\end{array}$ \\
\hline
\end{tabular}




\section{List of Acronyms}

$\begin{array}{ll}\text { AI } & \text { Authorizing Individual } \\ \text { AIM } & \text { Area integration Manager } \\ \text { AIR } & \text { Assembly, Installation, and Refurbishment } \\ \text { AIT } & \text { Area Integration Team } \\ \text { AM } & \text { Area Manager } \\ \text { ANSI } & \text { American National Standards Institute } \\ \text { APL } & \text { Assembly Point Leader } \\ \text { APM } & \text { Associate Project Manager } \\ \text { ARO } & \text { Assembly, Refurbishment and Operation } \\ \text { BIS } & \text { Beampath Infrastructure System } \\ \text { CAL/OSHA } & \text { California Occupational Safety and Health Administration } \\ \text { CBSC } & \text { California Building Standards Code } \\ \text { CCL } & \text { Control Center Leader } \\ \text { CCR } & \text { California Code of Regulations } \\ \text { CFR } & \text { Code of Federal Regulations } \\ \text { CHP } & \text { California Highway Patrol } \\ \text { CII } & \text { Construction Industry Institute } \\ \text { CM } & \text { Construction Manager } \\ \text { CR } & \text { Contractor Representative } \\ \text { CSO } & \text { Construction Safety Officer } \\ \text { DAPL } & \text { Deputy Assembly Point Leader } \\ \text { DOE } & \text { Department of Energy } \\ \text { DOT } & \text { Department of Transportation } \\ \text { EMD } & \text { Emergency Management Division (of HCD) } \\ \text { EPA } & \text { Environmental Protection Agency } \\ \text { EPD } & \text { LLNL's Environmental Protection Department } \\ \text { ES\&H } & \text { Environment, Safety, and Health } \\ \text { FAM } & \text { Field Area Manager } \\ \text { FHA } & \text { Fire Hazards Analysis } \\ \text { FPOC } & \text { Facility Point of Contact } \\ \text { FSAR } & \text { Final Safety Analysis Report } \\ \text { GFCI } & \text { Ground fault circuit interrupter } \\ \text { HCD } & \text { LLNL's Hazards Control Department } \\ \text { HSD } & \text { LLNL's Health Services Department } \\ \text { HWM } & \text { LLNL's Hazardous Waste Management division } \\ \text { ICCS } & \text { Integrated Computer Control System } \\ \text { IDLH } & \text { Immediately Dangerous to Life and Health } \\ \text { ICF } & \text { Inertial Confinement Fusion } \\ \text { IPT } & \text { Integrated Product Team } \\ \text { ISM } & \text { Integrated Safety Management } \\ \text { IWS } & \text { Integration Work Sheet } \\ & \\ & \\ & \end{array}$


JFI Jacobs Facilities Incorporated

JHA Job Hazards Analysis

LEP Laser Equipment Production

LLNL Lawrence Livermore National Laboratory

LMOT Laser Materials and Optics Technology

LRU Line Replaceable Unit

LTAB Laser and Target Area Building

MOR Master Oscillator Room

MPR Management Prestart Review

MSDS Material Safety Data Sheet

NEPA National Environmental Policy Act

NFPA National Fire Protection Association

NIF National Ignition Facility

NPSSP NIF Project Site Safety Program

NWBS NIF Work Breakdown Structure

OAB Optics Assembly Building

OCIP Owner Controlled Insurance Program

ORR Operational Readiness Review

OSHA Occupational Safety and Health Administration

OSR Operational Safety Requirement

OTP Operational Test Procedures

PAM Preamplifier Module

PAMMA Preamplifier Module Maintenance Area

PHA Preliminary Hazards Analysis

PICS Problem Identification \& Correction System

PPE Personal protective equipment

PSAR Preliminary Safety Analysis Report

QA Quality Assurance

QMC Quality Managers of Construction

RI Responsible Individual

SAAR Supervisor's Accident Analysis Report

SAR Safety Analysis Report

SDR System Design Requirement

SE Special Equipment

SHP Self-Help Program

SM Site Manager

SP Safety Plan

SPA Safe Plan of Action

SWPPP Storm Water Pollution Prevention Plan

TES Target Experimental System

UC University of California 